LUCAS PAULO BARBOSA DA SILVA

ESTIMATIVA DE DISTRIBUIÇÃO DE NUTRIENTES DE SOLO A PARTIR DE IMAGENS DE SATÉLITES 
LUCAS PAULO BARBOSA DA SILVA

\title{
ESTIMATIVA DE DISTRIBUIÇÃO DE NUTRIENTES DE SOLO A PARTIR DE IMAGENS DE SATÉLITES
}

\author{
Dissertação apresentada à Escola \\ Politécnica da Universidade de São \\ Paulo para obtenção do título de \\ Mestre em Ciências.
}

Área de Concentração:

Engenharia de Controle e Automação Mecânica

Orientador: Prof. Dr. Jun Okamoto Jr. 
Autorizo a reprodução e divulgação total ou parcial deste trabalho, por qualquer meio convencional ou eletrônico, para fins de estudo e pesquisa, desde que citada a fonte.

Este exemplar foi revisado e corrigido em relação à versão original, sob responsabilidade única do autor e com a anuência de seu orientador.

São Paulo, de de

Assinatura do autor:

Assinatura do orientador:

\section{Catalogação-na-publicação}

da Silva, Lucas Paulo

Estimativa de Nutrientes de Solo A Partir de Imagens de Satélites / L. P. da Silva -- versão corr. -- São Paulo, 2018.

$68 \mathrm{p}$.

Dissertação (Mestrado) - Escola Politécnica da Universidade de São Paulo. Departamento de Engenharia Mecatrônica e de Sistemas Mecânicos.

1.Agricultura de Precisão 2.Sensoriamento Remoto 3.Tratamento de Imagens I.Universidade de São Paulo. Escola Politécnica. Departamento de Engenharia Mecatrônica e de Sistemas Mecânicos II.t. 


\section{DEDICATÓRIA}

Aos que promovem a razão e o conhecimento. 


\section{AGRADECIMENTOS}

Agradeço ao meu orientador, Professor Jun Okamoto Jr, principalmente pela compreensão e disposição para com a minha disponibilidade compartilhada. Aos meus pais, que pavimentaram o meu caminho e alimentaram os meus sonhos. À comunidade científica e acadêmica que está sempre disposta a compartilhar o conhecimento. Ao Adair Moraz que tanto contribuiu com os dados necessários para a construção deste trabalho. E, principalmente, à minha esposa e companheira de estrada em busca da melhor versão de mim mesmo. 


\section{RESUMO}

Imagens aéreas de campos cultivados tem sido uma importante ferramenta na agricultura de precisão desde o início do século XX. A partir delas, tem sido possível identificar macro padrões de crescimento na lavoura, gerando informações importantes para o gerenciamento da produção. As informações de intensidade em diferentes bandas do espectro eletromagnético podem indicar a presença ou ausência de nutrientes na região de interesse. Diferentes relações entre estas bandas podem gerar informações ainda mais detalhadas. O conhecimento dos indicadores destes nutrientes no solo e na planta durante o crescimento é uma enorme vantagem para o agricultor que pretende otimizar sua cultura. Os desafios na implementação desta tecnologia vão desde a obtenção de tais imagens, a partir de plataformas orbitais até a análise relacionando estas informaç̃̃es aos parâmetros agrícolas de interesse. Este trabalho propõe-se a obter imagens geradas por satélites e, em seguida, estimar parâmetros agrícolas no solo, tais como a concentração de Potássio, Fósforo, Boro, Manganês, entre outros, mapeando as variações destes parâmetros por sobre a área estudada, e compreendendo os impactos da resolução e momento de captação das imagens. Os resultados mostram que uma relação contínua e direta entra os níveis de nutrientes e a refletância e índices de vegetação não alcaçariam a confiabilidade desejada. Porém com a aplicação de uma grade de níveis de concentração, o Fertigrama sugerido pelo laboratório responsável pelas análises químicas das amostras de solo, o mapa de variabilidade dos nutrientes se torna uma ferramenta importante para o pequeno produtor, descrevendo quais áreas merecem mais atenção em relação à distribuição por sobre a área de plantio de um determinado nutriente.

Palavras-chave: Sensoriamento remoto, agricultura de precisão, mosaico, solo, nutrientes, satélite. 


\begin{abstract}
Aerial imagery from crop fields have been an important tool in precision agriculture since the dawn of the 20th century. It has allowed identifying patterns in crop yields, generating usefull information to the production management. Reflectance intensity data in different ranges from the electromagnetic spectrum may indicate the presence or the absence of nutrients in the soil of an area. Different relations between these light bands may generate even more detailed information. The knowledge of these nutrients content in the soil or in the crop during its growth its a valuable asset to the farmer that seeks to optimize its yield. The challenges of implementing this technology ranges from the selection of the imagery, using orbital platforms to the extraction of the reflectance information from it and the analysis of its relationship with the parameters of interest. In this work, satelite imagery, is used to estimate some parameters, namely, the content of Potassium, Phosphorus, Boron, Manganese, among others, in the soil, creating variability maps over the studied area, and understanding the impacts of the image resolution and sample time frame. The results show that a direct and continuous correlation between the nutrient content levels and the reflectance and vegetation indexes do not reach the desirable levels. However, with the aplication of nutrient content frame, the Fertigram suggested by the very laboratory who analyzed the soil samples, the variability maps become important tools for the small producer who seeks information about deficiency spots upon the crop area.
\end{abstract}

Keywords: remote sensing, precision agriculture, mosaic, soil, nutrients, satelite 


\section{LISTA DE ILUSTRAÇÕES}

Figura 1 Fluxo de Informação. Fonte: Stafford et al, 2000 . . . . . . . . . 11

Figura 2 Trocas de Nutrientes do solo à raíz da planta. Fonte: Bierman et al, $2005 \ldots \ldots \ldots \ldots$

Figura 3 Ciclo de absorção de nutrientes por uma planta. Fonte Bierman et al,

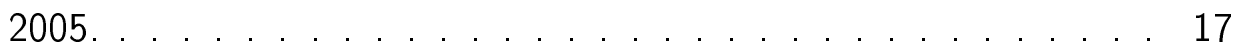

Figura 4 Capacidade de troca de cátions. Fonte: Bierman et al. 2005. . . . . 18

Figura 5 Exemplos de amostras tomadas, na bibliografia, com espaçamentos

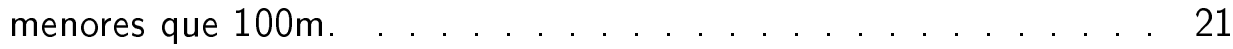

Figura 6 Comportamento da refletância para uma vegetação saudável. Fonte: Shiratsuchi et al, $2014 . \ldots \ldots$. . . . . . . . . . . 22

Figura 7 Fluxograma da análise correlação. Fonte: Gulhane et al, $2017 . \quad \ldots \quad 29$

Figura $8 \quad$ Imagens obtidas pelo Google Earth, com acesso às bandas vermelho, verde e azul. Resolução aprox. $50 \mathrm{~cm}$. Fonte: Google Earth. . . . . 32

Figura 9 Imagem obtida do satélite Landsat-8, apresentando a área de interesse indicada pela seta e pelo quadrado vermelho para referência da ordem de grandeza da imagem. . . . . . . . . . . . . . . . . 34

Figura 10 Imagens da propriedade em Coromandel-MG, nas bandas disponibilizadas pelo satélite. Resolução: 30m. Fonte: Landsat-8. . . . . . . . 35

Figura 11 Fotografia obtida pelo satélite Pleiades. Resolução: $50 \mathrm{~cm}$. Fonte: Pleiades . . . . . . . . . . . . . . . . 36

Figura 12 Propriedade escolhida para análise, em Coromandel, MG. Fotos tiradas no dia 17 de fevereiro, 2017. Fonte: Google Earth. . . . . . . . . 38

Figura 13 Localização de cada amostra tomada para análise química do solo, demonstrando o alcance do raio de $20 \mathrm{~m}$ para composição de cada amostra . . . . . . . . . . . . . . . . . . . 39

Figura 14 Áreas consideradas para comparação de índices de refletâncias e de vegetação com a primeira análise química. . . . . . . . . . . 40

Figura 15 Identificação das coordenadas do primeiro ponto de amostra química, pelo aplicativo Mapas do lphone. . . . . . . . . . . . . . . . 43

Figura $16 \quad$ Estimativas média de nutrientes. . . . . . . . . . . . . . . . 45 
Figura 17 Mapas de Variabilidade de nutrientes no solo para Boro, Cobre, Potássio, Manganês, Fósforo e Zinco, em $\mathrm{mg} / \mathrm{dm}^{3}$, exibidos de acordo com o fertigrama mostrado na tabela 1 , apartir das imagens do satélite Pleiades . . . . . . . . . . . . . . . . . . . 48

Figura 18 Mapas de Variabilidade de nutrientes no solo para Boro, Cobre, Potássio, Manganês, Fósforo e Zinco, em $\mathrm{mg} / \mathrm{dm}^{3}$, exibidos de acordo com o fertigrama mostrado na tabela 1, apartir do mosaico de imagens da área coberta de lavoura de milho, tomadas em 13 de maio

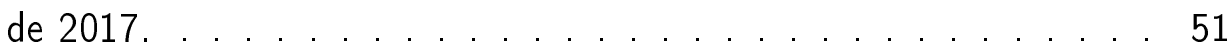

Figura 19 Mapas de Variabilidade de nutrientes no solo para Boro, Cobre, Potássio, Manganês, Fósforo e Zinco, em $\mathrm{mg} / \mathrm{dm}^{3}$, exibidos de acordo com o fertigrama mostrado na tabela 1 , apartir do mosaico de imagens da área sem a cobertura da lavoura, tomadas em 17 de fevereiro de 2017 . . . . . . . . . . . . . . . . . . . 53

Figura 20 Comparação entre as estimativas feitas a partir das imagens do Pleiades e do Google Earth, para os nutrientes $\mathrm{B}, \mathrm{Cu}, \mathrm{K}, \mathrm{Mn}, \mathrm{P}$ e Zn. . . . 57 


\section{LISTA DE TABELAS}

Tabela 1 Níveis ideiais de nutrientes. Fonte: Laudo de Análise de Solo, Laboratório Safrar . . . . . . . . . . . . . . . . . . . . . . . 19

Tabela 2 Bandas espectrais e algumas de suas possíveis interpretações para PA. Adaptado de Shiratsuchi et al. 2014. . . . . . . . . . . . . . . . 22

Tabela 3 Indices de vegetação mais comumente usados. Adaptado de Huang et al, 2013 e Albayrak et al, 2008. NIR: Infravermelho próximo. R: vermelho. G: verde . . . . . . . . . . . . . . . . . . . . . . . . 24

Tabela 4 Correlações entre propriedades de solo, de acordo com dados obtidos por Magri et al, 2005. . . . . . . . . . . . . . . . . . . . 25

Tabela 5 Bandas disponíveis nas imagens geradas pelo Landsat-8. Fonte: Landsat-

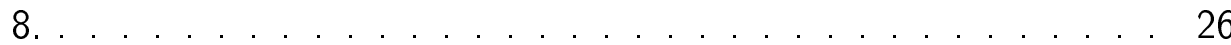

Tabela 6 Imagens coletadas por plataforma aérea, data, bandas disponíveis e aplicação. . . . . . . . . . . . . . . . . . . . . 31

Tabela $7 \quad$ Resultados das amostras de refletância e índices de vegetação. . . . . . 40

Tabela 8 Resultados das análises químicas para Fósforo disponível, cátions de Potássio, Boro, Cobre, Ferro, Manganês e Zinco, todos em $\mathrm{mg} / \mathrm{dm}^{3}$. 42

Tabela 9 Estimativas da concentração de fósforo usando a média da refletância das áreas apresentadas na figura14, em função do fertigrama. . . . 44

Tabela 10 stimativas da concentração de potássio usando a média da refletância das áreas apresentadas na figura14, em função do fertigrama. . . . 44

Tabela 11 Resultados nos pontos de amostragem para análise química, obtidos da imagem gerada pelo satélite Pleiades. . . . . . . . . . . . . 46

Tabela 12 Resultados da análise de correlação entre análise química versus refletâncias/índices de vegetação da imagem do satélite Pleiades. . . . 47

Tabela 13 Valores de refletância nas bandas NIR, vermelho, verde e azul. . . . . . 49

Tabela 14 Resultados da análise de correlação entre análise química versus refletâncias/índices de vegetação da imagem do Google Earth de maio de 2017 . . . . . . . . . . . . . . . . . . . 50 50

Tabela 15 Valores de refletância nas bandas NIR, vermelho, verde e azul, para mosaico de imagens de fevereiro 2017. . . . . . . . . . . . . 51

Tabela 16 Resultados da análise de correlação entre análise química versus refletâncias/índices de vegetação da imagem do Google Earth de fevereiro de 2017 . . . . . . . . . . . . . . . . . . . . . . 52 
Tabela 18 Valores de refletância e de índices de vegetação obtidos das imagens do Landsat-8. 


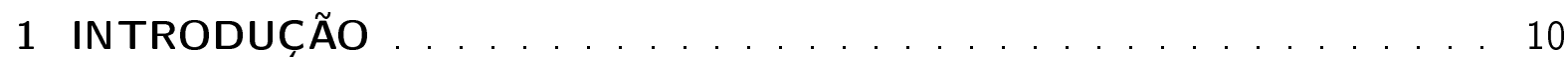

2 JUSTIFICATIVAE OBJETIVOS . . . . . . . . . . . . . . . 14

3 REVISÄO BIBLIOGRÁFICA E METODOLOGIA . . . . . . . . . . . . . 15

31 CICIO DE NUTRIENTES NO SOLO ENA PIANTA . . . . . . . 15

3.2 ANÁLISE QUIMICA DO SOLO . . . . . . . . . . . . . . . . . . . 19

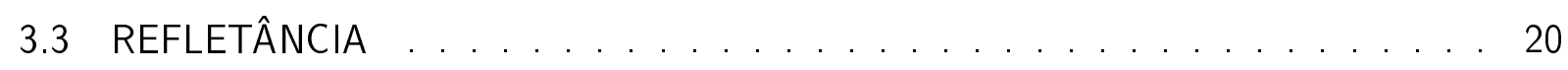

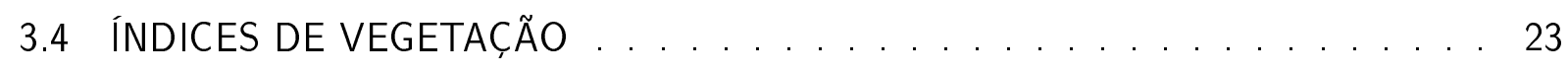

3.5 SENSORIAMENTOREMOTO . . . . . . . . . . . . . . 24

4 IMPLEMENTACÃO $\ldots \ldots \ldots \ldots$

41 ESCOLHA DA PROPRIEDADF AGRICOLA . . . . . . . . . . 30

42 COLETA DE IMAGENS . . . . . . . . . . . . . . . 30

4.2 .1 Imagens para Estimativa de Nutrientes . . . . . . . . . . . . . 31

4.2.1.1 Imagens com acesso às bandas vermelho, verde e azu . . . . . . . . . . 31

4.2 .1 .2 Imagens Com Acesso à NIR . . . . . . . . . . . . . . . 33

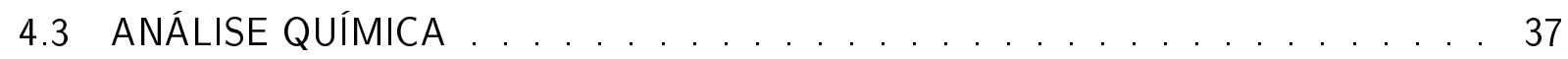

4.4 ESTIMATIVA DE NUTRIENTES POR BANDAS DE REFLETÂNCIA E ÍNDICES

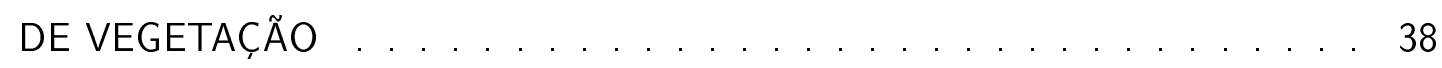

5 RESULTADOS E ANÁLISE . . . . . . . . . . . . . . . . . . . 42

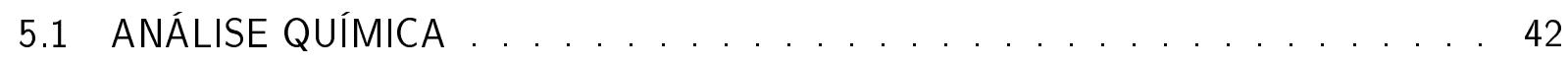

5.2 ESTIMATIVA DE NUTRIENTES: SOLO E VEGETACCÃO . . . . . . . . . 43

5.2 .1 Imagens do Landsat $\ldots \ldots \ldots \ldots \ldots \ldots$

5.2 .2 Imagens do Pleiades . . . . . . . . . . . . . . . . . . . 45

5.2 .3 Imagens do Google Earth $\ldots \ldots \ldots \ldots$

5.3 ANÁLISE QUÍMICA VERSUS ESTIMATIVAS POR IMAGENS . . . . . . . . . 53

5.4 IMAGENS DE SATÉLITE VERSUS GOOGLE EARTH . . . . . . . . . 56

6 CONCLUSÃO . . . . . . . . . . . . . . . . . . . . . . . . . . . . . . 59

Referências . . . . . . . . . . . . . . . . . . . . . . . . 62

Anexo A - Laudos da Análise Química . . . . . . . . . . . . . . . . . . 64 


\section{INTRODUÇÃO}

O produtor agrícola que tem acesso às melhores ferramentas para cada uma das etapas do processo produtivo, antes de iniciar-se uma nova cultura, faz uma análise física do solo, procurando por proporções de matéria orgânica, argila (fator determinante no processo de absorção e liberação de nutrientes por processos eletrolíticos) e de areia (que determinará a capacidade de absorção de água e nutrientes do solo). A seguir, procura pelas características químicas do solo, para determinar os tipos e proporções de nutrientes pré-existentes na área, que lhe poderão ser úteis ou danosos à cultura que ele vier a plantar. Por último ele procura pelas características biológicas do solo, para determinar a fauna ali existente, que pode vir a danificar a cultura e a sua produtividade no futuro. Somando estas informações à históricos e padrões climáticos, o agricultor pode ter em suas mãos todos os dados para selecionar a cultura à ser plantada, os métodos de plantio, o melhor processo de adubação que maximize as características do solo para alcançar a produtividade ótima da lavoura, o planejamento de rotação de culturas, e a melhor forma de lidar com a fauna que possa trazer ameaças à produção, além de minimizar os impactos ambientais. Uma característica única desta indústria é que ela gera vários produtos biológicos que são extremamente sensíveis tanto a condições ambientais como aos procedimentos aos quais são submetidos (1). Desta forma, é vital que o fazendeiro tome conhecimento de forma periódica de onde as variações existem em seus campos para que ele possa ajustar seus processos produtivos da forma mais adequada. Consequentemente, quaisquer técnicas que facilitem a estabilização ou o aumento da produção agrícola, ao mesmo tempo em que amenize os impactos de tais atividades sobre o ambiente ao redor serão benéficas à sociedade. Neste contexto, sensores capazes de detectar variações nos campos, tais como monitores de rendimento, têm sido utilizados combinados à GPS de alta precisão para gerenciamento destes problemas. Tais sistemas compõem a chamada Agricultura de Precisão, AP (2). Este termo sugere que o gerenciamento agrícola pode ser praticado com certo grau de precisão. Consequentemente, AP fornece meios palpáveis de monitoramento e controle de áreas produtivas com precisão de metros, redução e otimização do uso de componentes potencialmente danosos, e assim promover um ambiente mais saudável aos seres humanos. Apesar de beneficial, existem algumas restrições chaves na AP que precisam ser observadas, incluindo a ausência de sistemas apropriados de suporte para decisões.

A AP é definida como uma estratégia de gerenciamento agrícola que faz uso de tecnologia da informação para coletar dados de diferentes fontes que possam basear decisões relacionadas ao crescimento da lavoura. Ela tem o objetivo de oferecer benefícios como rentabilidade, produtividade, sustentabilidade, qualidade do produto, proteção ambiental e segurança alimentar. Para tal, métodos de coleta de informação, monitoramento de eficiência, amostragem de solo 
e folhas e sensoriamento remoto são estudados, aplicados e constantemente melhorados. Com estas informações, o produtor pode aplicar técnicas de taxas variáveis na aplicação de fertilizantes e sementes, de acordo com o mapa de parâmetros gerados pelo processamento destas informações coletadas (3).

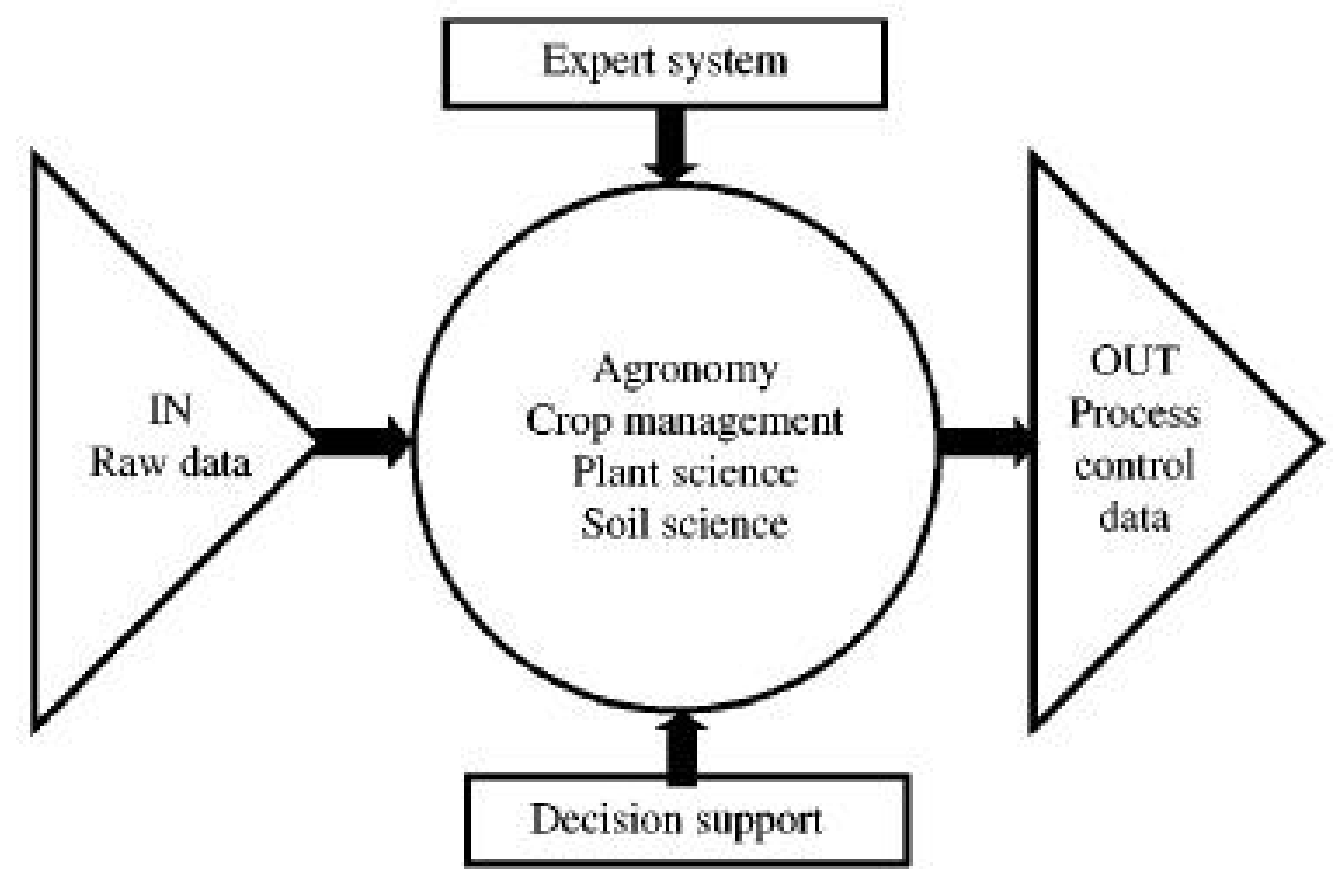

Figura 1 - Fluxo de Informação. Fonte: Stafford et al, 2000.

A etapa de levantamento de dados físicos, químicos e biológicos envolve os mais variados métodos (4). Um agricultor com acesso a melhores tecnologias poderia requisitar fotografias geradas por satélites em anos anteriores para identificação de manchas no solo e histórico hídrico e climático. Estes dados depois são verificados in loco, sendo retiradas amostras das áreas que apresentarem discrepâncias mais agudas em relação às características esperadas. Junto com as análises preliminares, estas amostras seguem para análises físicas, químicas e biológicas para determinação de um diagnóstico que aponte a causa da discrepância. Com estas informações o agricultor faz um planejamento de manejo do solo, preparando para o plantio, tratando cada área com as medidas correspondentes. Durante o crescimento da lavoura, o produtor tem poucos métodos eficazes de sensoriamento para lhe informar da produtividade da lavoura, da eficácia dos tratamentos planejados antes da cultura e do surgimento de novos fatores. Os métodos correntes envolvem amostragens de solo e de folhas da planta em pontos quaisquer da lavoura, para análise de laboratório, sendo que os resultados raramente são conhecidos a tempo de qualquer ação ainda naquele ano ou ciclo de produção. Desta forma, o agricultor terá de aplicar medidas corretivas apenas no ano seguinte. Porém, existe literatura 
acadêmica que propõe novos formatos de sensoriamento remoto, aplicando imagens aéreas, geradas por satélites de alta resolução ou veículos aéreos não tripulados, VANTs (5). Com esta nova ferramenta, o produtor rural teria informações detalhadas e rápidas o suficiente para aplicação de medidas ainda naquele ciclo de plantio, otimizando a produtividade e dando vantagem competitiva no mercado.

Mesmo ainda não sendo uma unanimidade entre produtores, os últimos 10 anos viram uma aceleração no crescimento da AP na comunidade agrícola. Porém, tudo aponta para que a direção que se está sendo seguida é a correta, buscando a otimização da produção, tanto em termos financeiros, como de qualidade e de impactos ambientais. Além disso, os procedimentos propostos pela AP permitem maiores rastreio e controle por parte dos governos e das associações de consumidores.

A AP consiste, basicamente, das etapas obtenção de dados, mapeamento da variabilidade dos campos, tomada de decisão e, finalmente, o gerenciamento de ações. O sensoriamento remoto, que pode ser aplicado às primeiras 3 etapas, é a obtenção de informações sobre um objeto sem que haja contato físico, sendo possível fazê-lo, por vezes, a longas distâncias. Estas informações remotas podem ser obtidas a partir de imagens aéreas tomadas de diversas plataformas, como satélites, aviões, balões, helicópteros e, mais recentemente, VANTs (4). Desde a década de 1930, fotografias aéreas têm sido utilizadas como fonte de informações para tomadas de decisões no gerenciamento agrícola. Nos Estados Unidos, a Administração de Ajustes Agrícolas (AAA) já demonstrava, através de experimentos, que fotografias aéreas poderiam prover informações acuradas à baixo custo para o produtor. O sensoriamento ambiental remoto faz uso de energia radiante para extrair informações sobre as propriedades do solo ao longo de extensas áreas cultivadas dentro de um curto período de tempo. A premissa básica para a aplicação de sensoriamento remoto em agricultura de precisão é que diferenças nas condições do solo e do crescimento da lavoura podem ser detectadas através de variações dentro de parâmetros espectrais (6). Especificamente, alterações em refletâncias detectadas remotamente podem ser observadas antes que maiores sintomas de condições danosas à lavoura sejam visíveis a olho nu.

A adoção de práticas de agricultura de precisão por parte dos produtores requer capital investido, tempo e conhecimento. Desta forma, a difusão desta prática ainda depende de fatores subjetivos, relativos à percepção dos agricultores, como confiança nos dados levantados e nos dados gerados após processamento, facilidade de implementação e uso, nível de instrução do agricultor, tamanho da fazenda, percepção da real utilidade e dos benefícios finais da AP. A combinação destes fatores, atrelados ao tempo, ao investimento e à curva de aprendizado na implantação nevoa as decisões dos produtores em aplicar a AP. Adrian et al, 2005(3) conduziu um estudo sobre a percepção de produtores agrícolas sobre a implantação de tecnologias de 
sensoriamento remoto no gerenciamento de culturas, e chegou a conclusão de que a facilidade dos produtores de compreender tanto as tecnologias de geração de informação assim como de interpretar os seus resultados são alguns dos fatores mais importantes para uma maior penetração do sensoriamento remoto e da AP no mercado agrícola, principalmente se tratando de pequenos e médios produtores, que, em muitas das vezes, não possuem os recursos ou volume de produção que o permitam aplicar tais técnicas.

Neste contexto, Gulhane et al. (2017) estudou a aplicação de imagens do Google Earth para estimativas de parâmetros tais como níveis de concentração de potássio e fósforo, além da condutivade elétrica do solo e seu $\mathrm{pH}$ de propriedades agrícolas de quatro grandes regiões produtoras da Índia, onde a análise química do solo também se mostra custosa e demorada demais para servirem de informações úteis para o agricultor (7). Ao autor tomou imagens do Google Earth em dois níveis de altitude, $500 \mathrm{~m}$ e $1 \mathrm{~km}$, além de amostras de solo destas regiões para correlação. Gulhane et al. fez uso de redes neurais para nao só correlacionar as informações espectrais com os dados das amostras químicas, mas também para prever os parâmetros agrícolas e validar o método.

De forma semelhante, neste trabalho conduz-se uma análise química de amostras de uma propriedade agrícola na região do triângulo, em Minas Gerais, obtém-se imagens orbitais dos satélites Pleiades, Landsat-8 e do Google Earth para correlacionar os parâmetros agrícolas com as informações de refletância destas imagens. Com isso, faz-se uma análise das informações obtidas, tendo em mente a perspectiva do pequeno produtor que procura informações simplificadas e de baixo custo. 


\section{JUSTIFICATIVA E OBJETIVOS}

Nos últimos anos, a agricultura de precisão tem ganhado importância na economia agrícola. A AP tem mostrado grande penetração dentre os produtores, principalmente nas economias agrícolas mais desenvolvidas, que, com acesso a financiamentos e informação, procuram otimizar ao máximo sua cultura, e desta forma estabelecem processos científicos sistêmicos, pondo ao seu dispor ferramentas das mais inovadoras. De acordo com a pesquisa de campo neste trabalho realizada, no Brasil, entretanto, pelo menor acesso ao crédito financeiro, quando se compara com as principais nações concorrentes na agricultura, como EUA e China, o alcance à equipamentos e métodos inovadores se torna mais difícil. Os métodos aplicados no mercado nacional, ainda são de pouca precisão espacial ou temporal, quando se compara à agricultura de precisão aplicada em outras economias desenvolvidas. Como exemplo, usemos a própria amostragem tomada neste estudo para comparação com o método de sensoriamento remoto: para avaliação físico-química de uma propriedade, é usual, para pequenos e médios produtores, tomar-se uma única amostra em um ponto qualquer da área de lavoura, e considerar aquele resultado como a média de uma área bem maior, impossibilitando o mapeamento preciso da distribuição de nutrientes. Isto ocorre devido, por vezes ao acesso financeiro, em outros momentos pela falta de conhecimento dos benefícios da agricultura de precisão, ou mesmo pelo não treinamento do produtor para lidar com as informações geradas pela última(2).

Desta forma, quaisquer avanços no uso de informações de fácil acesso para gerenciamento de culturas, como o uso de imagens do Google Earth, imagens de satélite com definição abaixo dos $50 \mathrm{~cm}$, ou a implementação de VANT s para obtenção de imagens aéreas, serão de grande valia para o progresso da economia agrícola, principalmente em se tratando de pequenos produtores. Os desafios que urgem por soluções iminentes passam por aproximação entre pesquisadores e produtores, para que se possa entender cada vez melhor as reais necessidades a serem atendidas, e pela padronização de informações geradas e especificações de coleta destas informações, para que possa existir campo para competição entre empreendedores e empresas que atuam em AP (2). Aliando a transmissibilidade da informação gerada com o uso de dados de fácil acesso para gerá-las em primeiro lugar, a concorrência de mercado tende a trazer grandes avanços para a AP, tanto tecnicamente, como na penetração de mercado. Por isso, este trabalho se baseia na necessidade identificada de aplicação de técnicas de sensoriamento remoto, usando diferentes fontes de informação, para aplicação em pequenas propriedades, gerando informações com as quais os produtores possam se familiarizar mais facilmente, permitindo o uso destas no gerenciamento de nutrientes para a lavoura. 


\section{REVISÃO BIBLIOGRÁFICA E METODOLOGIA}

Neste capítulo se descorre sobre os métodos utilizados neste trabalho, assim como o contexto no qual eles foram empregados. Serão discutidos o ciclo de nutrientes no solo e na planta, a metodologia de análise química de solo, serão apresentadas revisões sobre refletância e índices de vegetação, e sobre sensoriamento remoto.

\subsection{CICLO DE NUTRIENTES NO SOLO E NA PLANTA}

Existem ao menos 16 elementos químicos essenciais para o crescimento de uma planta (8). O fósforo, o cálcio, o magnésio, o potássio, o nitrogênio, o enxofre, o ferro, o manganês, o zinco, o cobre, o boro, o molibdênio e o cloro são os elementos vitais para o crescimento de qualquer planta, sendo absorvidos pela mesma durante o crescimento a partir do solo. Outros elementos, como o sódio, o silício, iodo e o selênio fazem parte do ciclo de algumas espécies e trazem grandes benefícios ao desenvolvimento vegetal quando corretamente administrados. A proporção na qual estes elementos são requeridos para o desenvolvimento da planta depende de vários fatores, como a genética da semente, das características físicas, químicas e biológicas pré-existentes no solo, clima, altitude e a rotação de plantio que o produtor escolhe fazer. Esta rotação é um dos fatores determinantes para a manutenção das características do solo e, principalmente, da vida útil do solo para atividades agrícolas, por que, a biomassa residual de um plantio é uma das maiores fontes de nutrientes do solo, e uma boa escolha de rotação de cultura pode potencializar o desenvolvimento da lavoura principal. O nitrogênio, o fósforo e o potássio são os nutrientes primários para o desenvolvimento vegetal, seguidos por cálcio, magnésio e enxofre. As proporções vão de $450 \mathrm{mg} / \mathrm{m}^{2}$ de $\mathrm{N}, \mathrm{P}$ e K, $150 \mathrm{mg} / \mathrm{m}^{2}$ de $\mathrm{Ca}, \mathrm{Mg}$ e $\mathrm{S}$, até $5 \mathrm{mg} / \mathrm{m}^{2}$ de outros elementos nutricionais menos vitais. A fertilidade do solo depende da correta proporção destes nutrientes, e da manutenção dos mesmos ao longo dos trabalhos nele realizados. A reciclagem dos elementos é a chave do bom gerenciamento de fertilidade agrícola (8).

O fósforo contido no solo é quimicamente e fisicamente ativo, significando que as transformações pelas quais o fósforo passa ainda no solo são críticas para a boa nutrição da planta. A necessidade de um ciclo de nutrientes dinâmico no solo pode ser compreendida ao se comparar as quantidades de fósforo requeridas para culturas e as concentrações típicas de fósforo no solo. Uma cultura de aproximadamente 10 toneladas por hectare de milho tem em média 18 $\mathrm{kg}$ de fósforo nos grãos, ou seja, a demanda por fósforo para esta cultura é de $18 \mathrm{~kg}$ por hectare (desconsiderando a demanda por fósforo na raiz). A solubilidade do fósforo no solo é consideravelmente baixa, sendo a concentração mais comum entre 0,01 e 1ppm. Devido às 


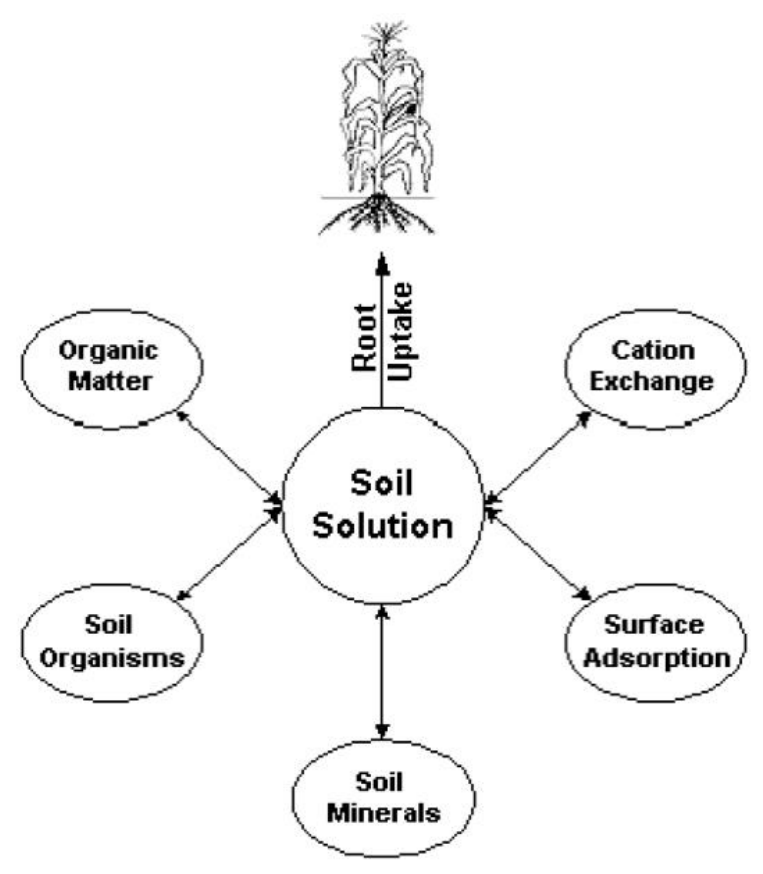

Figura 2 - Trocas de Nutrientes do solo à raíz da planta. Fonte: Bierman et al, 2005.

concentrações médias de fósforo nos fertilizantes e à capacidade de absorção de água do solo, as quantidades de fósforo no solo precisam ser repostas 400 vezes durante o crescimento da plantação (8). Portanto, ter a informação precisa de quanto fósforo deve ser reposto e onde na área de cultivo é uma grande vantagem em relação à tempo e custo de operação durante o cultivo.

O nitrogênio, considerado um dos nutrientes mais importantes para o desenvolvimento vegetal tem um ciclo nutricional complexo. Disponível em várias formas para a planta, o N é transmitido às células da planta por processos bioquímicos, tais como:

- Nitrificação: conversão da amônia, de carga positiva preso ao solo por um processo chamado Capacitância de troca de Cátions, em um nitrato de carga negativa de fácil absorção;

- Denitrificação: a conversão do nitrato disponível na planta em gases à base de nitrogênio, tornando-se indisponível para a planta;

- Mineralização: quebra biológica de moléculas nitrogenadas liberando amônia, ao alcance da planta;

- Imobilização: absorção de nitrogênio disponível no solo em formas inorgânicas e incorporação a componentes orgânicos, agora nitrogenados; 


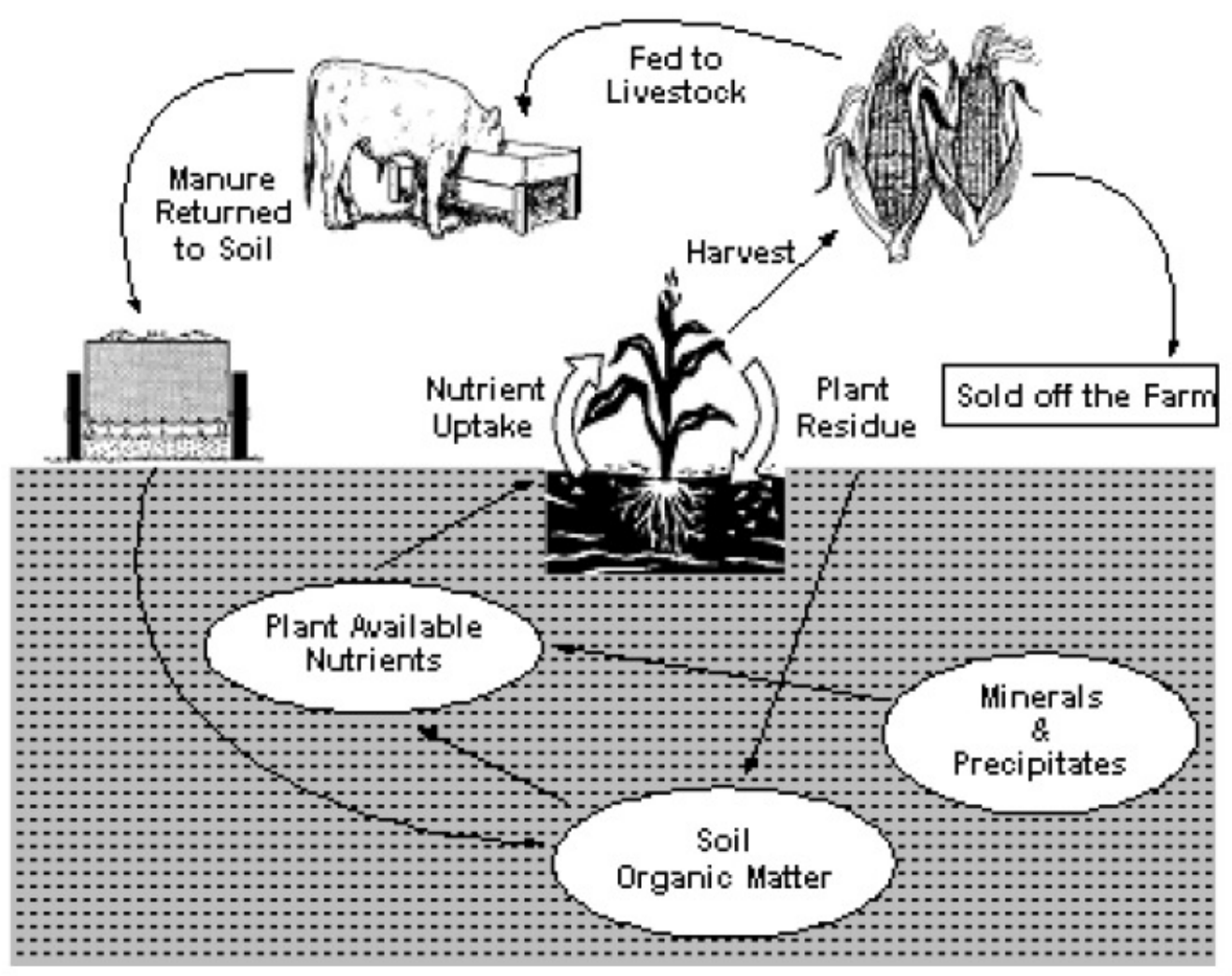

Figura 3 - Ciclo de absorção de nutrientes por uma planta. Fonte Bierman et al, 2005.

- Fixação: conversão do gás nitrogênio do ar em moléculas nitrogenadas, tornando-se disponível para absorção vegetal.

O nitrogênio é, na maioria dos casos, um dos nutrientes de maior fator limitante para o crescimento vegetal em ecossistemas terrestres. A taxa de crescimento e a concentração de clorofila em cultura milho, por exemplo, está relacionada à concentração de nitrogênio no solo(9). Desta forma, a quantidade de nitrogênio disponível gera respostas agudas para o desenvolvimento da lavoura. Além disso, quando na forma de nitratos, este elemento se torna extremamente solúvel, sendo o nutriente de maior acesso às plantas no solo, mas também de maior difusão por grandes áreas, tornando-se um potencial agente danoso ao meio ambiente.

Beeri et al. 2005 (10) mostra que o excesso de fertilização por nitrogênio afeta a qualidade da água e do ar, agredindo o ambiente circundante à lavoura. Uma forma de otimizar a aplicação de $\mathrm{N}$ pode ser pela estimativa de fertilizante remanescente nos resíduos da última lavoura no solo. Desta forma, o offset de $\mathrm{N}$ é definido como a carga nitrogenosa já existente, e as aplicações são feitas a partir dali. Esta estimativa pode ser feita a partir de dados fotográficos aéreos. A folha da cana de açúcar, por exemplo, com sua superfície rica em nitrogênio, por muitas das vezes cobre o solo após a colheita. Esta folha carrega até $47 \%$ do 
nitrogênio necessário para fertilizar a superfície do solo. Boa parte deste nitrogênio compõe a biomassa da folha, contribuindo com 100 a $450 \mathrm{~kg}$ por hectare, que no outono acaba sendo absorvido pelo solo. O principal desafio é a otimização do uso de nitrogênio de forma a garantir alta produtividade sem grandes riscos ambientais (11). O gerenciamento passa pela aplicação direcionada do fertilizando, com maior resolução temporal e espacial. O sistema tradicional agrícola, geralmente, aplica os fertilizantes nitrogenados de forma uniforme por toda a superfície da lavoura. A deficiência de nitrogênio nas folhas durante o crescimento pode ter como consequência o aumento da refletância na região ao redor do verde e na diminuição da refletância no infravermelho próximo (NIR), enquanto a refletância no vermelho se mantém constante para variados níveis de nitrogênio (12).

Elementos, como P, S e B acabam participando dos ciclos de nutrientes através do ciclo do carbono. Resíduos biológicos de outras plantas (entre safras, por exemplo), de animais ou de grãos retornam ao solo, disponibilizando compostos de carbono às raízes. Estes compostos se quebram em estruturas mais simples, ficando acessíveis aos próximos ciclos de nutrientes(8).

Um conceito importante de se mencionar é o CTC, capacidade de troca de cátions. Esta propriedade do solo permite a retenção de cátions de $\mathrm{K}, \mathrm{Ca}$ e $\mathrm{Mg}$ ao alcance da raiz da planta, além de permitir a retenção de $\mathrm{N}$ na amônia dissolvida no solo. Alguns métodos de gerenciamento de nutrientes tem como foco o balanço da razão entre nutrientes, principalmente o do balanço entre Cálcio e Magnésio. A razão entre estes dois elementos é importante para que a quantidade de um não afete a disponibilidade do outro no solo para a raiz da planta (8). (4) apresenta uma esquematização da capacidade de troca de cátions em matéria orgânica e em argila.

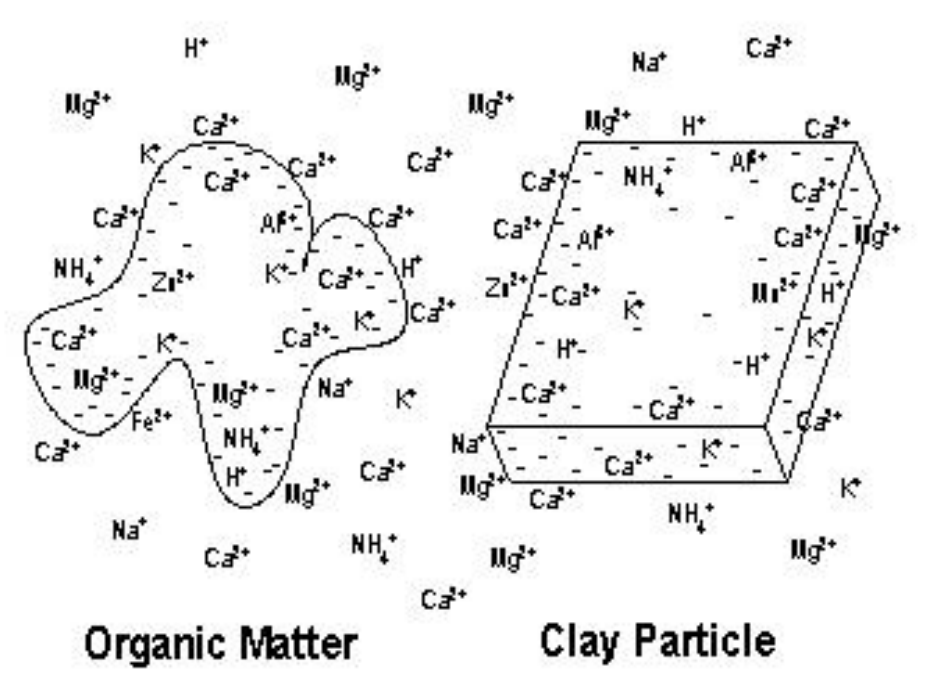

Figura 4 - Capacidade de troca de cátions. Fonte: Bierman et al. 2005. 
A compreensão destes ciclos é importante para o correto gerenciamento de nutrientes, mas raramente os produtores dispõem de tempo, recursos ou conhecimento para fazer a análise que o permita identificar onde, dentro do ciclo de nutrientes, sua lavoura se encontra. Por isso, como referência, alguns laboratórios de análise química de solo e folha oferecem tabelas, indicando os níveis ideais de nutrientes disponíveis no solo, e as respectivas medidas a serem administradas em cada caso. O laboratório escolhido neste trabalho para realizar as análises químicas, o Safrar, referencia os níveis ideais de nutrientes com o Boletim de de recomendação da Comissão de Fertilidade de Solo do Estado de Minas Gerais, CFSEMG, estabelecido em 1999 1. Como sugestão ilustrativa, o laboratório apresenta um Fertigrama, no qual se graduam os níveis de cada nutriente em faixas qualitativas de muito baixo até muito bom, permitindo uma compreensão das informações mais facilmente administrável pelo produtor. Obviamente que estas análises carecem de precisão espacial que permita a otimização tanto do gasto com a aplicação de adubos quanto na definição da estratégia de gerenciamento como um todo, porém elas permitem a contemplação macro do cenário de nutrição do solo naquele ponto de amostra.

\begin{tabular}{|c|c|c|c|c|c|c|c|c|c|c|c|c|c|c|}
\hline \multirow{2}{*}{\multicolumn{11}{|c|}{$\begin{array}{l}\text { Níveis ideais de nutrientes no solo segundo Boletim de recomendação CFSEMG(1999). } \\
\text { Obs: S-SO , B, Cu, Fe, Mn, Zn fonte: Boletim Técnico 100, IAC (1997). }\end{array}$}} & Argila & $\mathrm{P} \mathrm{meh}^{-1}$ & P rem. & $\mathrm{P} \mathrm{meh}^{-1}$ \\
\hline & & & & & & & & & & & $60-100$ & $8,1-12$ & $0-4$ & $6,1-9$ \\
\hline pH Água & $\mathrm{pH} \mathrm{CaCl}_{2}$ & $k^{+}$ & $\mathrm{S}-\mathrm{SO}_{4} \overline{\overline{4}}$ & $\mathrm{Ca}^{2+}$ & $\mathrm{Mg}^{2+}$ & $\mathrm{Al}^{3+}$ & $\mathrm{H}+\mathrm{Al}$ & SB & $t$ & $T$ & $35-60$ & $12,1-18$ & $4-10$ & $8,5-12,5$ \\
\hline \multirow[t]{2}{*}{$5,5-6,5$} & $4,9-5,9$ & $>80$ & $>10$ & $2,4-4,0$ & $0,9-1,5$ & $<0,2$ & $<2,0$ & $3,6-6,0$ & $4,6-8,0$ & $8,6-15,0$ & $15-35$ & $20,1-30$ & $10-19$ & $11,5-17,5$ \\
\hline & $\mathrm{m}$ & M.O. & $P$ resina & & & & & & & & $0-15$ & $30,1-45,0$ & $19-30$ & $15,9-24$ \\
\hline \multirow{2}{*}{$\frac{V}{60-80}$} & $<20$ & $2,1-4,5$ & $41-80$ & & & & & & & & & & $30-44$ & $29,1-33$ \\
\hline & & & & & & & & & & & & & $44-60$ & $30,1-60$ \\
\hline
\end{tabular}

(a) Valores ideiais para nutrientes presentes no solo.

\begin{tabular}{|c|c|c|c|c|c|c|c|c|c|c|}
\hline Graduação & $P$ & $K$ & $S-S O_{4}$ & $C a$ & $M g$ & $B$ & $C u$ & $F e$ & $M n$ & $Z n$ \\
\hline \hline Muito Bom & 30,9 & 164,8 & 18,2 & 4,5 & 1,8 & 0,93 & 2,21 & 49,1 & 13,3 & 2,64 \\
\hline Bom & 24,7 & 131,9 & 14,5 & 3,6 & 1,4 & 0,74 & 1,77 & 39,2 & 10,6 & 2,11 \\
\hline Médio & 18,5 & 98,9 & 10,9 & 2,7 & 1,1 & 0,56 & 1,32 & 29,4 & 8,0 & 1,58 \\
\hline Baixo & 12,4 & 65,9 & 7,3 & 1,8 & 0,7 & 0,37 & 0,88 & 19,6 & 5,3 & 1,06 \\
\hline Muito Baixo & 6,2 & 33,0 & 3,6 & 0,9 & 0,4 & 0,19 & 0,44 & 9,8 & 2,7 & 0,53 \\
\hline
\end{tabular}

(b) Fertigrama com gradação para cada nutrientes. Números em $\mathrm{mg} / \mathrm{dm}^{3}$.

Tabela 1 - Níveis ideiais de nutrientes. Fonte: Laudo de Análise de Solo, Laboratório Safrar.

\subsection{ANÁLISE QUÍMICA DO SOLO}

O objetivo de se reunir amostras de solo para análise química é compreender se o solo contém os nutrientes necessários, e não em excesso, que permitam o crescimento otimizado da cultura. Análises de solo convencionais fazem uso de soluções químicas, como ácidos, soluções 
alcalinas ou de sal, adicionadas de outros agentes, para extrair nutrientes (8). Análises de solo são esparsas no tempo, variando em ciclos de 1 a 3 anos, dependendo da rotação de lavouras, histórico da área e tipo de cultura. Áreas com rotações estáveis, com longo histórico de análises de solo e com gerenciamentos padrões de nutriente, chegam a dar intervalos de cinco anos entre uma análise e outra. Uma coleta representativa de amostras de solo costuma ser o fator limitante para análises químicas. Enquanto recomenda-se que as amostras sejam tomadas de áreas divididas por histórico de lavoura, textura e cor de solo e gerenciamento de nutrientes((8)), limitações de tempo e de dinheiro levam o pequeno e médio produtor a confiar em poucas amostras localizadas para estimar o conteúdo de nutrientes da sua área de lavoura. Amostras localizadas podem servir de estimativa para no máximo uma área de oito hectares, no caso de uma área plana e uniforme.

Para fins acadêmicos, autores fazem uso de maior número de amostras, menos espaçadas entre si, permitindo assim um estudo mais detalhado de correlação com outras propriedades como a própria refletância do solo, como será feito neste trabalho. Yusoff et al, (13), por exemplo, tomou 54 amostras espaçadas de 80 metros entre si, ou seja, cada amostra sendo representativa de uma área de 0,16 hectares. Obviamente, quanto maior o número de amostras espaçadas uniformente em distâncias cada vez menores umas das outras, mais fiel será o mapa de variabilidade de nutrientes gerado apartir das interpolações apropriadas. Magri at al, (14) tomou amostras espaçadas em 50m umas das outras. Já Bausch (12) fez uso de amostras espaçadas em $70 \mathrm{~m}$ umas das outras, mas não necessariamente formando uma grade de pontos equidistantes. Neste caso, o autor priorizou respeitar o histórico de administração de fertilizantes do que a simples equidistância entre os pontos de amostra.

\subsection{REFLETÂNCIA}

As assinaturas espectrais de um material são definidas por suas refletâncias e absorvências em relação ao espectro eletromagnético. Estas assinaturas resultam de transições de níveis dos elétrons e de vibrações nas configurações dos cristais de átomos do material. Algumas das características fundamentais da matéria orgânica presente no solo acontecem nas regiões de infravermelho térmico (2,5 a 25m), infravermelho curto (1 a 2,5m) e infravermelho próximo $(0,7$ a $1 \mathrm{~m})$. As regiões visíveis têm sido usadas para identificação de componentes ferrosos e alguns óxidos (15). Porém, devido à variedade dos tipos de solos que podem ser aplicados na cultura em questão, somada aos diferentes graus de umidade e de argila presentes neste solo, a relação direta entre as propriedades de solo e índices de refletância são geralmente calibrados por amostras tomadas diretamente da área e analisadas quimicamente.

Já quando se trata de vegetações, as saudáveis absorvem a maior parte da luz visível que lhe 


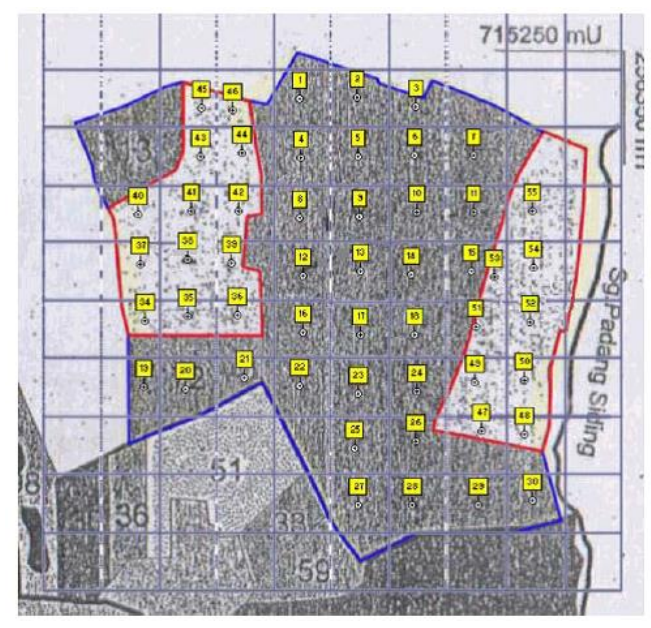

(a) Espaçamento de 80m. Fonte: Yusoff et al, 2006.

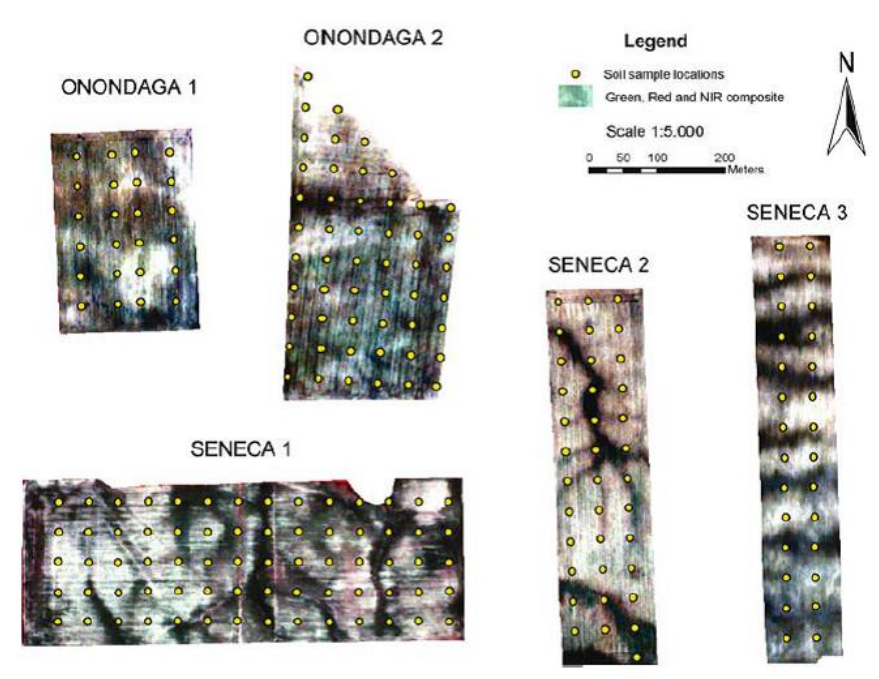

(b) Espaçamento de 50m. Fonte: Magri et al, 2005.

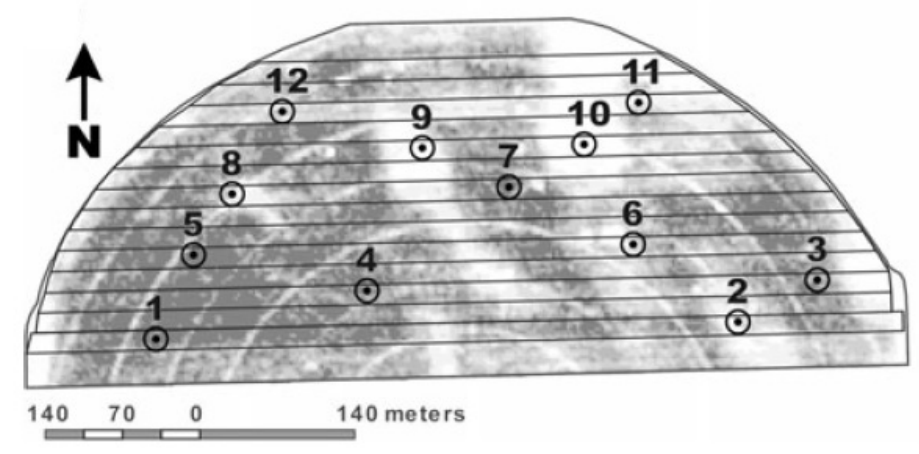

(c) Espaçamentos menores que 70m. Fonte: Bausch et al, 2010.

Figura 5 - Exemplos de amostras tomadas, na bibliografia, com espaçamentos menores que 100m.

incide, e reflete boa parte das frequências próximas ao infravermelho. Vegetações não saudáveis e esparsas, por outro lado, refletem mais as bandas visíveis e menos das bandas próximas ao infravermelho. Porções de terra descobertos, isto é, sem vegetação, refletem as bandas vermelha e infravermelha (4). Na folha, a relação entre refletância e macro nutrientes, como fósforo, potássio, magnésio e cálcio são esperadas, dadas as suas respectivas importâncias ao processo fotossintético (16). O comportamento da refletância para uma vegetação saudável pode ser observado na figura a seguir.

As informações de refletância, quando aliadas às respectivas características do solo apontadas, pode então permitir que estimativas sejam feitas sobre o conteúdo de nutrientes do solo e da vegetação na área de estudo, a partir de regressões matemáticas entre os números digitais de refletância e dos níveis de concentração de nutrientes aferidos de amostras em laboratório (4). 


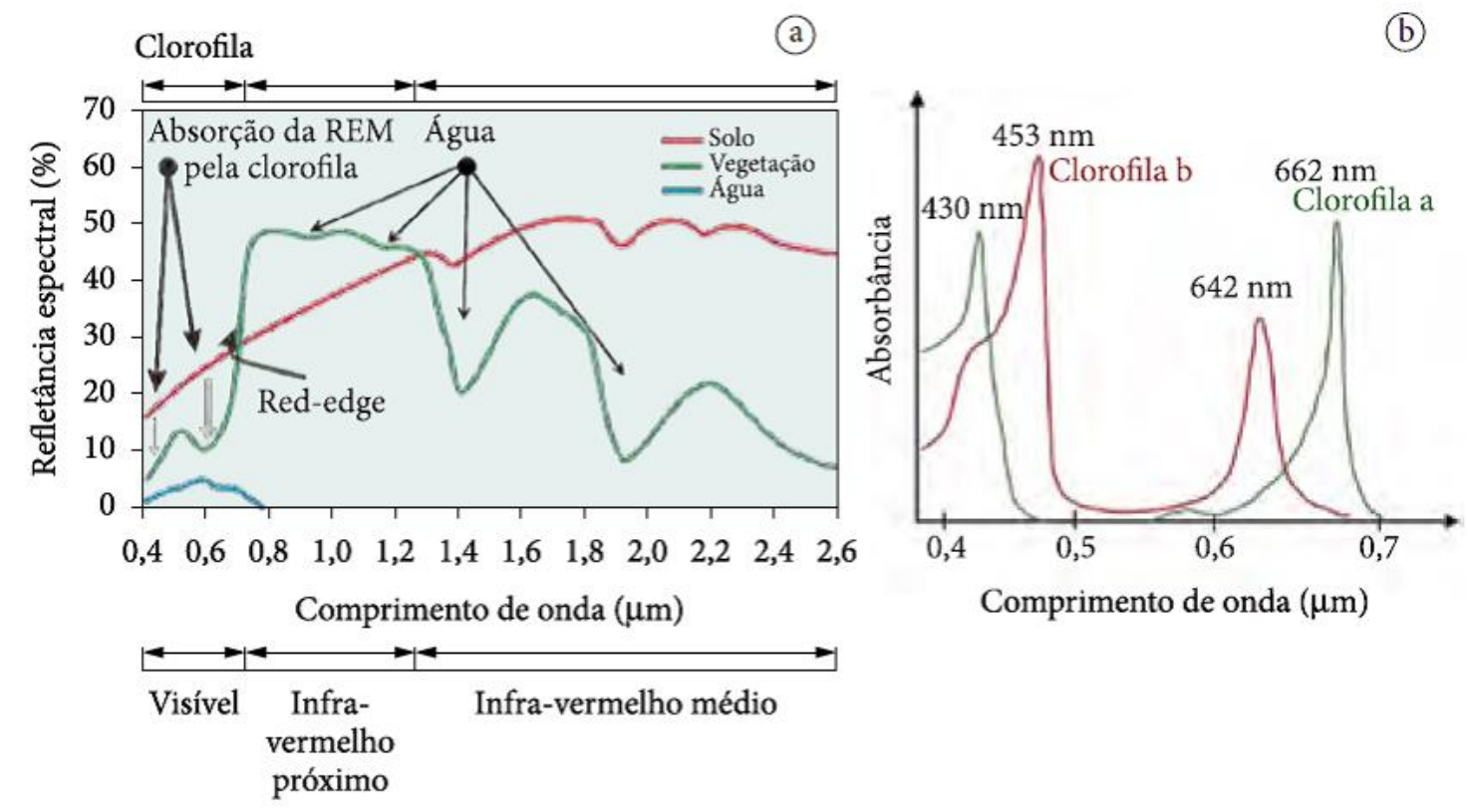

Figura 6 - Comportamento da refletância para uma vegetação saudável. Fonte: Shiratsuchi et al, 2014.

A clorofila reflete todo o espectro visível, tendo seu ápice de refletância no comprimento verde, entre 500 e $600 \mathrm{~nm}$ de comprimento de onda. A absorção máxima da clorofila, por outro lado, se dá nas faixas azul, de $400 \mathrm{~nm}$ a $500 \mathrm{~nm}$, e vermelho, de $600 \mathrm{~nm}$ a $700 \mathrm{~nm}$ de comprimento de onda. Em comprimentos de onda maiores, acima de 1300nm, o conteúdo de água nas folhas influencia na interação com luz incidente. A seguir, uma tabela relacionando as bandas do espectro com características das plantas.

\begin{tabular}{|c|c|c|}
\hline Banda & Comprimento de onda (m) & Aplicações em AP \\
\hline \hline Azul & 0,45 a 0,51 & Diferenciação entre solo e vegetação \\
\hline Verde & 0,53 a 0,59 & Refletância de vegetação sadia \\
\hline Vermelho & 0,64 a 0,67 & Absorção de clorofila \\
\hline NIR & 0,85 a 0,88 & Levantamento de Biomassa \\
\hline SWIR1 & 1,57 a 1,65 & Medidas de umidade de vegetação \\
\hline SWIR2 & 2,11 a 2,29 & Mapeamento hidrotermal \\
\hline Pancromática & 0,50 a 0,68 & Fusão de imagens \\
\hline TIRS1 & 10,6 a 11,19 & Temperatura de superfície \\
\hline TIRS2 & 11,5 a 12,51 & Temperatura de superfície \\
\hline
\end{tabular}

Tabela 2 - Bandas espectrais e algumas de suas possíveis interpretações para PA. Adaptado de Shiratsuchi et al. 2014. 


\section{4 ÍNDICES DE VEGETAÇÃO}

Índices de vegetação são números adimensionais, que medem a atividade de vegetações, utilizando em especial as faixas visíveis do EEM, além do infravermelho próximo (4). Uma vez conhecido a relação entre o comportamento vegetal e o espectro eletromagnético, é possível derivar informações dos VI s, focando nas bandas do espectro impressas nas fotografias obtidas por uma plataforma aérea devidamente equipada.

O Índice de vegetação diferencial normalizado (NDVI), por exemplo, é um indicador numérico que utiliza as bandas visíveis e de infravermelho do espectro eletromagnético. O NDVI tem aplicações amplas nos estudos de vegetações e tem sido usado para estimar colheitas e a performance da safra. Este VI é frequentemente relacionado diretamente a padrões de solo como nível de cobertura vegetal, atividade fotossintética da planta [relacionado ao nível de nitrogênio], água na superfície, IAF e quantidade de biomassa. Numericamente, o NDVI consiste na razão entre a diferença entre a intensidade da refletância em vermelho e infravermelho próximo e a soma da intensidade da refletância em vermelho e em infravermelho próximo.

A razão entre a diferença e a soma é usada para que se mitigue diferenças de intensidades relativas, como por exemplo, pontos sob sombra de nuvens e pontos ensolarados na mesma área. O resultado do NDVI obtido a partir dos valores dos pixels da imagem pode apontar presença de água líquida (valores negativos menores que -1), solo não cultivado (valores próximo de zero) e vegetação densa (valores acima de 6). Albayrak et al, 2008 (16) aplica uma simples razão entre os índices de refletância nas faixas de infravermelho próximo e vermelho para estimar as concentrações de nitrogênio, fósforo e potássio em uma plantação.

Utilizando imagens geradas em sobrevoos de VANT s a campos agrícolas, Berni et al. (2009) (17) calculou índices de vegetação como o NDVI para estimar o índice de cobertura vegetal, cIAF. O uso de uma relação empírica obtida por medições de clAF em campo mostrou coerência matemática dos dados $\left(r^{2}=0,88, R M S E=0,13\right)$, permitindo o mapeamento da variação de clAF dos campos estudados. O TCARI, índice de refletância da absorção da clorofila transformada, normalizado pelo OSAVI, índice otimizado de vegetação ajustada ao solo, para obter-se os índices de vegetação TCARI/OSAVI, demostrou-se bem sucedido ao minimizar o background do solo e a variação do IAF em lavouras, fornecendo relações que permitem prever concentrações de clorofila em conjuntos de imagens de plantações.

A obtenção de informações em infravermelho depende de equipamento preparado para tal. No caso da utilização de câmeras comuns, usa-se substituir o NDVI pelo índice normalizado da diferença verde-vermelho, NGRDI. As bandas de verde e de vermelho também variam de acordo com as condições do solo e da vegetação, apesar de a diferença entre as bandas para estas situações não seja tão expressiva como as diferenças entre infravermelho e vermelho (9). 
A aplicação do NGRDI também já se mostrou na literatura plausível para estimar níveis de biomassa, variações de IAF e de nitrogênio em culturas de milho e alfafa. A relação linear entre este $\mathrm{VI}$ e alguns parâmetros agrícolas será vital para o desenvolvimento deste trabalho.

Huang et al, 2013 (11) llista alguns dos índices de vegetação mais utilizados e suas respectivas equações. Ainda fornece duas tabelas relacionando índices de vegetação e alguns parâmetros agrícolas como biomassa, IAF, absorção e concentração de nitrogênio, SPAD e NNI.

A combinação dos índices de vegetação apresentados nos trabalhos de Huang et al, 2013 e Albayrak et al, 2008 serão os índices utilizados nesta análise, e podem ser vistos na tabela 3 .

\begin{tabular}{|c|c|}
\hline Índicie de Vegetação & Relação com faixas do espectro \\
\hline \hline NDVI - Normalized Difference Vegetation Index & $\frac{N I R-R}{N I R+R}$ \\
\hline Ratio Of Reflectance & $\frac{N I R}{R}$ \\
\hline NGRDI - Normalized Green-Red Difference Index & $\frac{(G-R)}{(G+R)}$ \\
\hline $\mathrm{Cl}$ - Chlorophyl Index & $\frac{N I R}{G}-1$ \\
\hline
\end{tabular}

Tabela 3 - Índices de vegetação mais comumente usados. Adaptado de Huang et al, 2013 e Albayrak et al, 2008. NIR: Infravermelho próximo. R: vermelho. G: verde.

Os trabalhos de Magri et al, 2005 (14), Thomasson et al, 2001 (18) e Yussof et al, 2006 (13) fornecem os valores de nutrientes relacionados com os valores de refletância e de índices de vegetação. Magri, por exemplo, tomou amostras de cinco áreas com solos diferentes em dois distintos anos, 1999 e 2000, e as analisou para o conteúdo de fósforo, potássio, nitratos, entre outros. Isso nos permite traçar uma regressão entre os dados de nutrientes e refletância para testar a possibilidade de criação de mapas de variabilidade. A tabela 耳 apresenta estas correlações e os respectivos $r^{2}$ que identificam o nível de correlação entre os dados.

\subsection{SENSORIAMENTO REMOTO}

O sensoriamento remoto aplicado em AP comumente faz uso de informações espectrais, mais precisamente refletância, para o cálculo de parâmetros agrícolas. A luz reflete em diferentes superfícies e interage com diferentes frequências do espectro visível (comprimentos de onda de 0.4 a 0.7 micrômetros). A medição desta reflexão da radiação eletromagnética é chamada de espectroscopia de refletância. A frequência denominada infravermelho próximo, NIR (do inglês Near Infra Red), é amplamente utilizada nos cálculos de parâmetros agrícolas. Cada comprimento de onda da radiação eletromagnética possui um comportamento particular em relação a superfícies de diferentes corpos. O comportamento espectral é resultado direto 


\begin{tabular}{|c|c|c|c|}
\hline Nutriente & Banda & Coeficiente de Correlação $r$ & Regressão Linear \\
\hline \hline \multirow{4}{*}{$N O_{3}$} & Vermelho & 0,07 & $N O_{3}=0,0415 *$ Red $+14,954$ \\
\cline { 2 - 4 } & Verde & $-0,26$ & $N O_{3}=-0,2084 *$ Green $+56,413$ \\
\cline { 2 - 4 } & NIR & $-0,37$ & $N O_{3}=-0,1425 *$ NIR $+38,343$ \\
\hline \multirow{4}{*}{$P$} & Vermelho & $-0,41$ & $P=-0,0618 *$ Red $+17,049$ \\
\cline { 2 - 4 } & Verde & $-0,50$ & $P=-0,1045 *$ Green $+24,548$ \\
\cline { 2 - 4 } & NIR & $-0,65$ & $K=-0,0651 *$ NIR $+14,751$ \\
\hline \multirow{3}{*}{$K$} & Vermelho & $-0,42$ & $K=-1,1932 *$ Green $+297,04$ \\
\cline { 2 - 4 } & Verde & $-0,54$ & $K=-0,761 *$ NIR $+187,16$ \\
\cline { 2 - 4 } & NIR & $-0,72$ & Red $+206,84$ \\
\hline
\end{tabular}

Tabela 4 - Correlações entre propriedades de solo, de acordo com dados obtidos por Magri et al, 2005.

das propriedades físicas e químicas do material sobre o qual a luz incide. As estruturas atômicas do material afetam como cada comprimento de onda é refletido, absorvido ou refratado. Desta forma, estruturas moleculares, como a das clorofilas a e b, na qual o elemento nitrogênio compartilha o protagonismo com o carbono, tem uma assinatura espectral que pode ser detectada sob o filtro adequado. Em comprimento de onda da região visível do espectro eletromagnético, a refletância pode ser relacionada aos níveis de distribuição de clorofila a e $b$, xantofilas, antocianinas e carotenoides. Já nos comprimentos de onda do infravermelho próximo, as estruturas internas das folhas são fatores determinantes para a assinatura espectral, permitindo avaliar tamanho da folha (índice IAF) e distribuição de nutrientes pela mesma. Avançando nos comprimentos de infravermelho, pode-se associar a refletância à absorção de água, lignina, celulose, amido, proteínas e compostos nitrogenados. Plataformas aéreas tem sido a escolha mais comum para sensoriamento remoto na agricultura. Imagens geradas por estas plataformas tem capacidade de cobertura de áreas maiores em um tempo menor do que técnicas terrenas. Se no passado balões, foguetes, pipas e até aves foram utilizados para este fim, atualmente as plataformas mais comuns são satélites, aeronaves e VANTs (4).

A tecnologia de sensoriamento remoto a partir de dados coletados via satélites tem se mostrado eficaz em monitorar o crescimento das lavouras. A evolução na resolução espacial e na precisão de posicionamento dos dados, além dos ciclos de passagem cada vez menores, tem permitido maior abrangência na aplicação de dados remotos na AP, e na literatura não é raro encontrar estudos mostrando a eficácia de satélites na estimativa de parâmetros agrícolas como o IAF, biomassa e concentração de N (11). Um dos satélites mais utilizados em AP é o QuickBird mas no início de 2015, ele fez sua reentrada na atmosfera terrestre, encerrando um ciclo de atividades de mais de 13 anos (http://www.satimagingcorp.com/satellite-sensors/quickbird/). 
Outros satélites utilizados para obtenção de dados espectrais já foram o Landsat 5 , o SPOT 5 e o lkonos 2 (10). O satélite Landsat 5 foi desativado em 2013. Hoje, o Landsat 8 (19) está em órbita, e imagens geradas por ele estão disponíveis, gratuitamente, nas bandas descritas na tabela $5 \mathrm{com}$ uma resolução de $30 \mathrm{~m}$. A variedade de bandas disponíveis permite ricas análises de solo e vegetação, mas a baixa resolução não permite sua aplicação na agricultura de precisão de pequenas e médias propriedades.

Neste contexto, o satélite Pleiades é uma fonte de dados mais precisa. Ele circunda o planeta a cada 26 dias tomando imagens pancromáticas com resolução de $50 \mathrm{~cm}$, cobrindo áreas de até um hectare. Como ele foi lançado em dezembro de 2012, poucos trabalhos na bibliografia o mencionam.

Huang et al. 2013 (11) obteve as imagens que alimentaram seus estudos de absorção de nitrogênio em plantações de arroz na China, a partir do satélite Formosat-2, que está equipado com sensores pancromático (resolução de $2 \mathrm{~m}$ ) e multiespectral de 4 bandas (resolução de $8 \mathrm{~m}$ ), capaz de cobrir uma área de $24 \mathrm{~km}$ por $24 \mathrm{~km}$ em uma única cena. Com uma taxa de uma volta por dia ao redor do planeta, o Formosat é capaz de manter a resolução temporal em níveis satisfatórios para aplicações em AP.

\begin{tabular}{|c|c|c|}
\hline Landsat-8 Bands & $\begin{array}{c}\text { Wavelength } \\
\text { (micrometers) }\end{array}$ & $\begin{array}{c}\text { Resolution } \\
\text { (meters) }\end{array}$ \\
\hline Band 1 - Coastal aerosol & $0.43-0.45$ & 30 \\
\hline Band 2 - Blue & $0.45-0.51$ & 30 \\
\hline Band 3 - Green & $0.53-0.59$ & 30 \\
\hline Band 4 - Red & $0.64-0.67$ & 30 \\
\hline Band 5 - Near Infrared (NIR) & $0.85-0.88$ & 30 \\
\hline Band 6 - SWIR 1 & $1.57-1.65$ & 30 \\
\hline Band 7 - SWIR 2 & $2.11-2.29$ & 30 \\
\hline Band 8 - Panchromatic & $0.50-0.68$ & 15 \\
\hline Band 9 - Cirrus & $1.36-1.38$ & 30 \\
\hline Band 10 - Thermal Infrared (TIRS) 1 & $10.60-11.19$ & 100 \\
\hline Band 11 - Thermal Infrared (TIRS) 2 & $11.50-12.51$ & 100 \\
\hline
\end{tabular}

Tabela 5 - Bandas disponíveis nas imagens geradas pelo Landsat-8. Fonte: Landsat-8.

Os veículos aéreos não tripulados, VANT, também chamados de drones ou UAV (do inglês Unmanned Aerial Vehicle) são aeronaves controladas por controle remoto, por estações de controle no solo, GCS (do inglês Ground Control Station), ou por sistemas embarcados de navegação autônoma. A sua trajetória de voo pode ser controlada manualmente, definida antes da decolagem na GCS ou automaticamente através de sensores e softwares de reconhe- 
cimento de objetos e sistemas de navegação. Dentre os variados tipos de VANT s disponíveis no mercado, os quadrotors ou quadcopters são os mais ágeis e versáteis, pelo fato de permitirem decolagens e pousos verticais, manobras de voos em todas as direções, mesmo que haja cargas adicionais à carenagem, como, neste caso, câmeras. Enquanto alguns VANT s carregam consigo módulos de IMU (inglês para unidade de medições inerciais) e de GPS (Sistemas de posicionamento global), outros tem sistemas de piloto automático, AFCS (do inglês autmonomous flight control system) embarcados. No AFCS já estão inclusos o IMU, GPS, sistema de radio com interface de servo e safety pilot e computador de voo.

Quando VANTs são a plataforma de coleta de dados escolhida, a questão das frequências do espectro disponíveis para análise se transforma em um gargalo, já que poucas câmeras comumente embarcadas em drones possuem sensibilidade à bandas abaixo do vermelho. Câmeras comuns já são utilizadas para detecção de falhas de plantio, de desenvolvimento da lavoura em geral e de modelos de elevação de terrenos. Trabalhos acadêmicos como o de Hunt et al. 2005 (9) ppropõem também o uso de câmeras comuns para a detecção de níveis de nitrogênio e de biomassa na lavoura. Câmeras térmicas, que detectam frequências de infravermelho próximo, podem ser utilizadas para avaliar a eficácia da irrigação. Câmeras multiespectrais são as mais indicadas para detecção de níveis nutricionais e fisiológicos, porém o seu custo é consideravelmente mais elevado do que o de câmeras comuns. As opções de câmeras multiespectrais ainda são limitadas. Algumas têm seu uso limitado pelo peso, outras pela definição de captação de certos comprimentos de onda. Nebiker et al. 2007 (20) desenvolveu um sensor multiespectral leve especialmente dedicado ao sensoriamento remoto. Já câmeras comerciais comuns tem como restrição o fato de possuírem filtros para frequências abaixo do espectro visível, o que exclui o infravermelho próximo.

Hunt et al, 2003, (21) compôs um sistema de sensoriamento remoto a partir de uma aeronave na tripulada de asa fixa que carrega uma câmera de filme comercial automática. O filme utilizado é sensível a infravermelho. Já em 2008 (22), o mesmo autor utilizou uma câmera Fuji FinePix S3 Pro UVIR de 12 megapixels de resolução, com um filtro customizado que bloqueia a banda vermelha e transmite banda NIR. Os resultados dos testes mostraram que os canais de vermelho/NIR da câmera tiveram resposta significativa na banda NIR. As bandas azul e verde foram satisfatoriamente filtradas pelo sistema da câmera. Em 2009, Berni et al (17) desenvolveu duas plataformas, modificando modelos de aeronaves. A aeronave tinha o seu posicionamento corrigido em tempo real durante o vô. Estas correções são cruciais para VANT s, por que servem de parâmetros para correção das imagens no momento do tratamento das mesmas. Este autor se utilizou de dois tipos diferentes de sensores embarcados nos VANT s: uma câmera multiespectral que consiste em seis sensores individuais com filtros óticos intercambiáveis, de acordo com os índices de vegetação desejados; e uma câmera térmica 
equipada com lentes de 40 graus de campo de visão, com resolução de 320x240 pixels e resposta espectral em nas bandas entre 7.5 a 13 micrômetros de comprimento de onda.

Em 2007, Laliberte et al (23) uutilizou um modelo modificado de aeronave não tripulado em voos testes com uma carga experimental de $1 \mathrm{~kg}$. Os voos duraram $30 \mathrm{~min}$ cada, tempo em que o motor queimaria 0.4 litros de gasolina. Além da câmera para obtenção de imagens aéreas de lavouras, o VANT levava um sistema de piloto automático, um sistema de estabilização de voo, baterias, sistema de GPS e circuitos de controle. A decolagem é controlada por rádio, assim como o pouso. Já o percurso era guiado por pontos carregados no sistema do GPS, que gravava as coordenadas dos pontos onde fotografias eram feitas. O autor ainda fez uso de um segundo VANT, tecnologicamente superior, que consiste em um sistema totalmente autônomo guiado por GPS, com uma estação terrestre para plano e software de voo, que, durante o voo, mostra os parâmetros do VANT como posicionamento, velocidade, altitude e consumo de combustível.

Em 2007, Nebiker et al (20) apresentou um protótipo de um sensor multiespectral de baixo peso embarcado em um pequeno UAS, demonstrando resultados favoráveis à aplicação deste equipamento em sensoriamento agrícola. A necessidade de imagens de alta resolução foi observada e se demonstrou que os sensores usados atendem a tal demanda. O micro sensor multiespectral, MSMS, foi desenvolvido primeiro investigando a viabilidade da aplicação de sensoriamento remoto em mini ou micro VANT s, e a seguir implementando um protótipo de sensor de baixo custo, de fácil operação. O autor realizou uma pesquisa de mercado que demonstrou a não existência de sensores multiespectrais com menos de um $1 \mathrm{~kg}$ que poderiam fornecer imagens em bandas diferentes (NIR, vermelho e verde) simultaneamente em canais de transmissão diferentes. A partir daí, o autor começou o desenvolvimento de um sensor de baixo custo e baixo peso, em um conceito de multi câmera modular, com uma câmera por banda a ser detectada. Cada câmera tem lentes de baixo peso e filtros de interferência para a seleção da banda espectral desejada. O peso total do protótipo é de apenas 350 gramas, incluindo os sistemas de controle e o frame de apoio da câmera. Os resultados dos testes mostraram que o hardware não compromete as estimativas dos índices de vegetação, tendo resultados consistentes com sensores convencionais. Desta forma, provou-se que sistemas de baixo custo e de baixo peso são viáveis e aplicáveis a atividades como a agricultura de precisão.

Todos estes trabalhos acima citados demonstram o interesse, já estabelecido, de se consagrar VANT s como o principal veículo de sensoriamento remoto em agricultura de precisão. Porém, ainda não estão presentes no mercado tecnologias e/ou metodologias de lida com esta técnica que permita o sucesso desta aplicação. Uma terceira via de sensoriamento remoto seriam imagens obtidas através de softwares de mapeamento comuns, nominalmente Google Earth. As imagens disponíveis no Google Earth cobrem todo o globo terrestre e foram obtidas pelos 
satélites Landsat 7 e Landsat 8. A resolução das imagens varia de 15 metros a 15 centímetros. O software permite a localização de coordenadas com precisão, a medição de distâncias entre pontos, a estimativa de altitude de observação, a obtenção de imagens em formato JPEG em alta resolução, com acesso às bandas de vermelho, verde e azul. Além disso, ele também permite a simulação de sobrevoos em uma trajetória escolhia pelo usuário.

Gulhane et al, 2017, (7) chegou à conclusão, em seu estudo, de que as imagens disponibilizadas pelo Google Earth poderiam ser utilizadas para estimativas do conteúdo químico de solos. O autor chegou a estimativas confiáveis de potássio, fósforo e carbono, comprovadas por análises químicas previamente realizadas na área. O autor estudou quatro grandes áreas de cultivo na India, das quais amostras de solo foram tomadas para análises químicas. Estas análises procuraram por informações tais como nível de $\mathrm{pH}$, condutividade elétrica, nível de concentração de carbono, fósforo e potássio. Imagens destas mesmas áreas foram obtidas a partir do Google Earth, a altitudes de 500 e 1000m, e com estas imagens fez-se a procurouse a correlação entre os níveis de refletância em cada banda disponível com os parâmetros estudados nas análises químicas das amostras de solo.

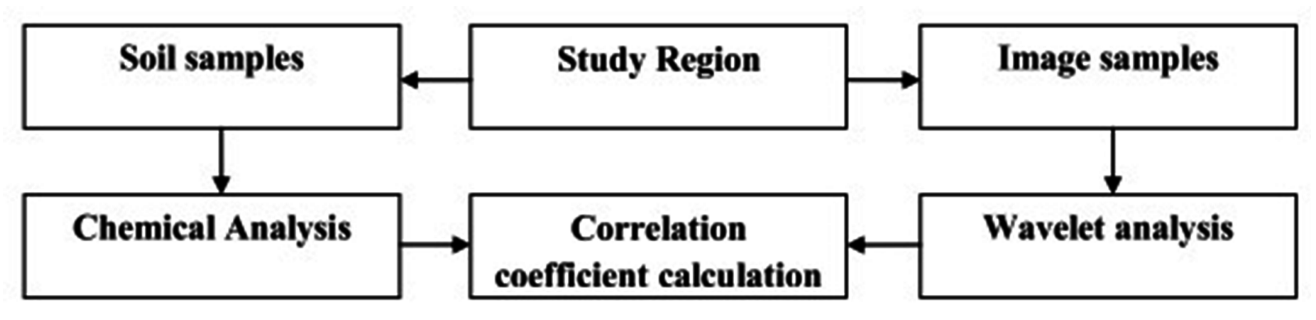

Figura 7 - Fluxograma da análise correlação. Fonte: Gulhane et al, 2017.

O autor fez uso de redes neurais para garantir a performance das correlações. Cada nutriente estudado teve uma rede de 20 neurônios por camada. Os resultados para carbono e fósforo foram melhores do que para estimativa de condutividade elétrica do solo e da concentração de potássio. De qualquer forma, as correlações entre os níveis de refletância e os resultados das análises químicas se mostraram fortes e consistentes.

A análise feita neste trabalho se baseia no fluxo de informações para a análise de correlação utilizada por Gulhane et al, 2017, apresentada na figura 7 . 


\section{IMPLEMENTAÇÃO}

Neste capítulo é apresentado como cada passo da metodologia foi implementado no contexto deste trabalho.

\subsection{ESCOLHA DA PROPRIEDADE AGRÍCOLA}

A fazenda escolhida para as análises está localizada na área rural de Coromandel, MG. De acordo com a definição do INCRA, se trata de um minifúndio, com aproximadamente 35 hectares de área agrícola. Estas características permitem uma análise não só técnica, mas também econômica da implementação da agricultura de precisão para pequenos produtores brasileiros. A cultura principal da propriedade é a soja, que é plantada nos meses de chuva. A cultura de entressafra é a de milho cuja colheita acontece entre julho e agosto de cada ano. Nos meses de fevereiro e de setembro, que seguem o fim da colheita anterior, o solo está o mais próximo de estar exposto, o que permite avaliações a partir de imagens aéreas possam ser mais assertivas.

\subsection{COLETA DE IMAGENS}

As imagens coletadas foram escolhidas de acordo com as análises e comparações desejadas: imagens para construção do mosaico, análise de nutrientes de solo e de nutrientes de vegetação. A combinação dos fatos de a área agrícola escolhida para estudos ser de pequeno porte e de a plataforma de sensoriamento escolhida (satélite) gerar imagens unitárias de áreas da ordem de 2500 hectares, imagens de fontes diferentes foram usadas para validar cada etapa do processo proposto. Para as estimativas de nutrientes do solo, imagens do satélite Pleiades foram obtidas, permitindo acesso às bandas de vermelho, verde, azul e infravermelho próximo, durante um período em que a área estava aguardando plantio, ou seja, com o solo exposto à imagem. Além disso, imagens do Google Earth foram obtidas em dois momentos diferentes, permitind acesso às bandas de vermelho, verde e azul. Outras imagens foram obtidas para análises paralelas, como mostra a tabela 6 . 


\begin{tabular}{|c|c|c|c|c|}
\hline Plataforma Aérea & Resolução & Data de Captura & Bandas Disponíveis & Aplicação neste trabalho \\
\hline Google Earth & \multirow{2}{*}{$15 \mathrm{~m}-15 \mathrm{~cm}$} & $17 / 02 / 2017$ & Vermelho, Verde e Azul & Estimativa de Nutrientes \\
\cline { 3 - 5 } & & $13 / 05 / 2017$ & Vermelho, Verde e Azul & Estimativa de Nutrientes \\
\hline Satélite Pleiades & $50 \mathrm{~cm}$ & $14 / 05 / 2017$ & NIR, Vermelho, Verde e Azul & Estimativa de Nutrientes \\
\hline Satélite Landsat-8 & $30 \mathrm{~m}$ & $03 / 09 / 2017$ & NIR, Vermelho, Verde, Azul e outros & Estimativa de Nutrientes \\
\hline
\end{tabular}

Tabela 6 - Imagens coletadas por plataforma aérea, data, bandas disponíveis e aplicação.

\subsubsection{Imagens para Estimativa de Nutrientes}

\subsubsection{Imagens com acesso às bandas vermelho, verde e azul}

Como apresentado no capítulo anterior, existe extensa bibliografia que relaciona bandas do espectro visível a parâmetros agrícolas. Dado o fácil acesso a imagens com apenas bandas de vermelho, verde e azul, tomadas em períodos recentes, avaliou-se, neste trabalho, as informações que se pode obter de tais dados, mesmo que a resolução não tenha a mesma qualidade da de satélites especializados. Tendo as análises de nutrientes resultados positivos utilizando estas imagens, isso representará um indicativo de que informações de fácil acesso podem ser usadas para sensoriamento remoto.

As imagens com as bandas de vermelho, verde e azul utilizadas foram obtidas através do Google Earth. Duas imagens foram tomadas: uma de fevereiro de 2017, quando o solo estava exposto, e outra de maio de 2017 quando havia o cultivo de milho na área. . As imagens tem resolução de aproximadamente $50 \mathrm{~cm}$. A áre de interesse, a fazenda de 35 hectares de onde as amostras de solo foram tomadas, está apresentada na figura 80 . 


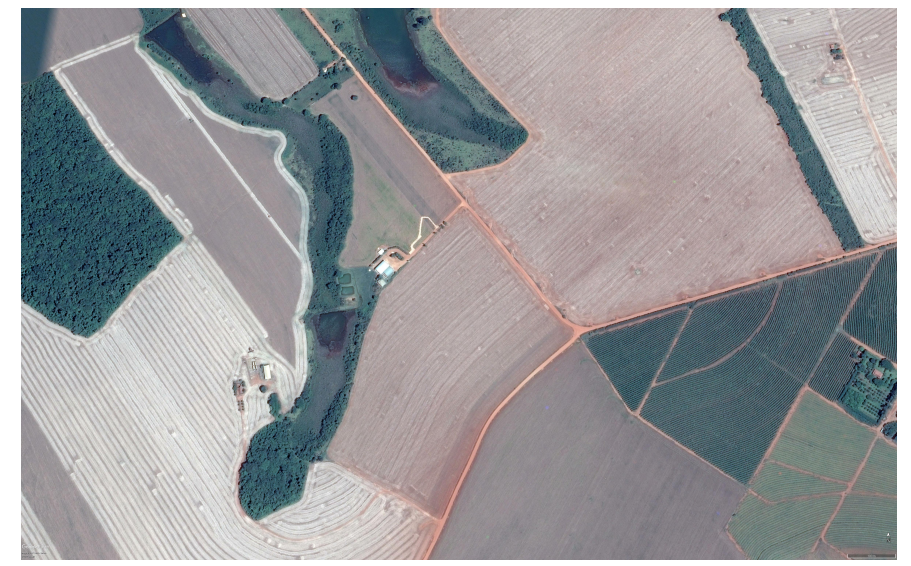

(a) Imagem obtida no dia 17 de Fevereiro de 2017, mostrando área com o solo exposto.

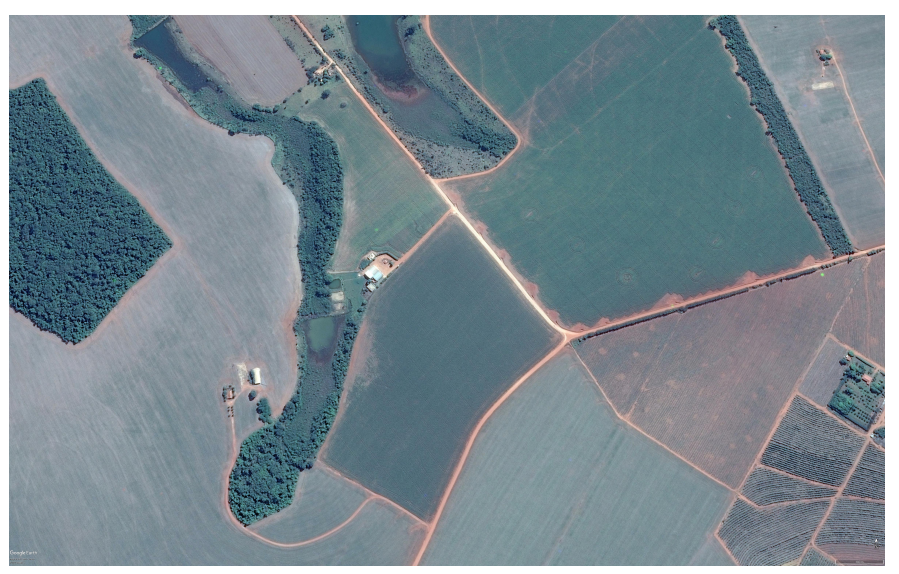

(b) Imagem obtida no dia 13 de Maio de 2017, mostrando área com plantio de milho.

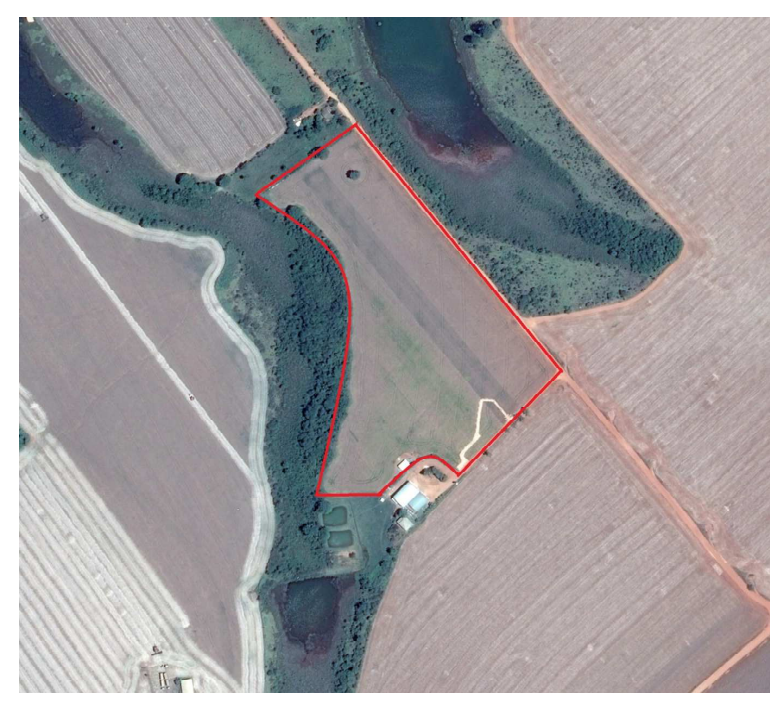

(c) Detalhe da área de interesse: fazenda em Coromandel com área de 35 hectares.

Figura 8 - Imagens obtidas pelo Google Earth, com acesso às bandas vermelho, verde e azul. Resolução aprox. $50 \mathrm{~cm}$. Fonte: Google Earth. 


\subsubsection{Imagens Com Acesso à NIR}

A bibliografia disponível que relaciona parâmetros agrícolas a bandas de refletância converge quase que em sua totalidade no uso de bandas de infravermelho para tal. Acontece que estas bandas invisíveis do espectro estão disponíveis apenas em imagens geradas por satélites especializados, ou em VANT s com câmeras multiespectrais. Neste trabalho, utilizaram-se imagens geradas por satélites.

A primeira abordagem foi buscar imagens multiespectrais de satélite que estivessem disponíveis gratuitamente. Nesta abordagem, obteve-se imagens geradas pelo satélite Landsat-8, que disponibiliza imagens da área solicitada nos comprimentos de onda e resoluções descritas na tabela 5. Estes dados serão base para avaliação do impacto da resolução na acuracidade da análise. As imagens do Landsat-8 tem resolução de trinta metros e cobrem uma área de aproximadamente cinco mil hectares, o que é muito superior à ordem de grandeza da área em questão. A figura 9 mostra a imagem original, composta das bandas visíveis, cobrindo a área que o satélite permite. 


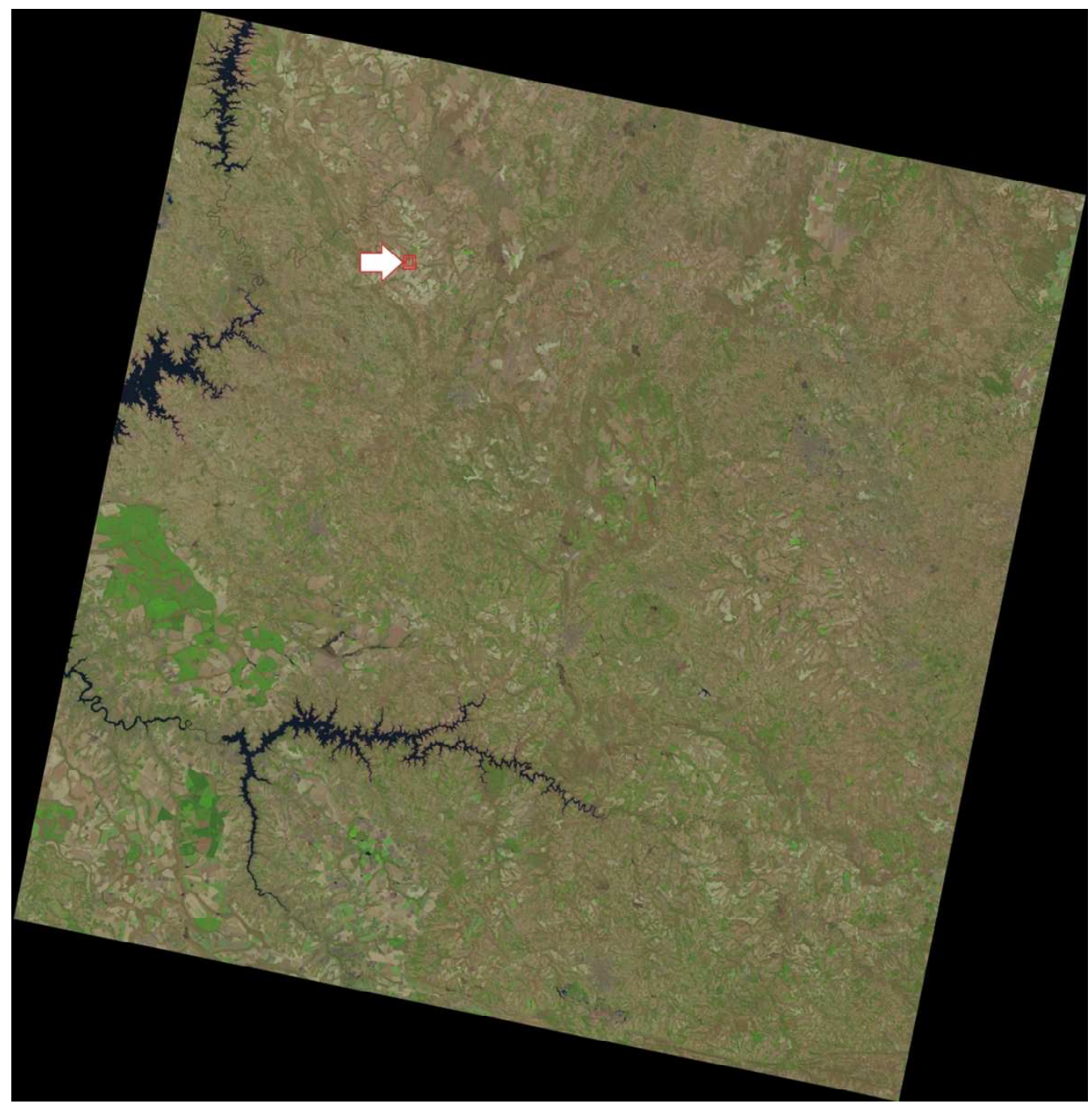

Figura 9 - Imagem obtida do satélite Landsat-8, apresentando a área de interesse indicada pela seta e pelo quadrado vermelho para referência da ordem de grandeza da imagem.

A imagem do Landsat foi disponibilizada nas onze bandas descritas na tabela 5. Para a análise da área de interesse, isolou-se as coordenadas da fazenda e extraiu-se os valores de refletância nas bandas do azul, verde, vermelho e NIR, como mostrado nas imagens da figura 10. 


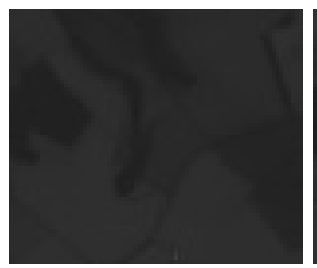

(a) Azul

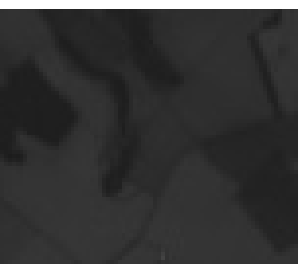

(b) Verde

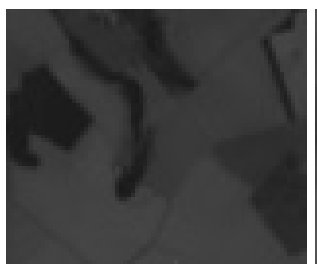

(c) Vermelho

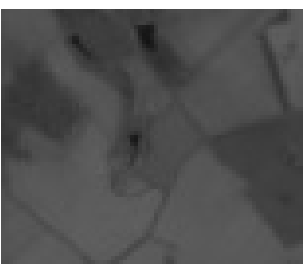

(d) NIR

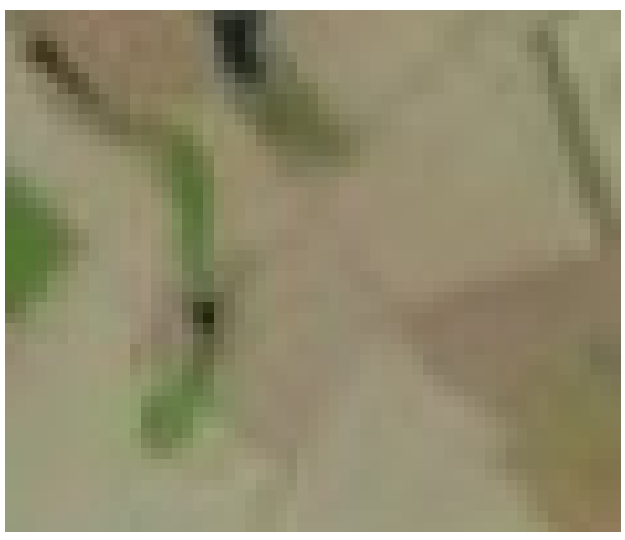

(e) Imagem composta com as bandas visíveis.

Figura 10 - Imagens da propriedade em Coromandel-MG, nas bandas disponibilizadas pelo satélite. Resolução: 30m. Fonte: Landsat-8.

A abordagem seguinte foi a de buscar imagens com acesso à banda de infravermelho desejada, com uma resolução que permitisse a análise detalhada da distribuição de nutrientes pela área de cultivo. Com isto em mente, obtiveram-se imagens tomadas no dia 14 de maio de 2017 pelo satélite Pleiades. As imagens dá acesso às bandas de vermelho, verde e azul, além do infravermelho próximo. 


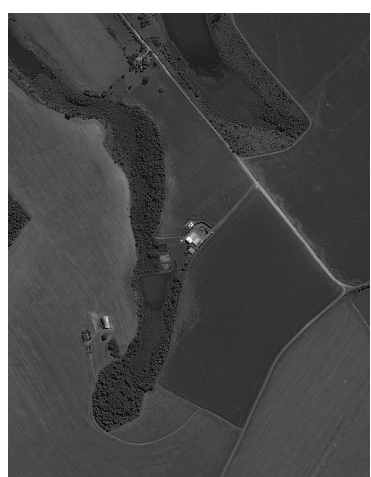

(a) Azul

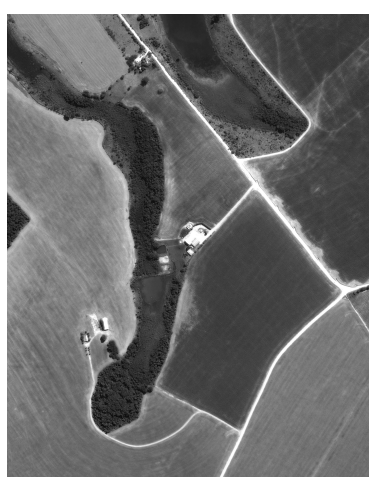

(c) Vermelho

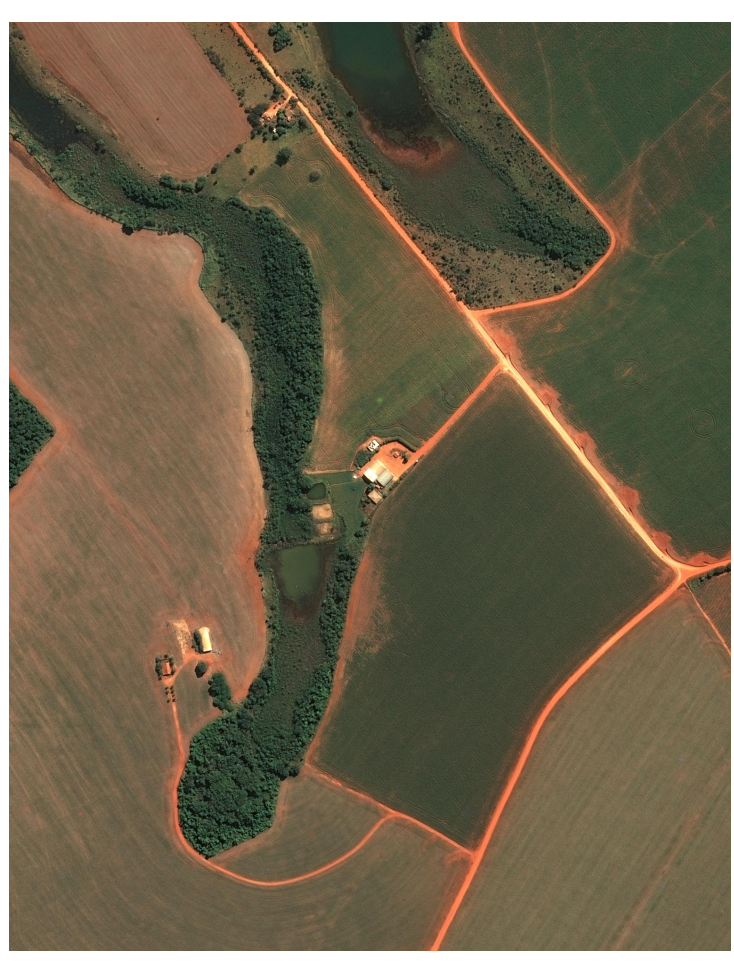

(e) Imagem composta com as bandas visíveis.

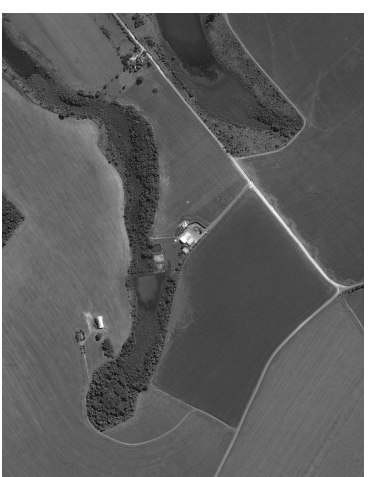

(b) Verde

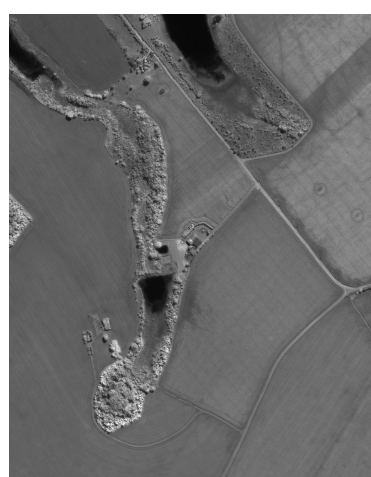

(d) Infravermelho próximo

Figura 11 - Fotografia obtida pelo satélite Pleiades. Resolução: 50cm. Fonte: Pleiades 


\subsection{ANÁLISE QUÍMICA}

Em setembro de 2017, foram coletadas amostras de solo para análise química no laboratório Safrar, de Uberlândia-MG. A análise foi feita a partir de sete pontos diferentes: um ponto central, e seis pontos ao redor deste primeiro, num raio de $20 \mathrm{~m}$. As amostras foram então misturadas, e a análise foi feita para obter, então, os valores médios dos parâmetros procurados para aquela área, e não os valores discretos para os pontos de amostra. Ou seja, a resolução da análise química é de aproximadamente 35 hectares, o próprio tamanho da propriedade. Este tipo de análise é o praticado na rotina do produtor desta área em questão, e dos produtores de porte similar: uma única amostra é tomada como representante de toda a área agrícola.

O laudo foi feito, dentre outros, para os seguintes parâmetros:

- $\mathrm{pH}$ da $\mathrm{H}_{2} \mathrm{O}$

- $\mathrm{pH} \mathrm{CaCl}_{2}$

- Fósforo (P) disponível em $m g / d m^{3}$

- Cátion de potássio $(\mathrm{K}+)$ disponível em $\mathrm{mg} / \mathrm{dm}^{3}$.

- Concentração dos Cátions de Cálcio, Magnésio e Alumínio em $\mathrm{cmolc} / \mathrm{dm}^{3}$.

- Concentração dos metais Boro, Cobre, Ferro, Manganês e Zinco em $\mathrm{mg} / \mathrm{dm}^{3}$.

- Razão entre bases, e capacidade de troca de cátions (CTC)

Para o produtor, os resultados deste laudo seriam assumidos como os valores médios para toda a propriedade, o que iria conduzir a sua estratégia de gerenciamento de nutrientes para a próxima lavoura.

A figura 12 identifica os limites da propriedade, assim como uma ilustração do ponto de amostragem. 


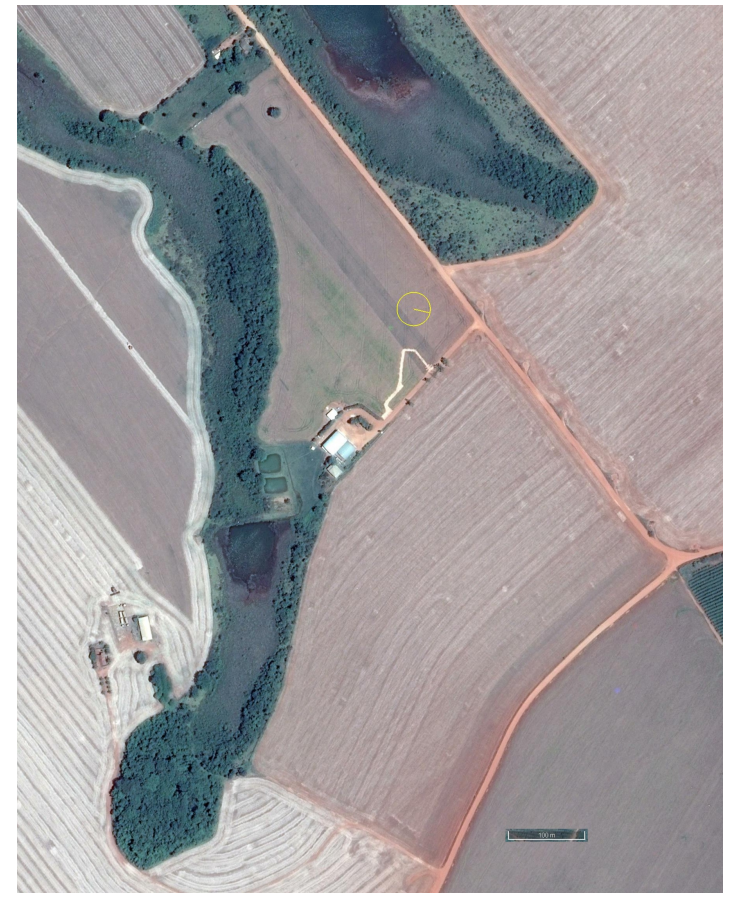

(a) Imagem Aérea da propriedade.

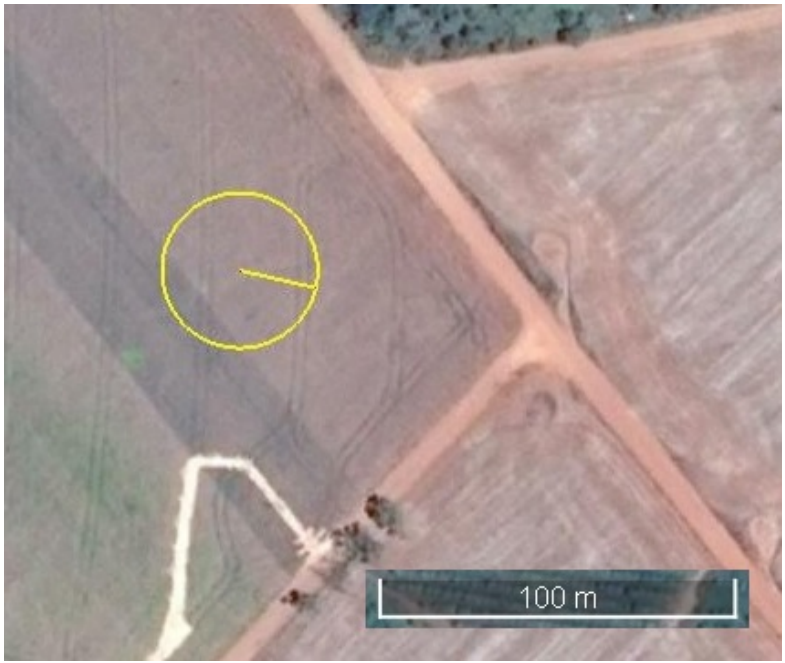

(b) Detalhe do ponto das amostras para análise química do solo.

Figura 12 - Propriedade escolhida para análise, em Coromandel, MG. Fotos tiradas no dia 17 de fevereiro, 2017. Fonte: Google Earth.

Para fins acadêmicos, outro grupo de amostras foi tomado, desta vez, de quatro pontos espalhados pela propriedade. Isso permite uma grade mais acurado das propriedades químicas do solo, uma vez que a resolução aumenta para aproximadamente seis hectares.

As amostras foram tomadas de forma a cobrir toda a área de estudo, e indicar tendências de gradientes de nutrientes devido à proximidade da área às bordas da propriedade, onde existem estradas, matas e a sede da fazenda. As amostras foram tomadas no mesmo procedimento da primeira: um ponto central, mais seis amostras sobre a circunferência de $20 \mathrm{~m}$ de raio, sendo o primeiro ponto o centro desta circunferência. A figura 13 apresenta a localização das amostras para a primeira e para a segunda análise. Mais a diante neste trabalho usaremos a combinação das duas amostras para construir os mapas de variabilidade para cada nutriente.

\subsection{ESTIMATIVA DE NUTRIENTES POR BANDAS DE REFLETÂNCIA E ÍNDICES DE VEGETAÇÃO}

Dada variedade dos dados disponíveis, algumas abordagens diferentes foram usadas para as estimativas de nutrientes. Como mostrado na tabela 4 , a literatura aqui estudada oferece um conjunto de dados que foram usados para estimar uma correlação entre os valores digitais de refletância e as concentração de alguns nutrientes. 


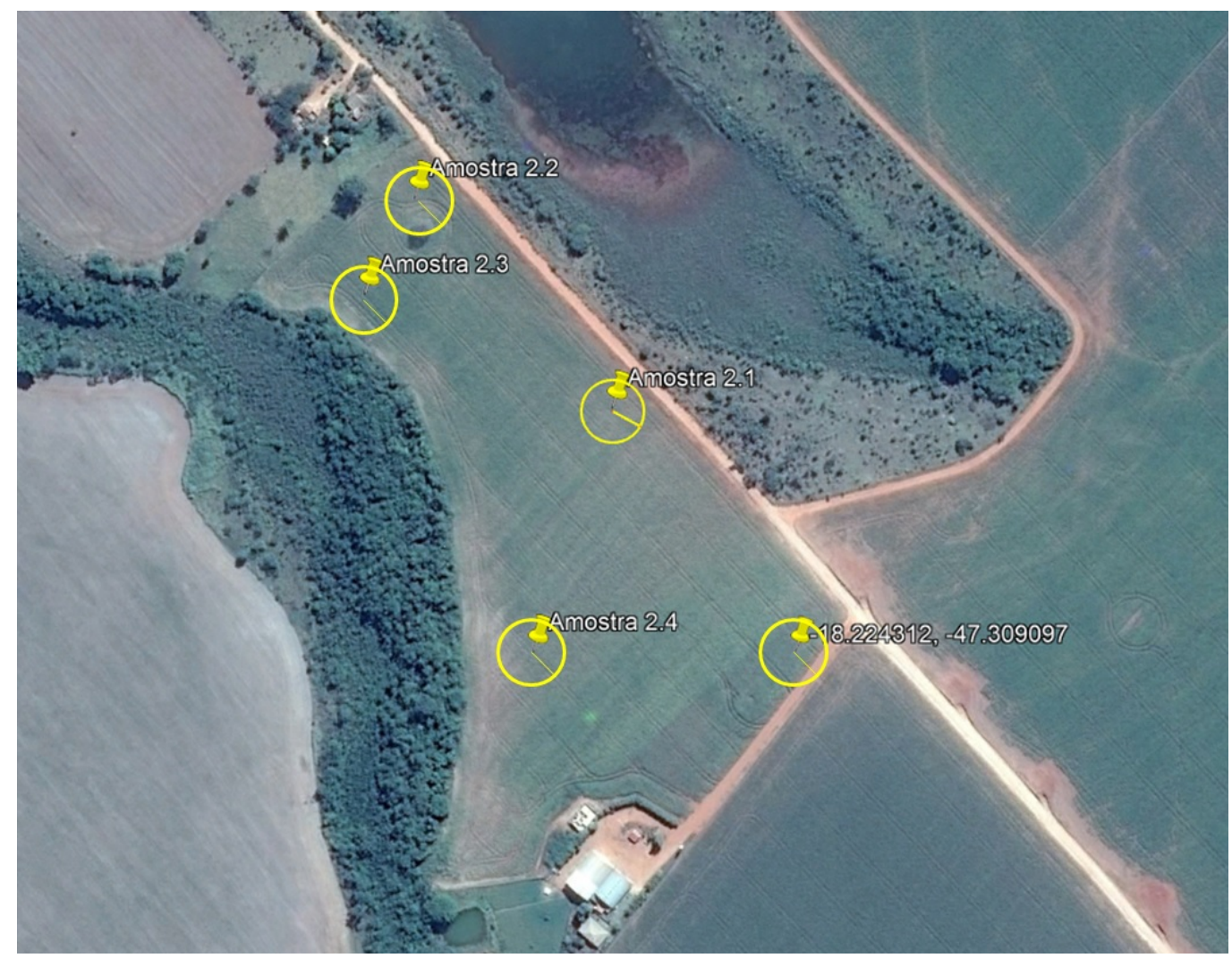

Figura 13 - Localização de cada amostra tomada para análise química do solo, demonstrando o alcance do raio de $20 \mathrm{~m}$ para composição de cada amostra.

Tendo disponível a análise química média da área, podemos calibrar as correlações entre os valores de refletância da mesma área com as concentrações de nutrientes. Como este tipo de análise química tem os seus resultados interpretados como a média para toda a área de interesse, abordou-se da mesma forma os valores de refletância e de índices de vegetação. Ou seja, usaram-se os valores médios de refletância para as bandas disponíveis e dos índices de vegetação. Os valores podem ser vistos na tabelaZ. Cada fonte de imagem forneceu seus dados em espaço amostral maior, dentro do qual se isolou a área de interesse para se chegar à análise desejada. O satélite Pleiades forneceu imagens que cobrem uma área de 25 quilômetros quadrados. Para esta análise, isolou-se uma pequena área de aproximadamente 1,3 hectares ao redor do ponto da primeira amostra. A mesma área foi isolada nas imagens do Google Earth.

Com isso, pode-se ter a magnitude dos níveis de refletância para cada banda, para diferentes satélites e em momentos diferentes, tendo em mente, que as imagens do Landsat- 8 e Google Earth de fevereiro/2017 mostram a área sem cobertura vegetal, e as imagens do Pleiades e do Google Earth de maio/2017 mostram a área com a cobertura de uma lavoura de milho.

Extrapolando a mesma técnica para os outros pontos de amostras, agora fazendo uso das 


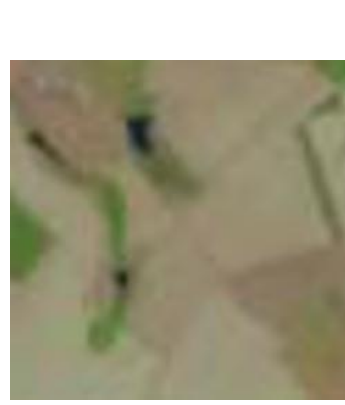

(a) Landsat-8 03/09/2017

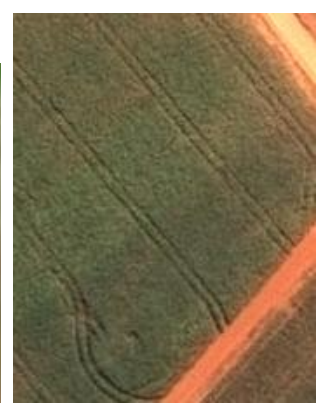

-(b) Pleiades 14/05/2017

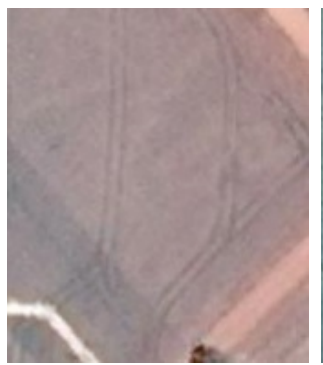

-(c) Google Earth $17 / 02 / 2017$

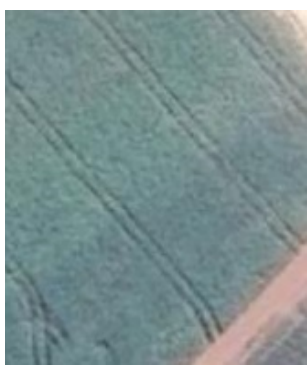

-(d) Google Earth 13/05/2017

Figura 14 - Áreas consideradas para comparação de índices de refletâncias e de vegetação com a primeira análise química.

\begin{tabular}{|c|c|c|c|c|c|c|c|c|}
\hline Satélite & \multicolumn{2}{|c|}{ Pleiades } & \multicolumn{2}{c|}{ Landsat-8 } & \multicolumn{2}{c|}{ Google Earth (Solo) } & \multicolumn{2}{c|}{ Google Earth (Plantio) } \\
\hline Área Coberta & \multicolumn{2}{|c|}{1,3 hectare } & \multicolumn{2}{|c|}{400 hectares } & \multicolumn{2}{c|}{1,4 hectare } \\
\hline \hline Índice & Média & Desvio padrão & Média & Desvio padrão & Média & Desvio padrão & Média & Desvio padrão \\
\hline NIR & 115,26 & 2,8815 & 74,4345 & 3,2895 & N/A & N/A & N/A & N/A \\
\hline Vermelho & 114,75 & 16,9575 & 52,989 & 3,315 & 146,8545 & 1,6575 & 121,1505 & 2,193 \\
\hline Verde & 100,0875 & 8,1855 & 43,2225 & 1,632 & 144,9675 & 1,3005 & 140,0205 & 1,5045 \\
\hline Azul & 68,085 & 4,7685 & 40,2645 & 1,02 & 143,3355 & 1,1475 & 141,984 & 1,479 \\
\hline NVDI & 0,0232 & 0,0385 & 0,173 & 0,0337 & N/A & N/A & N/A \\
\hline NGRDI & $-0,0528$ & 0,0251 & $-0,0948$ & 0,0194 & $-0,0059$ & 0,0049 & N/A \\
\hline CI & 0,1742 & 0,0232 & 0,7261 & 0,0798 & N/A & N/A & N/A \\
\hline
\end{tabular}

Tabela 7 - Resultados das amostras de refletância e índices de vegetação.

imagens dos outros satélites, isolou-se a área de aproximadamente 1260 metros quadrados ao redor de cada amostra, como apresentado na figura 13, e calculou-se a média, para cada banda de refletância disponível e índices de vegetação. Esta foi a abordagem que Albayrak, 2008 (16) tomou para estimar o conteúdo de nitrogênio em uma lavoura. Assim, ele pode comparar os níveis de refletância e dos índices de vegetação com os valores de concentração de nutrientes obtidos nas análises químicas. Estas comparações geram regressões lineares que são utilizadas para construir o mapa de variabilidade de cada nutriente.

As regressões lineares foram feitas unidimensionalmente, ou seja, relacionando cada banda com cada um dos nutrientes estudados separadamente. Uma análise multivariável não seria de valia neste caso pelo pequeno tamanho da propriedade e pelo pequeno número de amostras. Cada amostra de solo, representada pelo círculo de 1260 metros quadrados, teve a as médias de refletância para cada banda e dos índices de vegetação relacionados com os resultados das 
análises químicas. Dentro do conjunto de dados de uma mesma banda/índice de vegetação e de concentração de cada nutriente, se traçou os coeficientes de correlação, $r^{2}$. Observando cada um destes coeficientes, tomou-se os de melhor desempenho de correlação, ou seja, os mais próximos de 1 , e assumiu-se a correlação linear correspondente como melhor preditor da distribuição do respectivo nutriente por sobre a área de estudo. 


\section{RESULTADOS E ANÁLISE}

Nas seções deste capítulo, serão apresentados os resultados obtidos após a implementação dos métodos e abordagens explicitadas no capítulo anterior.

\subsection{ANÁLISE QUÍMICA}

As análises químicas foram feitas em dois momentos e com diferentes propósitos. A primeira foi feita a partir de um único ponto, simulando o tipo de informação que os agricultores estão acostumados a receber. O ponto de tomada foi logo na entrada da propriedade, o que implicaria certos ruídos de elementos que não participem dos ciclos de nutrientes. Este tipo de análise é comumente usado pelos produtores para estimar a necessidade média de nutrientes que devem ser gerenciados no solo. A segunda análise tomou amostras de quatro pontos distintos, diferentes do primeiro, de forma a cobrir a área como um todo. O maior número de amostras permite uma melhor relação estatística com os índices de refletância, permitindo uma estimativa de nutrientes com boa resolução. Para isto, os pontos de tomada de amostras para análise química foram identificados com o auxílio de um aplicativo de celular que fornece as coordenadas de sua localidade. Esta informação foi gerada para cada ponto de amostragem. Os pontos foram tomados de forma a cobrir toda a área da lavoura em questão.

Os resultados das duas análises ( 1 e 2) são apresentados na tabela 8 . Como dito, eles serão usados para comparação com os índices de refletância e de vegetação. A primeira amostra será comparada com os dados do satélite Landsat-8, e a soma da primeira com a segunda amostra será usada para a criação dos mapas de distribuição de nutrientes a partir das imagens do Google Earth e do Pleiades.

\begin{tabular}{|c|c|c|c|c|c|c|c|}
\hline Amostra & P meh & K & B & Cu & Fe & Mn & Zn \\
\hline \hline 1 & 13,6 & 150 & 0,45 & 2,8 & 16 & 6,5 & 1,5 \\
\hline 2.1 & 30,2 & 190 & 0,38 & 1,7 & 26 & 5,7 & 1,9 \\
\hline 2.2 & 138,6 & 154 & 0,39 & 2,2 & 31 & 5,3 & 5,6 \\
\hline 2.3 & 32,3 & 168 & 0,29 & 2,0 & 26 & 5,7 & 2,1 \\
\hline 2.4 & 16,5 & 156 & 0,21 & 1,7 & 24 & 4,0 & 1,3 \\
\hline
\end{tabular}

Tabela 8 - Resultados das análises químicas para Fósforo disponível, cátions de Potássio, Boro, Cobre, Ferro, Manganês e Zinco, todos em $m g / d m^{3}$. 


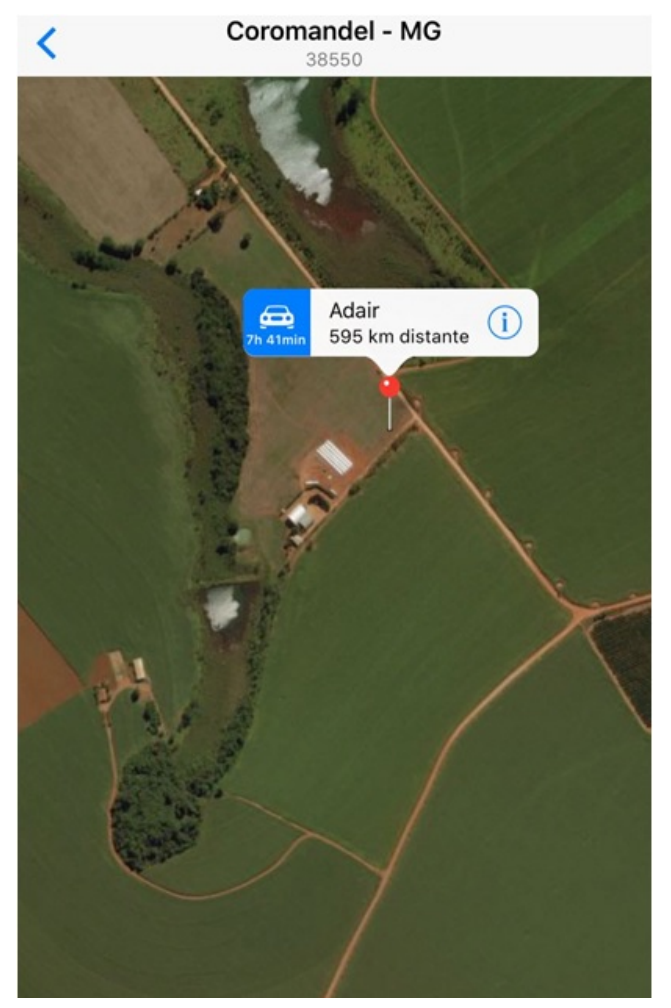

Figura 15 - Identificação das coordenadas do primeiro ponto de amostra química, pelo aplicativo Mapas do Iphone.

\subsection{ESTIMATIVA DE NUTRIENTES: SOLO E VEGETAÇÃO}

Nesta seção estão apresentados os resultados das estimativas de nutrientes usando como base dados da bibiliografia, resultados das análises químicas, imagens do satélite Landsat- 8 , Pleiades e do mosaico construído com imagens do Google Earth na sequência 4N3×2.

\subsubsection{Imagens do Landsat}

As imagens do Landsat-8 permitiram o uso de bandas abaixo do vermelho visível, mas, devido sua baixa resolução $(30 \mathrm{~m})$, só foi possível estimar a média da concentração dos nutrientes na área total da propriedade agrícola.

Como as análises químicas para propriedades deste porte também são realizadas desta forma, isto se mostrou uma oportunidade para comparação de dados e métodos. Desta forma, fazendo uso das regressões apresentadas na tabela 4 construiu-se uma estimativa média para as concentrações de cátions de Potássio e de Fósforo disponível no solo. Estas regressões foram aplicadas por sobre as informações de refletância das amostras de imagens dos satélites Landsat-8 e Pleiades, além das imagens do Google Earth de fevereiro e de maio de 2017, como 
apresentadas na figura 14.

No laudo, o laboratório representa em uma discreta de cinco estágios se as concentrações de cada nutriente estão em níveis muito baixos, baixos, médios, bons ou muito bons. Isto torna a tomada de decisão pelo produtor mais ágil, e também nos permite aplicar estes níveis às estimativas. Desta forma, se fez possível compreender como o agricultor, em posse de uma única amostra entenderia as informações de conteúdo de nutrientes, e como a análise a partir de uma única amostra impactaria a estimativa a partir de imagens orbitais. Os resultados para fósforo e potássio, em função do fertigrama estão nas tabelas 9 e 10, respectivamente.

\begin{tabular}{|c|c|c|c|c|c|c|c|c|}
\hline Fósforo & \multicolumn{2}{|c|}{ Landsat-8 } & \multicolumn{2}{|c|}{ Pleiades } & Google Earth - Fev $/ 17$ & Google Earth - Mai/17 \\
\hline \hline NIR & Baixo & $9,9 \mathrm{mg} / \mathrm{dm}^{3}$ & Baixo & $7,2 \mathrm{mg} / \mathrm{dm}^{3}$ & \multicolumn{2}{|c|}{ NA } & \multicolumn{2}{c|}{ NA } \\
\hline Vermelho & Médio & $13,4 \mathrm{mg} / \mathrm{dm}^{3}$ & Baixo & $9,2 \mathrm{mg} / \mathrm{dm}^{3}$ & Baixo & $7,0 \mathrm{mg} / \mathrm{dm}^{3}$ & Baixo & $8,8 \mathrm{mg} / \mathrm{dm}^{3}$ \\
\hline Verde & Médio & $20,0 \mathrm{mg} / \mathrm{dm}^{3}$ & Médio & $14,1 \mathrm{mg} / \mathrm{dm}^{3}$ & Baixo & $9,4 \mathrm{mg} / \mathrm{dm}^{3}$ & Baixo & $9,9 \mathrm{mg} / \mathrm{dm}^{3}$ \\
\hline Análise Química & Médio & $13,6 \mathrm{mg} / \mathrm{dm}^{3}$ & Médio & $13,6 \mathrm{mg} / \mathrm{dm}^{3}$ & Médio & $13,6 \mathrm{mg} / \mathrm{dm}^{3}$ & Médio & $13,6 \mathrm{mg} / \mathrm{dm}^{3}$ \\
\hline
\end{tabular}

Tabela 9 - Estimativas da concentração de fósforo usando a média da refletância das áreas apresentadas na figura144, em função do fertigrama.

\begin{tabular}{|c|c|c|c|c|c|c|c|c|}
\hline Potássio & \multicolumn{2}{|c|}{ Landsat-8 } & \multicolumn{2}{c|}{ Pleiades } & Google Earth - Fev $/ 17$ & Google Earth - Mai/17 \\
\hline \hline NIR & Médio & $130 \mathrm{mg} / \mathrm{dm}^{3}$ & Médio & $99 \mathrm{mg} / \mathrm{dm}^{3}$ & \multicolumn{2}{c|}{ NA } & \multicolumn{2}{c|}{ NA } \\
\hline Vermelho & Muito Bom & $170 \mathrm{mg} / \mathrm{dm}^{3}$ & Médio & $129 \mathrm{mg} / \mathrm{dm}^{3}$ & Médio & $107 \mathrm{mg} / \mathrm{dm}^{3}$ & Médio & $124 \mathrm{mg} / \mathrm{dm}^{3}$ \\
\hline Verde & Muito Bom & $245 \mathrm{mg} / \mathrm{dm}^{3}$ & Muito bom & $177 \mathrm{mg} / \mathrm{dm}^{3}$ & Médio & $124 \mathrm{mg} / \mathrm{dm}^{3}$ & Médio & $129 \mathrm{mg} / \mathrm{dm}^{3}$ \\
\hline Análise Química & Bom & $150 \mathrm{mg} / \mathrm{dm}^{3}$ & Bom & $150 \mathrm{mg} / \mathrm{dm}^{3}$ & Bom & $150 \mathrm{mg} / \mathrm{dm}^{3}$ & Bom & $150 \mathrm{mg} / \mathrm{dm}^{3}$ \\
\hline
\end{tabular}

Tabela 10 - stimativas da concentração de potássio usando a média da refletância das áreas apresentadas na figural14, em função do fertigrama.

Como cada nível do fertigrama representa um quinto da escala total, então se tomou como margem de aceitação das estimativas de concentração de nutrientes valores que estivessem dentro da margem de $10 \%$ para cima ou $10 \%$ para baixo do valor apontado na análise química. Para uma análise comparativa mais visual, na figura 16, pode-se observar os resultados para as estimativas das médias de concentrações de $\mathrm{K}$ e $\mathrm{P}$ para cada banda, e suas comparações com os resultados das análises químicas, usando as imagens do Pleiades (11), do Landsat-8 (10), e do Google Earth quando o solo estava exposto (8a) e de quando havia plantio de milho na área (8b), todos tomando os dados da área de amostra de solo 1. 


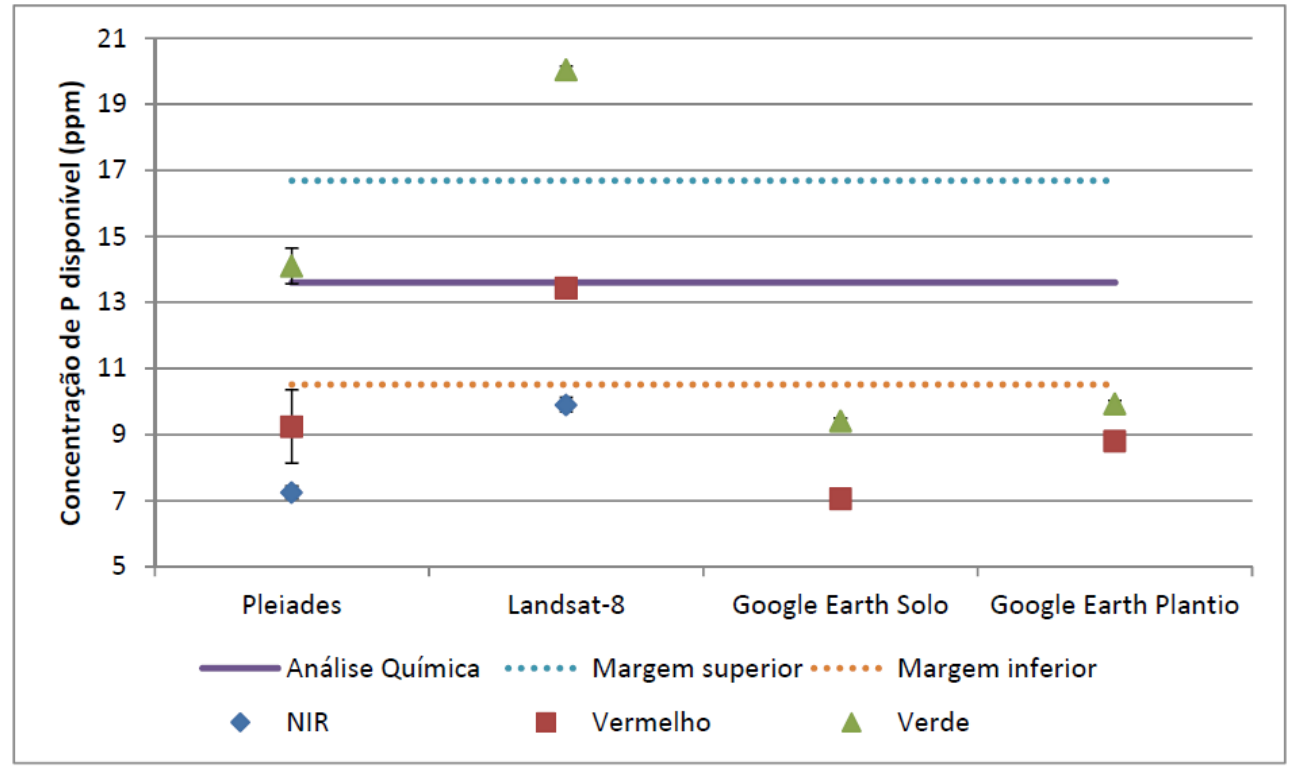

(a) Resultado da estimativa da concentração de Fósforo disponível pelas bandas disponíves por cada fonte de imagens usada.

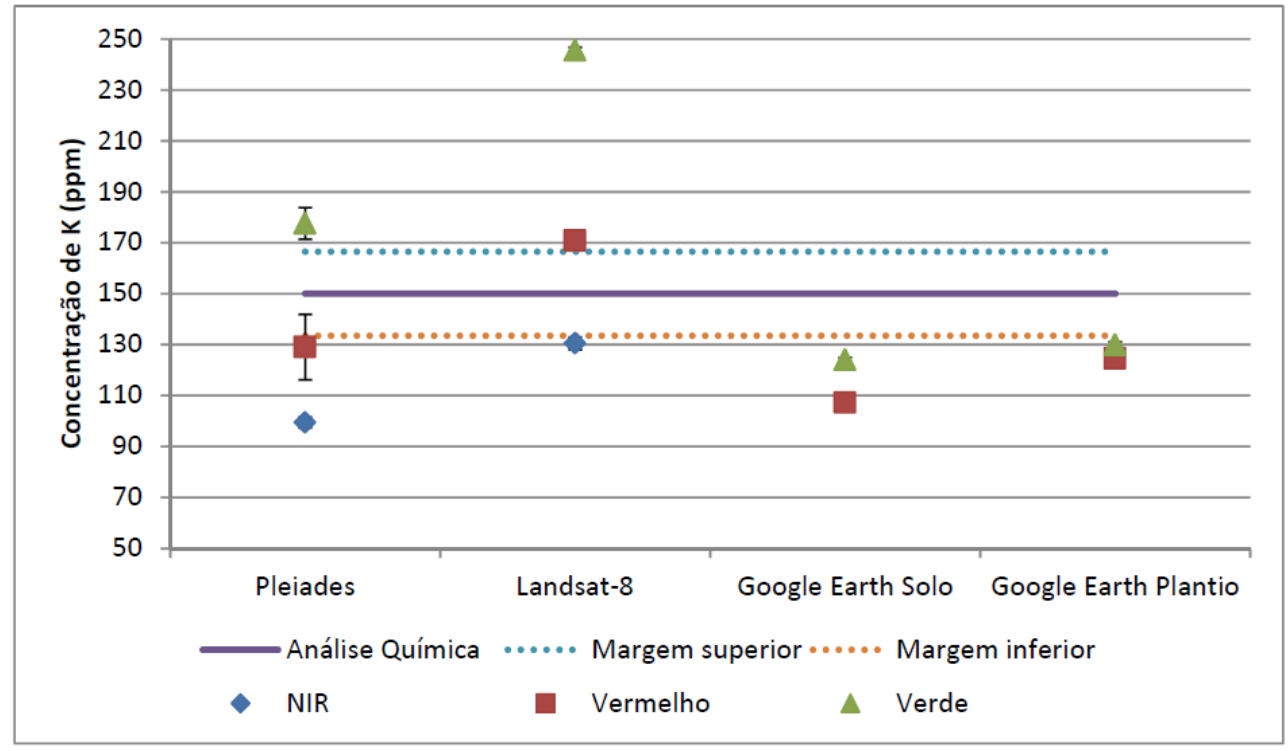

(b) Resultado da estimativa da concentração de Fósforo disponíveis pelas bandas disponíves por cada fonte de imagens usada.

Figura 16 - Estimativas média de nutrientes.

\subsubsection{Imagens do Pleiades}

O satélite Pleiades fornece imagens com resolução maior em relação às imagens do Landsat, também com acesso à banda de infravermelho. Isso permitiu uma estimativa com maior descrição da distribuição de cada nutriente pela área estudada. Esta maior resolução permitiu que se usassem os dados gerados pelas análises químicas para encontrar correspondências 
entre bandas de refletâncias ou índices de vegetação e a distribuição de nutrientes pela área analisada. A seguir, um círculo de 20 metros de raio foi determinado ao redor de cada ponto, de forma a cobrir os outros 6 pontos de tomada de amostras para cada ponto principal. A seguir, os valores médios de refletância para as bandas de vermelho, verde, azul, infra vermelho próximo, e dos índices de vegetação NDVI, NIR/Vermelho, NGRDI e Cl foram tomados para estas áreas na imagem gerada pelo satélite Pleiades.

\begin{tabular}{|c|c|c|c|c|c|c|c|c|}
\hline \multirow{2}{*}{ Amostra } & \multicolumn{2}{|c|}{ NIR } & \multicolumn{2}{c|}{ Vermelho } & \multicolumn{2}{c|}{ Verde } & \multicolumn{2}{c|}{ Azul } \\
\cline { 2 - 9 } & Média & Desvio Padrão & Média & Desvio Padrão & Média & Desvio Padrão & Média & Desvio Padrão \\
\hline 1 & 0,4611 & 0,0057 & 0,3741 & 0,0053 & 0,3692 & 0,0066 & 0,2556 & 0,0064 \\
\hline 2.1 & 0,4042 & 0,0032 & 0,4803 & 0,0074 & 0,3799 & 0,0041 & 0,2576 & 0,0042 \\
\hline 2.2 & 0,4170 & 0,0054 & 0,4181 & 0,0110 & 0,3661 & 0,0064 & 0,2510 & 0,0060 \\
\hline 2.3 & 0,4179 & 0,0070 & 0,3229 & 0,0187 & 0,3363 & 0,0136 & 0,2328 & 0,0119 \\
\hline 2.4 & 0,4075 & 0,0036 & 0,4082 & 0,0052 & 0,3687 & 0,0045 & 0,2521 & 0,0046 \\
\hline
\end{tabular}

(a) Valores de refletância nas bandas NIR, vermelho, verde e azul. Valores em DN $(0<\mathrm{DN}<1)$.

\begin{tabular}{|c|c|c|c|c|c|c|c|c|}
\hline \multirow{2}{*}{ Amostra } & \multicolumn{2}{|c|}{ NVDI } & \multicolumn{2}{c|}{ NIR/Vermelho } & \multicolumn{2}{c|}{ NGRDI } & \multicolumn{2}{c|}{} \\
\cline { 2 - 9 } & Média & Desvio Padrão & Média & Desvio Padrão & Média & Desvio Padrão & Média & Desvio Padrão \\
\hline 1 & 0,1053 & 0,0098 & 1,2388 & 0,0219 & $-0,007$ & 0,0036 & 0,2557 & 0,0103 \\
\hline 2.1 & $-0,0842$ & 0,0073 & 0,8491 & 0,0122 & $-0,0116$ & 0,0072 & 0,0681 & 0,0100 \\
\hline 2.2 & 0,0015 & 0,0164 & 1,0116 & 0,0371 & $-0,0655$ & 0,0055 & 0,1489 & 0,0240 \\
\hline 2.3 & 0,1321 & 0,0162 & 1,3267 & 0,0259 & 0,0230 & 0,0045 & 0,2554 & 0,0235 \\
\hline 2.4 & $-0,0001$ & 0,0059 & 1,0016 & 0,0124 & $-0,0511$ & 0,0035 & 0,1089 & 0,0097 \\
\hline
\end{tabular}

(b) Valores dos índices de vegetação NVDI, NIR/Vermelho, NGRDI e CI.

Tabela 11 - Resultados nos pontos de amostragem para análise química, obtidos da imagem gerada pelo satélite Pleiades.

Com a posse destas informações, pode-se procurar uma relação entre os valores apontados na análise química para diferentes nutrientes e os índices de refletância e vegetação. Cada relação entre banda de refletância/índice de vegetação e concentração de nutriente gera um $r^{2}$, pelo qual se pode, para o dado número de amostras (5), estabelecer a melhor correlação, além de estimar uma regressão entre as duas propriedades. Na tabela 12a, os valores mais próximos do verde são os coeficientes de correlação que mais se aproximaram de 1 . É possível observar que a refletância no infra-vermelho próximo foi responsável pela melhor correlação em cinco dos sete nutrientes estudados, com destaque positivo para o cobre que alcançou $r^{2}=0,9288$, e negativo para o potássio que teve a melhor correlação também no NIR com 
apenas $r^{2}=0,9288$. Os níveis de correlação do cobre merece mais destaque ainda pelo fato de nos índices, $\mathrm{Cl}$, NVDI e NIR/Red ter obtidos $r^{2}$ melhores que todos os do potássio.

\begin{tabular}{|c|c|c|c|c|c|c|c|c|}
\hline$r^{2}$ & NIR & Vermelho & Verde & Azul & NVDI & NIR/Red & NGRDI & CI \\
\hline P meh & 0,2699 & 0,0168 & 0,0735 & 0,1305 & 0,0503 & 0,033 & 0,596 & 0,0301 \\
\hline $\mathrm{K}$ & 0,3368 & 0,2544 & 0,2600 & 0,0015 & 0,2939 & 0,222 & 0,2815 & 0,2581 \\
\hline $\mathrm{Cu}$ & 0,9288 & 0,1733 & 0,0029 & 0,0105 & 0,3719 & 0,3719 & 0,2485 & 0,5408 \\
\hline $\mathrm{Fe}$ & 0,6093 & 0,0713 & 0,0200 & 0,0685 & 0,1868 & 0,1681 & 0,1527 & 0,212 \\
\hline $\mathrm{Mn}$ & 0,4677 & 0,0372 & 0,0059 & 0,0001 & 0,1487 & 0,1729 & 0,0676 & 0,3222 \\
\hline $\mathrm{Zn}$ & 0,0236 & 0,0178 & 0,0003 & 0,0015 & 0,0257 & 0,0296 & 0,0476 & 0,0071 \\
\hline $\mathrm{B}$ & 0,3971 & 0,0342 & 0,1141 & 0,1757 & 0,0011 & 0,0012 & 0,0132 & 0,0621 \\
\hline
\end{tabular}

(a) Coeficientes de correlação $r^{2}$ entre nutrientes e bandas/VIs. Em escala de verde a vermelho, os $r^{2}$ máximos e mínimos, respectivamente.

\begin{tabular}{|c|c|c|c|}
\hline Nutriente & Banda & $r^{2}$ & Regressões \\
\hline \hline $\mathrm{P}$ & NGRDI & 0,5960 & $P=-47,035 * N G R D I+24,202$ \\
\hline $\mathrm{K}$ & $\mathrm{NIR}$ & 0,3368 & $K=-1,6114 * N I R+336,81$ \\
\hline $\mathrm{Cu}$ & $\mathrm{NIR}$ & 0,9288 & $C u=0,0751 * N I R-5,9931$ \\
\hline $\mathrm{Fe}$ & $\mathrm{NIR}$ & 0,6093 & $F e=-0,7299 * N I R+103,06$ \\
\hline $\mathrm{Mn}$ & $\mathrm{NIR}$ & 0,4677 & $M n=0,1072 * N I R+6,0868$ \\
\hline $\mathrm{Zn}$ & NGRDI & 0,0476 & $Z n=-6,8092 * N G R D I+2,185$ \\
\hline $\mathrm{B}$ & NIR & 0,3971 & $B=0,0102 * N I R+0,7494$ \\
\hline
\end{tabular}

(b) Regressões para as melhores correlações.

Tabela 12 - Resultados da análise de correlação entre análise química versus refletâncias/índices de vegetação da imagem do satélite Pleiades.

Dadas estas regressões, e os níveis de concentração de cada nutriente, mostrados na tabela12, pode-se plotar um mapa de distribuição de cada um destes nutrientes. Obviamente, a acuracidade de cada um destes mapas está diretamente ligada ao $r^{2}$ de cada correlação. A figura 17 mostra os mapas de variabilidade gerados a partir destas regressões aplicadas por sobre a área de interesse. Dada a alta resolução das imagens do Pleiades, mesmo dentro dos níveis do fertigrama, pode-se observar os degraus de variação de concentração de cada nutriente com nitidez. Como referência, por sobre as coordenadas de cada amostra, plotou-se os valores obtidos nas respectivas análises químicas, já dentro da graduação do fertigrama. 


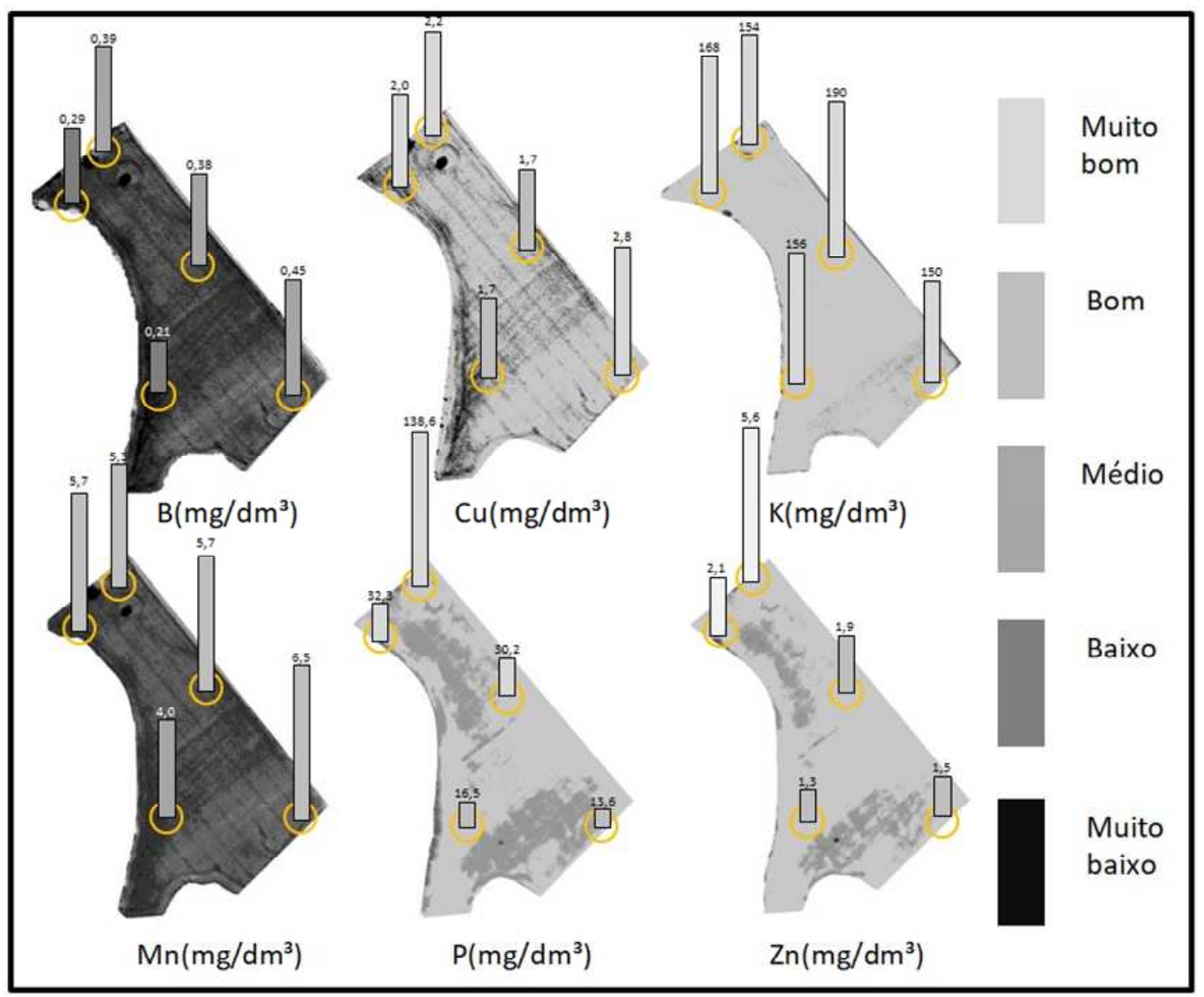

Figura 17 - Mapas de Variabilidade de nutrientes no solo para Boro, Cobre, Potássio, Manganês, Fósforo e Zinco, em $\mathrm{mg} / \mathrm{dm}^{3}$, exibidos de acordo com o fertigrama mostrado na tabela 团, apartir das imagens do satélite Pleiades.

Vale relembrar, que nas imagens obtidas pelo satélite Pleiades, a área conta com cobertura vegetal de plantação de milho. Desta forma, uma interpretação dos mapas é a de que os nutrientes apontados pela análise química já estão absorvidos pelas plantas, ou das porções de solo visíveis por entre a cobertura vegetal.

\subsubsection{Imagens do Google Earth}

A mesma abordagem foi implementada quando se usou os mosaicos gerados a partir de imagens do Google Earth da propriedade agrícola. Desta vez, dada características das imagens, outras análises podem ser feitas. A principal diferença desta análise é a ausência das bandas de infravermelho. Este fator reduz também o número de índices de vegetação utilizáveis para apenas o NGRDI. Estas condições são ideais para a simulação do uso de VANT s embarcados com câmeras comuns para sensoriamento remoto. 


\begin{tabular}{|c|c|c|c|c|c|c|c|c|}
\hline Índice & \multicolumn{2}{|c|}{ Vermelho } & \multicolumn{2}{c|}{ Verde } & \multicolumn{2}{c|}{ Azul } & \multicolumn{2}{c|}{ NGRDI } \\
\hline \hline Amostra & Média & Desvio padrão & Média & Desvio padrão & Média & Desvio padrão & Média & Desvio padrão \\
\hline 1 & 0,4287 & 0,0041 & 0,5402 & 0,0037 & 0,5467 & 0,0042 & 0,1155 & 0,0030 \\
\hline 2.1 & 0,5010 & 0,0046 & 0,5541 & 0,0030 & 0,5558 & 0,0031 & 0,0510 & 0,0034 \\
\hline 2.2 & 0,4701 & 0,0092 & 0,5360 & 0,0072 & 0,5434 & 0,0067 & 0,0663 & 0,0052 \\
\hline 2.3 & 0,4061 & 0,0138 & 0,5123 & 0,0137 & 0,5244 & 0,0142 & 0,1191 & 0,0060 \\
\hline 2.4 & 0,5368 & 0,0042 & 0,5761 & 0,0047 & 0,5854 & 0,0042 & 0,0380 & 0,0025 \\
\hline
\end{tabular}

Tabela 13 - Valores de refletância nas bandas NIR, vermelho, verde e azul.

A tabela 14 mostra os valores de $r^{2}$ para cada correlação e a das respectivas regressões, relativas às imagens do dia 13 de maio de 2017. Os coeficientes de correlação para esta imagem não obteve os mesmos desempenhos apresentados pela regressão feita sobre a imagem do Pleiades. A melhor correlação foi encontrada no conteúdo manganês, que se relacionou bem com vermelho, azul e NGRDI, com destaque para o primeiro. Fósforo disponível, potássio, ferro e zinco tiveram correlações baixíssimas. 


\begin{tabular}{|c|c|c|c|c|}
\hline$r^{2}$ & Vermelho & Verde & Azul & NGRDI \\
\hline P meh & 0,0005 & 0,0687 & 0,0766 & 0,0259 \\
\hline K & 0,0296 & 0,0001 & 0,0069 & 0,067 \\
\hline S-SO4 & 0,1729 & 0,0066 & 0,0109 & 0,309 \\
\hline $\mathrm{B}$ & 0,1928 & 0,1141 & 0,2049 & 0,1591 \\
\hline $\mathrm{Cu}$ & 0,4115 & 0,1612 & 0,1708 & 0,4955 \\
\hline $\mathrm{Fe}$ & 0,0545 & 0,0175 & 0,0166 & 0,1887 \\
\hline $\mathrm{Mn}$ & 0,5876 & 0,4036 & 0,5165 & 0,5653 \\
\hline $\mathrm{Zn}$ & 0,0072 & 0,1006 & 0,1113 & 0,0097 \\
\hline
\end{tabular}

(a) Coeficientes de correlação $r^{2}$ entre nutrientes e bandas/VIs. Em escala de verde a vermelho, os $r^{2}$ máximos e mínimos, respectivamente.

\begin{tabular}{|c|c|c|c|}
\hline Nutriente & Banda & $r^{2}$ & Regressões \\
\hline \hline $\mathrm{P}$ & Azul & 0,0766 & $P=-648,62 * A z u l+403,72$ \\
\hline $\mathrm{K}$ & NGRDI & 0,0670 & $K=-112,5 * N G R D I+172,37$ \\
\hline $\mathrm{Cu}$ & NGRDI & 0,4955 & $C u=8,5893 * N G R D I-1,4102$ \\
\hline $\mathrm{Fe}$ & NGRDI & 0,1887 & $F e=-63,589 * N G R D I+29,559$ \\
\hline $\mathrm{Mn}$ & Vermelho & 0,5876 & $M n=-13,261 *$ Vermelho $+11,653$ \\
\hline $\mathrm{Zn}$ & Azul & 0,1113 & $Z n=-26,514 *$ Azul $+17,093$ \\
\hline $\mathrm{B}$ & Azul & 0,2049 & $B=-1,9124 *$ Azul $+1,398$ \\
\hline
\end{tabular}

(b) Regressões para as melhores correlações.

Tabela 14 - Resultados da análise de correlação entre análise química versus refletâncias/índices de vegetação da imagem do Google Earth de maio de 2017.

O mapa de distribuição de nutrientes, construído apartir dos mosaicos com imagens da área coberta pela cultura de milho, para cada correlação apresentada é mostrado na figura 18. 0 mapa de variabilidade, tendo sido construído por sobre os níveis do fertigrama, dilui a baixa correlação encontrada entre os valores das análises químicas e os índices de refletância e NGRDI para fósforo disponível, potássio, ferro e zinco. Isso pode ser observado ao analisar os valores das concentrações de cada nutriente provindos da análise química, que estão representados por sobre os pontos de amostras no mapa. 


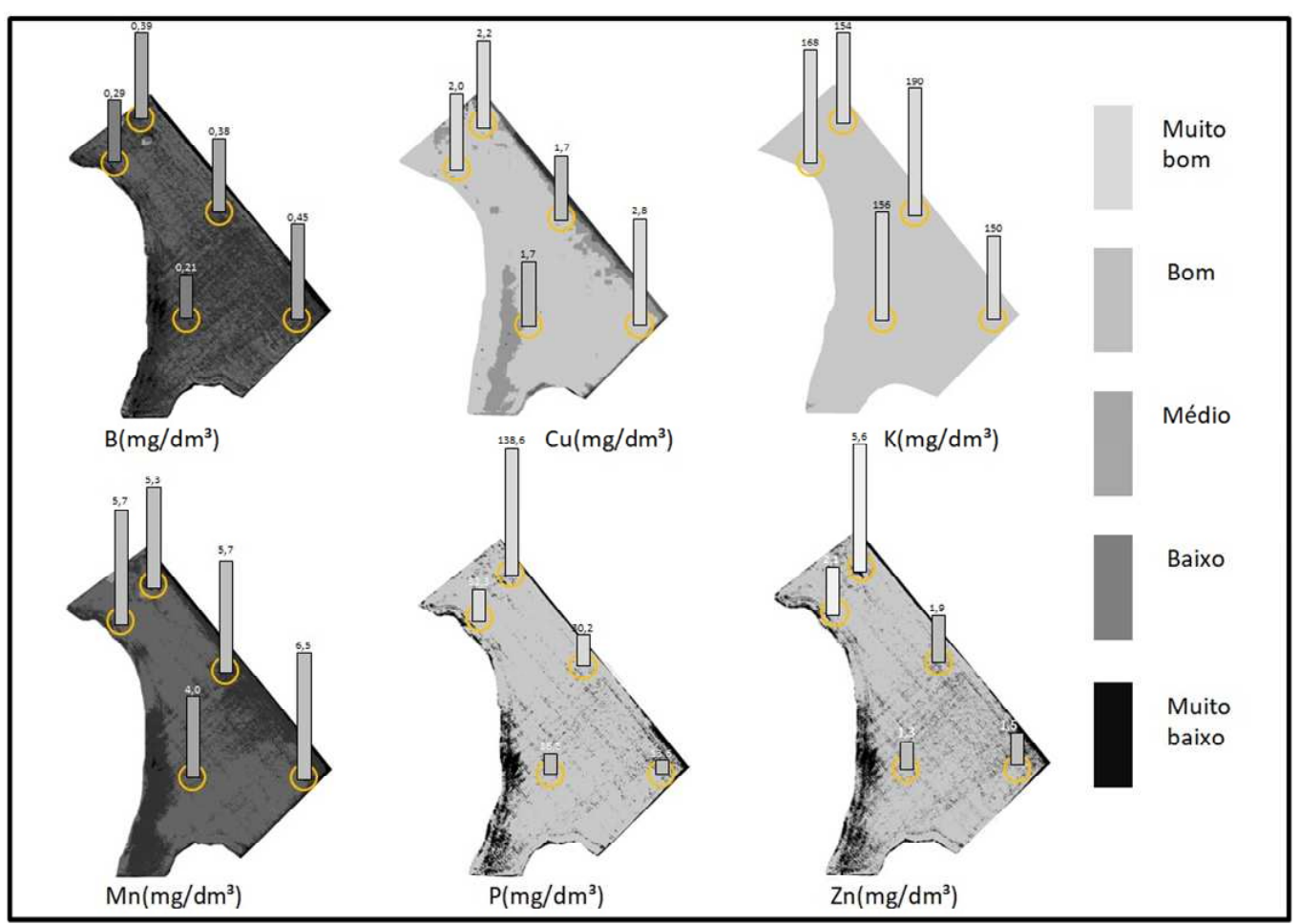

Figura 18 - Mapas de Variabilidade de nutrientes no solo para Boro, Cobre, Potássio, Manganês, Fósforo e Zinco, em $\mathrm{mg} / \mathrm{dm}^{3}$, exibidos de acordo com o fertigrama mostrado na tabela 四, apartir do mosaico de imagens da área coberta de lavoura de milho, tomadas em 13 de maio de 2017.

A vantagem do Google Earth é a que ele deu acesso a imagens da área tomadas em fevereiro de 2017, em um momento em que ela não estava coberta por cultura alguma, expondo o solo a uma análise direta dos índices de refletância. Isso nos permite a análise do impacto da cobertura vegetal no sensoriamento remoto aplicado em avaliação de adequabilidade de solos para agricultura.

\begin{tabular}{|c|c|c|c|c|c|c|c|c|}
\hline \multirow{2}{*}{ Amostra } & \multicolumn{2}{|c|}{ Vermelho } & \multicolumn{2}{c|}{ Verde } & \multicolumn{2}{c|}{ Azul } & \multicolumn{2}{c|}{ NGRDI } \\
\cline { 2 - 8 } & Média & Desvio Padrão & Média & Desvio Padrão & Média & Desvio Padrão & Média & Desvio Padrão \\
\hline 1 & 0,6261 & 0,0158 & 0,5628 & 0,0092 & 0,5688 & 0,0075 & $-0,0528$ & 0,0048 \\
\hline 2.1 & 0,6053 & 0,0030 & 0,5593 & 0,0028 & 0,5709 & 0,0034 & $-0,0396$ & 0,0020 \\
\hline 2.2 & 0,5768 & 0,0439 & 0,5463 & 0,0466 & 0,5584 & 0,0434 & $-0,0306$ & 0,0347 \\
\hline 2.3 & 0,5393 & 0,0148 & 0,5380 & 0,0135 & 0,5544 & 0,0144 & $-0,0004$ & 0,0032 \\
\hline 2.4 & 0,5945 & 0,0073 & 0,5785 & 0,0037 & 0,5726 & 0,0042 & $-0,0133$ & 0,0048 \\
\hline
\end{tabular}

Tabela 15 - Valores de refletância nas bandas NIR, vermelho, verde e azul, para mosaico de imagens de fevereiro 2017.

Com as regressões entre as refletâncias e as concentrações de nutrientes para os respectivos $r^{2}$ mais altos, se pôde, mais uma vez, gerar mapas de distribuição. Os desempenho dos 
coeficientes de correlação foi mais distribuído do que no caso das imagens que mostrava uma camada de vegetação por sobre o solo. Enquanto que nas imagens do Pleiades e do Google Earth de Maio de 2017, as melhores correlações se concentravam em um ou dois índices de refletância, no caso das imagens de fevereiro de 2017, todas as bandas e o NGRDI foram usados para as regressões. Vale menção, novamente, a baixa correlação do potássio, repetindo o desempenho das imagens do Pleiades e do Google Earth de Maio de 2017.

\begin{tabular}{|c|c|c|c|c|}
\hline$r^{2}$ & Vermelho & Verde & Azul & NGRDI \\
\hline P meh & 0,0914 & 0,2365 & 0,2859 & 0,0002 \\
\hline K & 0,0105 & 0,0257 & 0,0144 & 0,0024 \\
\hline S-SO4 & 0,4057 & 0,0435 & 0,0603 & 0,4607 \\
\hline $\mathrm{B}$ & 0,2289 & 0,0784 & 0,0019 & 0,7137 \\
\hline $\mathrm{Cu}$ & 0,1235 & 0,0265 & 0,0251 & 0,3239 \\
\hline $\mathrm{Fe}$ & 0,3911 & 0,2054 & 0,2363 & 0,2141 \\
\hline $\mathrm{Mn}$ & 0,0415 & 0,2336 & 0,059 & 0,3175 \\
\hline $\mathrm{Zn}$ & 0,0948 & 0,2793 & 0,3232 & 0,0011 \\
\hline
\end{tabular}

(a) Coeficientes de correlação $r^{2}$ entre nutrientes e bandas/VIs.Em escala de verde a vermelho, os $r^{2}$ máximos e mínimos, respectivamente.

\begin{tabular}{|c|c|c|c|}
\hline Nutriente & Banda & $r^{2}$ & Regressões \\
\hline \hline $\mathrm{P}$ & Azul & 0,2859 & $P=-648,62 *$ Azul $+403,72$ \\
\hline $\mathrm{K}$ & Verde & 0,0257 & $K=-112,5 * N G R D I+172,37$ \\
\hline $\mathrm{Cu}$ & NGRDI & 0,3239 & $C u=8,5893 * N G R D I-1,4102$ \\
\hline $\mathrm{Fe}$ & Vermelho & 0,3911 & $F e=-63,589 * N G R D I+29,559$ \\
\hline $\mathrm{Mn}$ & NGRDI & 0,3175 & $M n=-13,261 *$ Vermelho $+11,653$ \\
\hline $\mathrm{Zn}$ & Azul & 0,3232 & $Z n=-26,514 *$ Azul $+17,093$ \\
\hline $\mathrm{B}$ & NGRDI & 0,7137 & $B=-1,9124 *$ Azul $+1,398$ \\
\hline
\end{tabular}

(b) Regressões para as melhores correlações.

Tabela 16 - Resultados da análise de correlação entre análise química versus refletâncias/índices de vegetação da imagem do Google Earth de fevereiro de 2017.

De qualquer forma, o mapa de variabilidade gerado nos níveis do fertigrama permite o ajuste da interpretação do conteúdo de cada nutriente, como pode ser observado quando se compara os valores obtidos da análise química com o nível apresentado no ponto de amostra no mapa. 


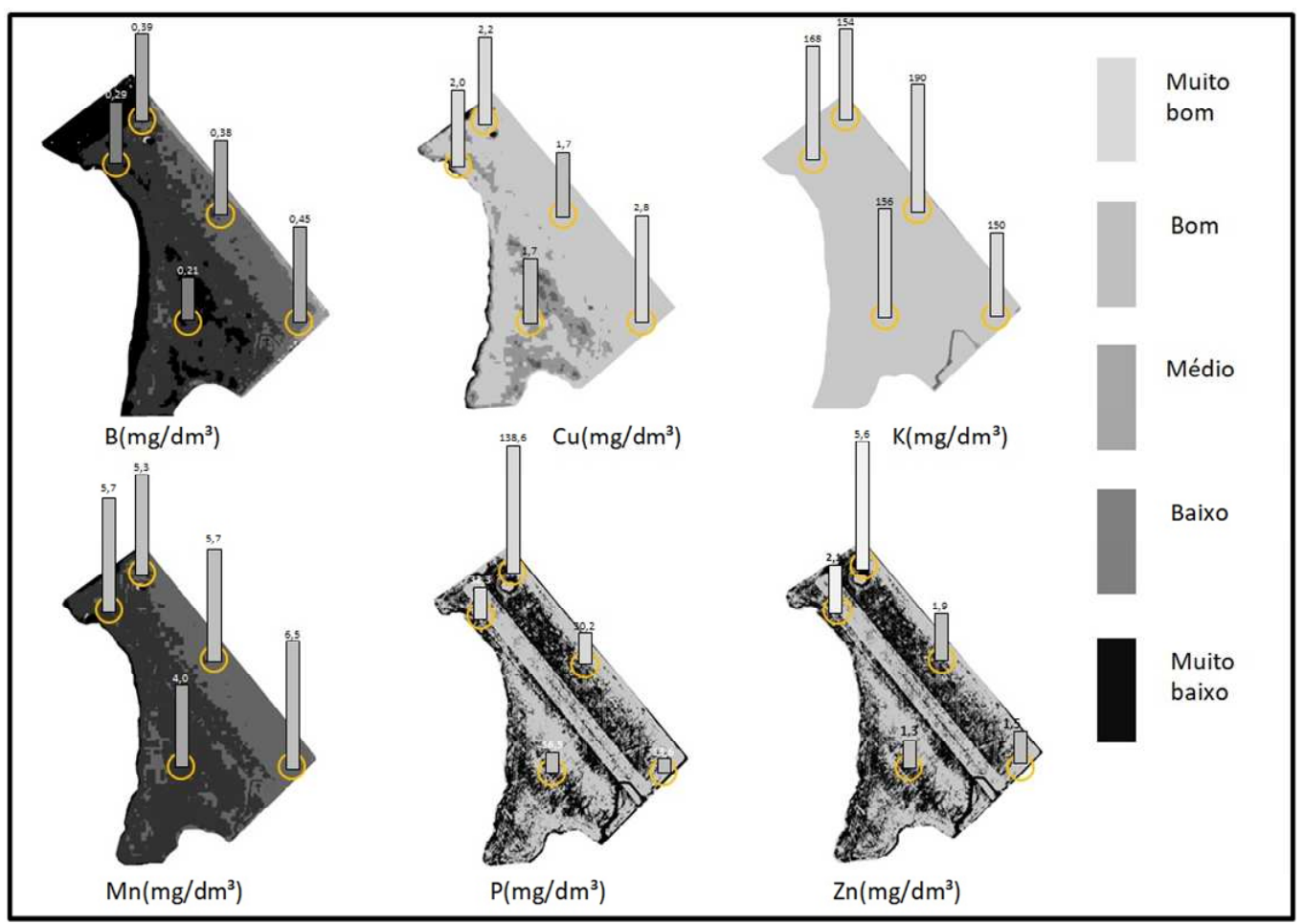

Figura 19 - Mapas de Variabilidade de nutrientes no solo para Boro, Cobre, Potássio, Manganês, Fósforo e Zinco, em $\mathrm{mg} / \mathrm{dm}^{3}$, exibidos de acordo com o fertigrama mostrado na tabela 四, apartir do mosaico de imagens da área sem a cobertura da lavoura, tomadas em 17 de fevereiro de 2017.

\subsection{ANÁLISE QUÍMICA VERSUS ESTIMATIVAS POR IMAGENS}

Os laudos das análises químicas das amostras selecionadas geraram dados com os quais se puderam procurar uma relação direta com os índices de refletância e de vegetação, mas o pequeno número de amostras não nos permite traçar correlações conclusivas. O fato de ter-se utilizado imagens de fontes diferentes e de momentos diferentes permitiu identificar que as estimativas feitas a partir delas têm razoável grau de relevância, porém foi necessário usar os dados da análise química para cada conjunto de imagens para gerar correlações confiáveis. Como apresentado na tabela 四, o agricultor está de certa forma acostumado a receber as informações sobre os níveis de nutrientes em suas terras de uma forma discriminada em níveis de adequabilidade. Então, para uma análise mais próxima ao que o produtor estaria esperando, a tabela 17 traduz os resultados das análises de cada uma das amostras em termos do fertigrama. 


\begin{tabular}{|c|c|c|c|c|c|c|c|}
\hline Amostra & $\mathrm{P}$ & $\mathrm{K}$ & $\mathrm{B}$ & $\mathrm{Cu}$ & $\mathrm{Fe}$ & Mn & $\mathrm{Zn}$ \\
\hline \hline 1 & Médio & Muito Bom & Médio & Muito Bom & Baixo & Médio & Médio \\
\hline 2.1 & Bom & Muito Bom & Médio & Bom & Médio & Médio & Médio \\
\hline 2.2 & Muito bom & Muito Bom & Médio & Muito Bom & Bom & Médio & Muito Bom \\
\hline 2.3 & Muito bom & Muito Bom & Baixo & Muito Bom & Baixo & Médio & Muito Bom \\
\hline 2.4 & Médio & Muito Bom & Baixo & Bom & Médio & Baixo & Médio \\
\hline
\end{tabular}

Tabela 17 - Resultados das análises químicas para cada amostra, em termos do Fertigrama [1.

Esta escala permite ampliar o alcance da estimativa feita a partir das imagens, reduzindo de certa forma a margem de erro dos cálculos. Tomando as estimativas feitas com as imagens do Landsat-8, pode-se verificar a acurácia, dentro dos limites do fertigrama, dos dados gerados, quando se utilizam as regressões obtidas do trabalho de Magri et al, apresentados na tabela 4.

\begin{tabular}{|c|c|c|c|c|}
\hline Nutriente & \multicolumn{2}{|c|}{ P } & \multicolumn{2}{c|}{ K } \\
\hline Fonte de medição & $m g / d m^{3}$ & Fertigrama & $m g / d m^{3}$ & Fertigrama \\
\hline NIR & 7,25 & Baixo & 99,45 & Bom \\
\hline Vermelho & 9,25 & Baixo & 129,05 & Bom \\
\hline Verde & 14,10 & Médio & 177,62 & Muito Bom \\
\hline Análise Química & 13,60 & Médio & 150,00 & Bom \\
\hline
\end{tabular}

Tabela 18 - Valores de refletância e de índices de vegetação obtidos das imagens do Landsat-8.

Esta análise nos mostra que, apesar de próximos, os resultados não são conclusivos ao tentar se traçar uma correlação entre os níveis de refletância e de concentração de nutrientes. Atribui-se a isso o fato de que os dados usados para se obter as regressões foram obtidos de uma terceira fonte, não relacionada com esta área, o que também nos permite concluir que as correlações entre refletâncias e nutrientes não são absolutas. Ou seja, o uso de dados de campo, mais especificamente da área estudada, se farão necessários para traçar o perfil de estimativas a serem adotados.

Expandindo para as estimativas com imagens do Pleiades e do Google Earth, a tabela 17 também apresenta os resultados das análises químicas das quatro amostras retiradas adicionais da área estudada, em termos do fertigrama. Cada ponto amostrado estava a uma distância de aproximadamente 220 metros de outro ponto, como exceção dos pontos 2.2 e 2.3 que tem seus pontos centrais distanciados um do outro em 60 metros. Dadas dimensões da área estudada, esta grade tinha o potencial de apresentar uma estimativa razoável dos nutrientes presentes 
na área. Os números mostram uma área interessantemente heterogênea na sua distribuição de nutrientes, o que permitiria um bom terreno para correlações com os índices de refletância e vegetação. Destacam-se o fósforo e o zinco no quesito magnitude do desvio padrão entre os valores apresentados nos laudos.

As regressões que foram geradas apresentaram variações de correlações. Enquanto o $r^{2}$ da correlação entre a concentração de cobre e o índice de refletância em infravermelho próximo das imagens do Pleiades nos fornece um nível de confiabilidade de aproximadamente 95\%, a correlação entre o NGRDI, obtido do mosaico de imagens do Google Earth, e fósforo é praticamente nula. Ao se comparar as mesmas correlações para imagens de fontes diferentes, também se identificam consideráveis discrepâncias nos níveis de confiabilidade. O potássio se relaciona com a banda de vermelho da imagem tirada em 14 de maio de 2017 pelo satélite Pleaides com um $r^{2}=0,2544$, enquanto com o vermelho obtido do Google Earth nas imagens de 13 de maio de 2017, apenas um dia antes, se relaciona com um $r^{2}=0,0105$. Estas diferenças impedem uma relação absoluta entre os parâmetros medidos quimicamente e os níveis de refletância, mesmo que em bandas fora do espectro visível.

Vários são os fatores que geram esta diferença de nível de correlação, dentre eles alguns controláveis, como a sensibilidade da câmera embarcada no satélite, momento de tomada das imagens; outros fora do nosso controle, como condições atmosféricas e. Considerando esta gama de fatores, e adicionando o fato de que quanto maior a variedade de imagens disponíveis, de momentos diferentes, e de fontes diferentes, mais flexível será a capacidade de análise pelo produtor. Portanto, a utilização de imagens de satélite ou de aplicativos como o Google Earth pode vir a ser um recurso rápido e flexível para a criação de mapas de variabilidade, caso análises químicas de uma quantidade suficiente de amostras estejam disponíveis.

Novamente, a utilização do Fertigrama para balizar os níveis de cada nutriente permite que as estimativas a partir do sensoriamento remoto se tornem mais efetivas, mesmo com um nível de correlação menor na origem dos dados. Ao se comparar os resultados apresentados nas figuras 17, 18] e 19] com a tabela [7], observa-se um grande grau de equivalência dos resultados. As estimativas mostram, com boa definição e consistência entre as origens de sensoriamento, regiões de desníveis de concentração dos nutrientes estudados.

A implementação de VANTs nesta aplicação tenderia a reduzir as diferenças entre as correlações entre uma análise e outra, dada a possibilidade de tomada de imagens customizadas e controladas das áreas de interesse. Obviamente que esta técnica traria outros desafios, mas o mercado tem se mostrado receptivo aos drones como plataforma de sensoriamento remoto, principalmente pelas incontáveis outras aplicações simultâneas que o VANT pode ter na AP. Uma análise caso deve ser feita para a aplicação de VANTs para garantir que estes obstáculos técnicos não se sobreponham aos benefícios da obtenção de imagens em altíssima 
resolução, principalmente considerando a capacidade cada vez maior dos satélites de realizar sensoriamento remoto em alta resolução espacial e temporal, com mínimas distorções.

\subsection{IMAGENS DE SATÉLITE VERSUS GOOGLE EARTH}

Ainda que os níveis de correlação tenham variado entre as amostras, os resultados das regressões calculadas sobre os máximos $r^{2}$ pra cada nutriente mostraram boa consistência, como se pode observar na figura 30 , que compara os mapas de variabilidade para o mesmo nutriente, calculados a partir de imagens de origens e tempos diferentes. Mesmo com níveis de confiança diferentes, quando se constrói os mapas de variabilidade graduando as concentrações, da forma que os próprios laboratórios fazem (muito baixo, baixo, médio, bom, muito bom), os resultados se mostraram coerentes entre si. 


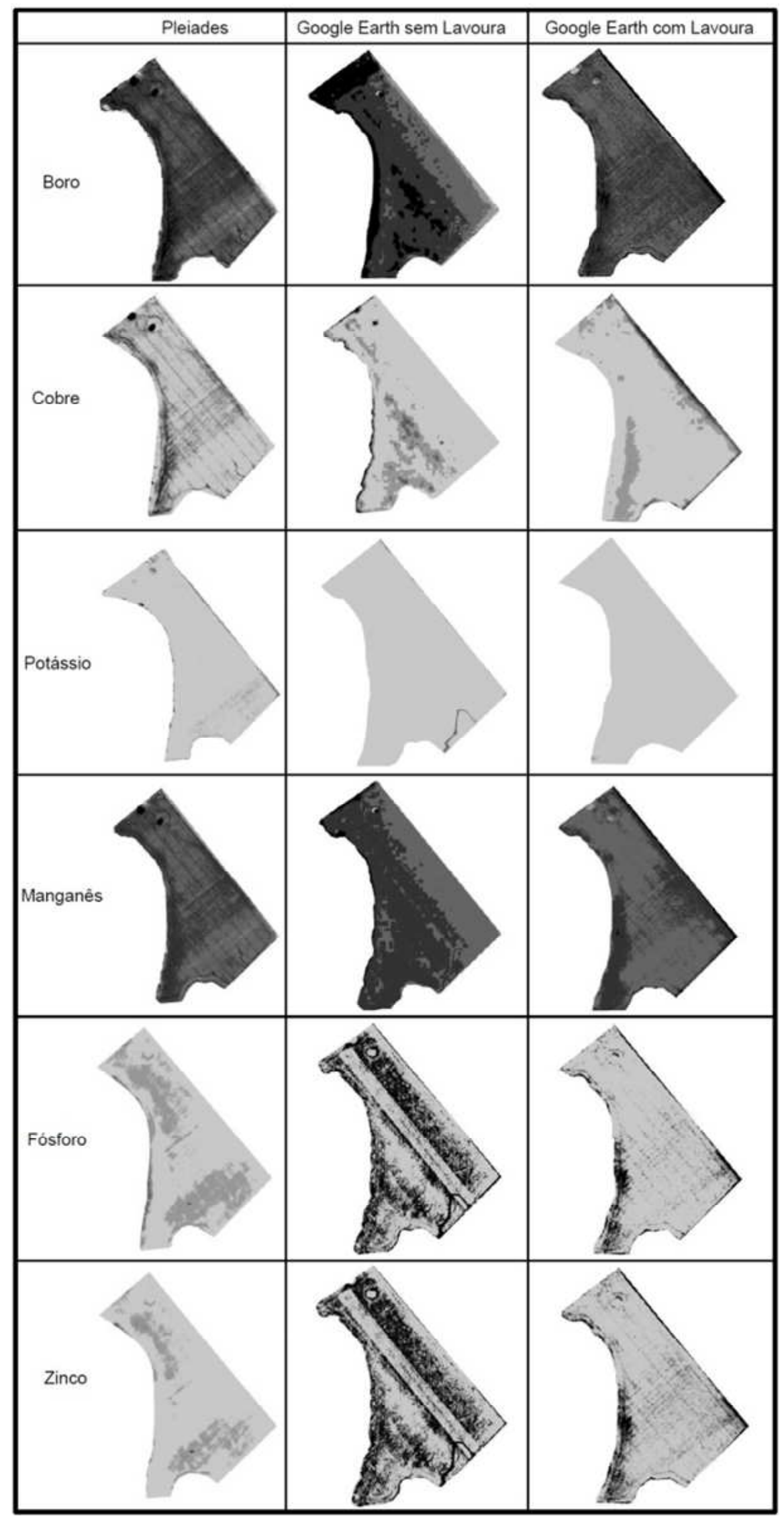

Figura 20 - Comparação entre as estimativas feitas a partir das imagens do Pleiades e do Google Earth, para os nutrientes $\mathrm{B}, \mathrm{Cu}, \mathrm{K}, \mathrm{Mn}, \mathrm{P}$ e $\mathrm{Zn}$. 
Outro ponto que vale a discussão é o nível de detalhamento de cada mapa. As imagens do Pleiades geraram mapas de variabilidade de maior resolução, em relação às imagens do Google Earth. De qualquer forma, a consistência entre os mapas de variabilidade com imagens do Pleiades e do Google Earth comprovam a confiabilidade do segundo para este tipo de aplicação. Esta é uma discussão valida de ser levada a diante em futuros estudos, por que demonstra que informações de refletância dentro do espectro visível podem gerar estimativas razoáveis das concentrações de nutrientes, o que implicaria em menores custos para o produtor ao recorrer ao sensoriamento remoto para gerenciamento agrícola. A imagem do Pleiades usada neste trabalho custou US $\$ 145,00$, enquanto cada amostra química custou $R \$ 25,00$, oque soma um custo total aproximado de $\mathrm{R} \$ 640,00$. Enquanto este já é um custo baixo para o nível de detalhe das informações geradas, o custo cairia para $\mathrm{R} \$ 125,00$ caso apenas imagens do Google Earth fossem utilizadas, representando uma redução de mais $80 \%$. 


\section{CONCLUSÃO}

Durante este trabalho, ficou evidente que o agricultor, principalmente o médio e o pequeno produtor, tem boa vontade em relação à agricultura de precisão. Os grandes produtores já tem acesso a processos de sensoriamento remoto compatíveis com grandes propriedades, além de terem os meios financeiros de absorverem os altos custos de tecnologias ainda incipientes no mercado. Os métodos correntes de coleta de dados são ainda, para este nicho, baseados em informações tomadas in loco e de longo tempo de processamento, e ao receber as informações, a baixa resolução dos resultados não apresentam base para gerenciar com precisão a distribuição de nutrientes por sobre a área de lavoura.

Satélites que fornecem imagens gratuitas, como o Landsat-8, não disponibilizam dados em alta resolução que possam ser utilizados para gerenciamento agrícola de precisão em pequenas propriedades. Como quaisquer estimativas de nutrientes a partir de imagens requereriam dados tomados in loco, o próprio propósito de estimar as concentrações dos nutrientes sob esta resolução se perderia, ou seja, a resolução das imagens nas bandas de interesse é, de fato, um fator determinante na viabilidade desta aplicação de sensoriamento remoto.

Imagens do Google Earth mostraram boa resolução apesar do acesso gratuito. Caso as imagens sejam produzidas dentro de um período de um ano, ainda estarão dentro do período que os produtores agrícolas brasileiros estão acostumados a obterem informações para o gerenciamento agrícola. Mas a periodicidade não é constante, o que impossibilita tornar o aplicativo uma ferramenta perene entre os produtores.

Em relação à estimativa de nutrientes, fora o desafio da calibração da refletância utilizando a análise química do solo, uma das restrições impostas por este recurso é o fato de ele não permitir acesso às bandas abaixo do vermelho. Porém, dentro do que as bandas disponíveis permitem estimar, o fato de que, a uma altitude de 100 a 150 metros, as imagens manterem boa resolução permite um sensoriamento relativamente próximo ao solo. Isso seria permitido com a tomada de um conjunto de imagens, da construção do mosaico, e da posterior análise de nutrientes a partir dos índices de refletância e vegetação. Por outro lado, o desempenho das imagens de satélite, mesmo que sem acesso à bandas térmicas ou de infra-vermelho, como avaliado neste trabalho, mostra que talvez os esforços de se lidar com os desafios técnicos de se implementar VANTs no sensoriamento remoto agrícola talvez não seja recompensador como se deseja.

Imagens de satélite permitem o acesso a bandas invisíveis do espectro, mas algum custo. Ou o custo é a baixíssima resolução, que permite apenas a estimativa da média dos nutrientes na área estudada, ou o custo é financeiro para obtenção de imagens de alta resolução. No primeiro caso, como a análise química tem custo relativamente acessível ao produtor agrícola, 
esta aplicação tem mais viés acadêmico do que prático; a não ser que se trate de grandes propriedades ou áreas estudadas, da ordem de cinco mil hectares, que a ordem de grandeza da área coberta por uma única imagem gerada pela plataforma gratuita do Landsat-8, valor para o qual a resolução de trinta metros já começa a disponibilizar informações utilizáveis.

No segundo caso, o custo financeiro de obtenção dos dados para análise e estimativas de distribuição de nutrientes, ao redor dos $U \$ 150,00$, que é acima do custo comum de uma análise química, ao redor dos $\mathrm{R} \$ 25,00$, só se justifica de forma prática e comercial se o produtor agrícola estiver procurando uma análise química de alta resolução, para um gerenciamento mais preciso. As imagens obtidas pelo satélite Pleiades tem altíssima resolução, além de acesso à bandas de infravermelho que permitem uma análise mais precisa da refletância. Porém, como a geração de imagens depende da passagem do satélite por sobre a área, a frequência amostral está na ordem de meses. Isso implica que as imagens podem ser tomadas fora do tempo ideal de avaliação para gerenciamento de nutrientes. Outro fator a ser observado é a presença de nuvens ou gases atmosféricos que podem distorcer ou bloquear a imagem desejada (o que não aconteceu nos dados coletados neste trabalho). Estes fatores engrossam a demanda por geração de imagens a partir de veículos aéreos não tripulados, que apesar de apresentarem uma gama de desafios diferenciada, uma vez um método estabelecido e os desafios devidamente endereçados, não dependem de condições atmosféricas e podem gerar as informações a qualquer momento que o produtor precisar.

As estimativas da presença de nutrientes no solo aqui realizadas demonstraram resultados coerentes entre si, com mapas correspondentes através das diferentes fontes de dados de sensoriamento. Mesmo quando o coeficiente $r^{2}$ se mostrou baixo, principalmente para o potássio, o fato de ter-se discretizado a escala de níveis de nutrientes em apenas cinco níveis, como apresentado no fertigrama, permitiu a identificação de porções de terra cuja concentração de cada nutriente estaria deficiente. Isso pode ser notado, por exemplo, quando se compara os níveis de Manganês apontados nos mapas de variabilidade gerados pelos dados do Pleiades e pelos dados de Maio de 2017 do Google Earth, como apresentado na figura 20 . Ambos apresentam a área com uma concentração do nutriente considerada média, com manchas longitudinais de maior deficiência de Manganês. Pode-se interpretar isto como as áreas por onde a refletância pode ser detectada, já que nas duas imagens, a área estava coberta de vegetação. Mas as imagens de Fevereiro de 2017 corroboram o diagnóstico de que a área tem uma concentração de Manganês entre 5,3 e $8 \mathrm{mg} / \mathrm{m}^{3}$, e que existem manchas onde a concentração está abaixo dos $5,3 \mathrm{mg} / \mathrm{m}^{3}$. Esta conclusão se repete para os outros nutrientes, o que nos permite afirmar que os mapas de variabilidade apresentados oferecem boa base para tomada de decisões e para o gerenciamento dos nutrientes por sobre a área de lavoura.

Mais uma conclusão, portanto, é que a variação da concentração dos nutrientes não variou 
entre os períodos de fevereiro, maio e setembro. Vários fatores teriam de ser analisados para entender as razões por traz disto, como, por exemplo, a facilidade com que estes nutrientes são levados pelas águas da chuva, o quanto eles são repostos durante as safras e entre safras, tanto pelo gerenciamento de nutrientes como pelos próprios nutrientes depositados no solo pelos ciclos naturais da planta. Estes fatores devem ser analisados in loco com análises mais aprofundadas. Mas, pode-se concluir que esta variação entre o tempo de tomada das fotos e das amostras para análise química não foi um fator a invalidar as estimativas e as gerações dos mapas de variabilidade.

Em estudos futuros, após depurar os resultados deste trabalho, o próximo passo seria reunir todos os processos aqui estudados e implementados em uma única aplicação, talvez utilizando imagens geradas por VANTs, o que traria maior versatilidade ao processo. O VANT sobrevoaria a área de interesse, embarcado de uma câmera multiespectral e de sensores e controles de orientação devidamente calibrados, obteria as fotos espaçadas umas das outras de forma que garantam tanto a resolução da imagem, como a captura de características críticas em pelo menos duas imagens para permitir a correta construção do mosaico. 


\section{Referências}

1 H. P. W. Jayasuriya K. C. Swain, S. J. Thomson. Adoption of an Unmanned Helicopter for LowAltitude Remote Sensing To Estimate Yield and Total Biomass of a Rice Crop. Am. Soc. Agric. Biol. Eng., 53(1):21-27, 2010.

2 John V. Stafford. Implementing Precision Agriculture in the 21st Century. J. Agric. Eng. Res., 76(3):267-275, 2000.

3 Anne Mims Adrian, Shannon H. Norwood, and Paul L. Mask. Producers' perceptions and attitudes toward precision agriculture technologies. Comput. Electron. Agric., 48(3):256$271,2005$.

4 Luciano Shozo Shiratsuchi, Ziany Neiva Brandão, Luiz Eduardo Vicente, Daniel de Castro Victoria, Jorge Ricardo Ducati, Ronaldo Pereira de Oliveira, and Marina de Fátima Vilela. Sensoriamento Remoto: conceitos básicos e aplicações na Agricultura de Precisão. Agric. precisão Result. um novo olhar, pages 58-73, 2014.

5 Lúcio André, De Castro Jorge, and Ricardo Y Inamasu. Uso de veículos aéreos não tripulados em Agricultura de Precisão. Agric. Precisão Result. um Novo Olhar, (EMBRAPA):109134, 2014.

6 G Warren and G Metternicht. Agricultural applications of high-resolution digital multispectral imagery: evaluating within-field spatial variability of canola (brassica napus) in western australia. Photogramm. Eng. Remote Sensing, 71(5):595-602, 2005.

7 Viraj A Gulhane. Wavelet for Predicting Soil Nutrients using Remotely Sensed Satellite Images. Int. J. Comput. Appl., 174(4):35-38, 2017.

$8 \mathrm{Pm}$ Bierman and $\mathrm{Cj}$ Rosen. Nutrient cycling and maintaining soil fertility in fruit and vegetable crop systems. Univ. Minesota, pages 1-26, 2005.

9 E. Raymond Hunt, Michel Cavigelli, Craig S T Daughtry, James E. McMurtrey, and Charles L. Walthall. Evaluation of digital photography from model aircraft for remote sensing of crop biomass and nitrogen status. Precis. Agric., 6(4):359-378, 2005.

10 Ofer Beeri, Rebecca Phillips, Pete Carson, and Mark Liebig. Alternate satellite models for estimation of sugar beet residue nitrogen credit. Agric. Ecosyst. Environ., 107(1):21-35, 2005.

11 Shanyu Huang, Yuxin Miao, Guangming Zhao, Xiaobo Ma, Chuanxiang Tan, Georg Bareth, Uwe Rascher, and Fei Yuan. Estimating rice nitrogen status with satellite remote sensing in Northeast China. 2013 2nd Int. Conf. Agro-Geoinformatics Inf. Sustain. Agric. AgroGeoinformatics 2013, (31071859):550-557, 2013. 
12 W. C. Bausch and R. Khosla. QuickBird satellite versus ground-based multi-spectral data for estimating nitrogen status of irrigated maize. Precis. Agric., 11(3):274-290, 2010.

13 Malek Mohd Yusoff, K Jusoff, and MH Ismail. Soil Nutrient Varibility Mapping in UiTM Research Station, Arau, Perlis Using Landsat TM and Geostatistical Analysis. Proc. 2nd WSEAS Int. Conf. Remote Sensing, Tenerife, Canar. Islands, Spain, December 16-18, 2006 77 Soil, pages 77-84, 2006.

14 Antoni Magri, Harold M. Van Es, Michael A. Glos, and William J. Cox. Soil test, aerial image and yield data as inputs for site-specific fertility and hybrid management under maize. Precis. Agric., 6(1):87-110, 2005.

15 Keith D. Shepherd and Markus G. Walsh. Development of Reflectance Spectral Libraries for Characterization of Soil Properties. Soil Sci. Soc. Am. J., 66(3):988, 2002.

16 Sebahattin Albayrak. Use of reflectance measurements for the detection of $N, P, K, A D F$ and NDF contents in sainfoin pasture. Sensors, 8(11):7275-7286, 2008.

17 Jose a J Berni, Pj Pablo J Zarco-tejada, L Suarez, Elias Fereres, Student Member, and Lola Suárez. Thermal and Narrowband Multispectral Remote Sensing for Vegetation Monitoring From an Unmanned Aerial Vehicle. IEEE Trans. Geosci. Remote Sens., 47(3):722-738, 2009.

18 J. A. Thomasson, R. Sui, M. S. Cox, and A. AlÜRajehy. Soil Reflectance Sensing for Determining Soil Properties in Precision Agriculture. Trans. ASAE, 44(6):1445-1453, 2001.

19 U S Geological Survey. Landsat 8 (L8) Data Users Handbook. America (NY)., 8(1993):1993-1993, 2005.

$20 \mathrm{H}$ Eugster and S Nebiker. Geo registration of video sequences captured from mini UAV - approaches and accuracy assessment. Mob. Mapp. Technol. Symp. MMT, pages 1-8, 2007.

21 Charles L. Hunt, Raymond; Daughtry, Craig S. T.; Walthall. Agricultural Remote Sensing using Radio-Controlled Model Aircraft, 2003.

22 E Raymond Hunt, W Dean Hively, Associate Soil Scientist, Craig S T Daughtry, Greg W Mccarty, Soil Scientist, Stephen J Fujikawa, T L Ng, Michael Tranchitella, Aeronautical Engineer, David S Linden, David W Yoel, and Intellitech Microsystems. Remote Sensing of Crop Leaf Area Index Using Unmanned Airborne Vehicles. October, 17:18-20, 2008.

23 Andrea S Laliberte, Remote Sensing Scientist, Jeff Herrick, and Rangeland Scientist. UNMANNED AERIAL VEHICLES FOR RANGELAND MAPPING AND MONITORING : A COMPARISON OF TWO SYSTEMS. 2007. 


\section{Anexo A - Laudos da Análise Química}

Laudo da amostra 1

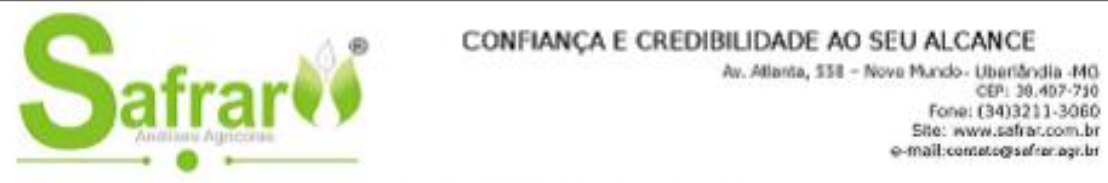

Laudo de Análise de Solo

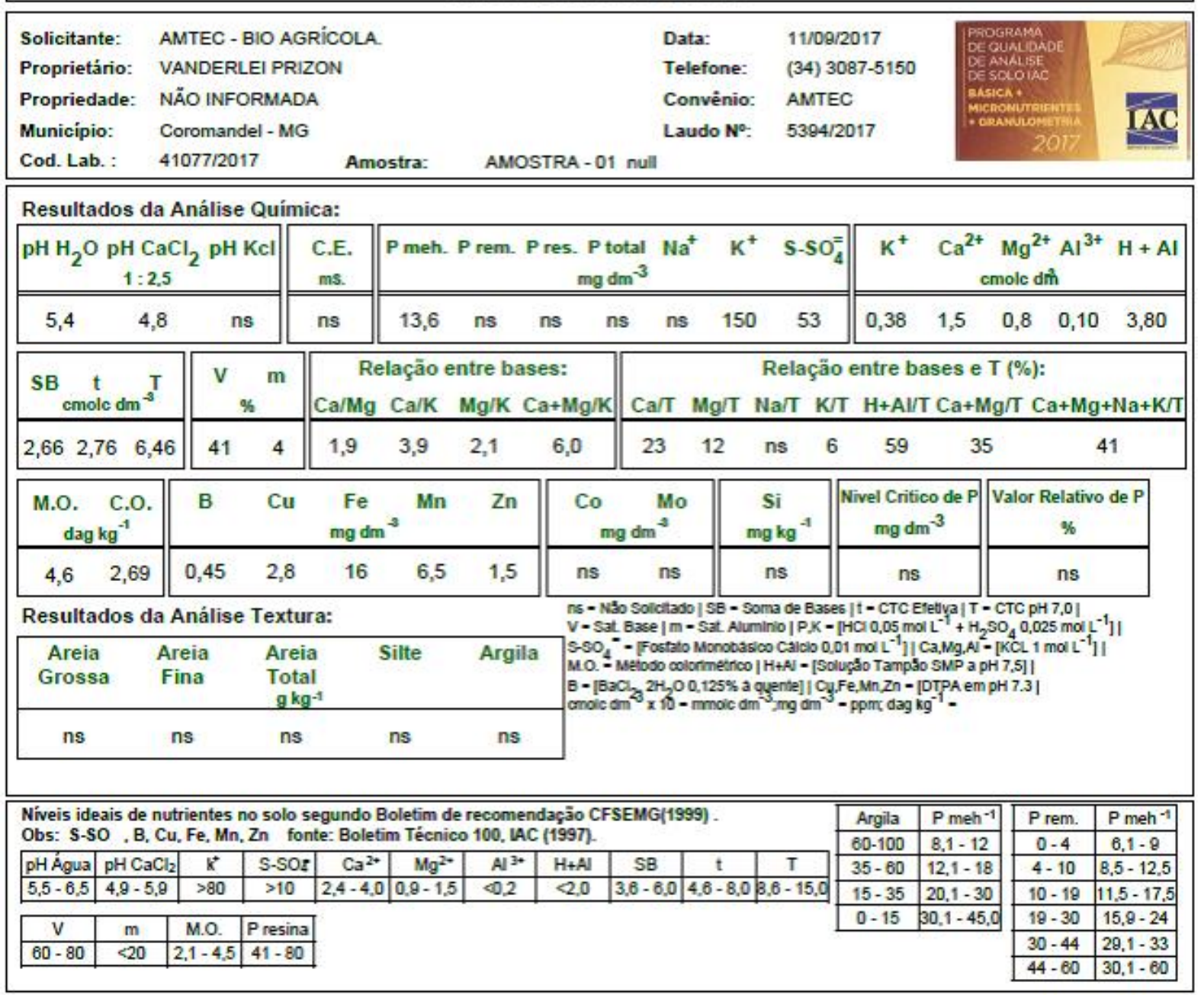

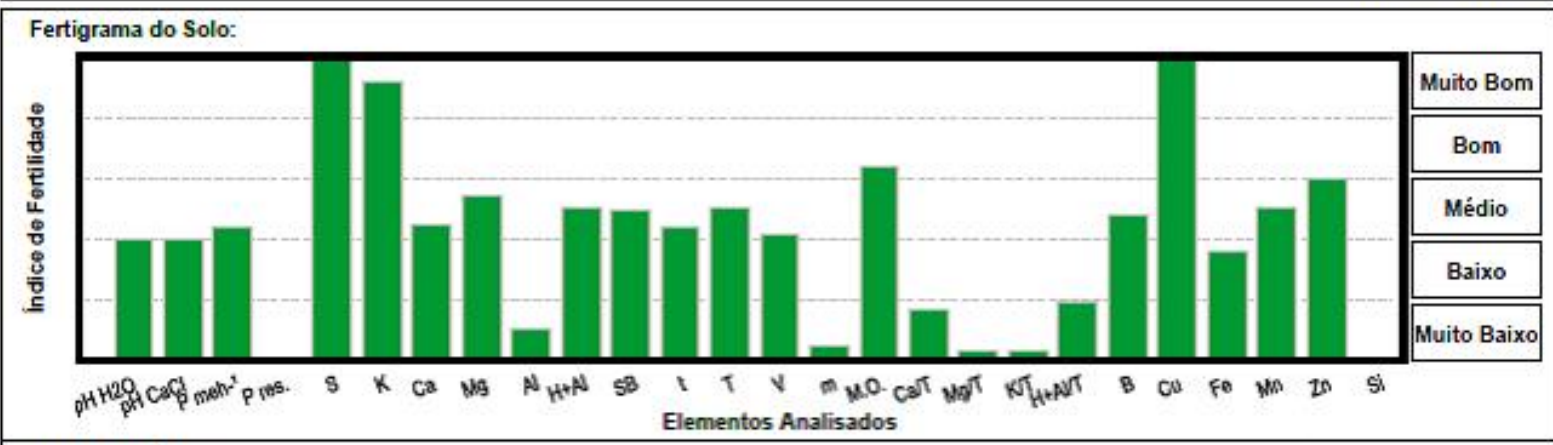

Observações:

Gráfico de $\mathrm{P}$ meh -1 depende da análise granulométrica (vide tabela acima).

A interpretaçä́o de Al, $\mathrm{H}+\mathrm{Al}, \mathrm{m}$ e H+AlT lé-se Alto e Muito Alto no lugar de Bom e Muito Bom.

Fertigrama apresentado como mera sugestäo ilustratriva.

O laboratório não responsabiliza por interpretaçojes dos resultados das análises.

Após 45 dias todas as amostras serảo descartadas.

Este laudo näo tem fins juridicos.

Pagna 1

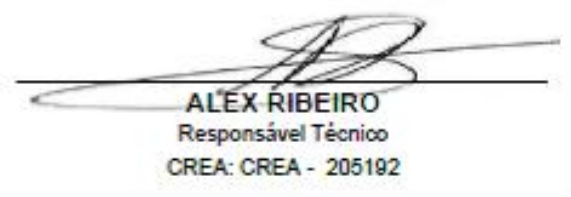


Laudos da amostra 2

Talhão 2.1

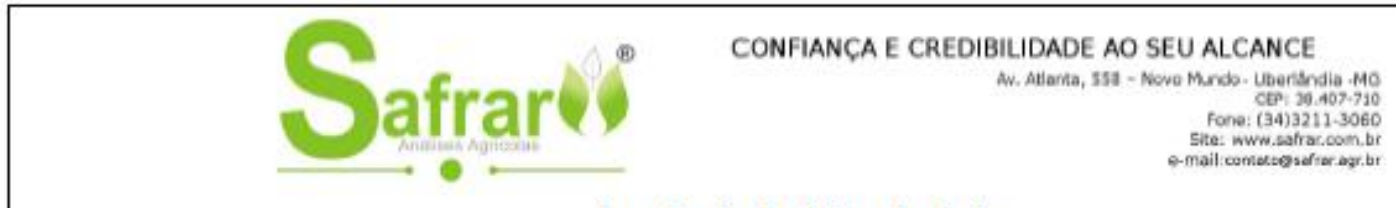

Laudo de Análise de Solo

\begin{tabular}{|c|c|c|c|c|c|}
\hline Solicitante: & AMTEC - BIO AGRICOLA. & & Data: & $01 / 11 / 2017$ & PEOTRAMA \\
\hline Proprietário: & VANDERLEI PRIZON & & Telefone: & (34) $3087-5150$ & DEANALEE \\
\hline Propriedade: & NÄO INFORMADA & & Convènio: & AMTEC & 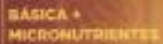 \\
\hline $\begin{array}{l}\text { Município: } \\
\text { Cod. Lab. : }\end{array}$ & $\begin{array}{l}\text { Coromandel - MG } \\
52983 / 2017\end{array}$ & TALHÃO - 01 null & Laudo $\mathbf{N}^{\circ}$ : & $6647 / 2017$ & 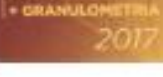 \\
\hline
\end{tabular}

\begin{tabular}{|c|c|c|c|c|c|c|c|c|c|c|c|c|c|c|c|}
\hline \multicolumn{16}{|c|}{ ise Química: } \\
\hline \multicolumn{3}{|c|}{\begin{tabular}{|c}
$\mathrm{pH} \mathrm{H}_{2} \mathrm{O} \mathrm{pH} \mathrm{CaCl}$ \\
$1: 2,5$
\end{tabular}} & \multirow{2}{*}{$\begin{array}{c}\begin{array}{c}\text { C.E. } \\
\mathrm{ms} .\end{array} \\
\mathrm{ns}\end{array}$} & \multirow{2}{*}{$\begin{array}{r}\text { P meh. } \\
30,2\end{array}$} & \multicolumn{3}{|c|}{$\begin{array}{r}\text { P rem. P res. P total } \\
\mathrm{mg} \mathrm{dm} \\
\end{array}$} & \multirow[t]{2}{*}{$\mathrm{Na}^{+}$} & \multirow{2}{*}{\multicolumn{2}{|c|}{$\begin{array}{|cc|}\mathrm{K}^{+} & \mathrm{S}^{-\mathrm{SO}_{4}}= \\
190 & 6 \\
\end{array}$}} & \multicolumn{5}{|c|}{$\begin{array}{c}\mathrm{K}^{+} \mathrm{Ca}^{2+} \mathrm{Mg}^{2+} \mathrm{Al}^{3+} \mathrm{H}+\mathrm{Al} \\
\text { cmole dm } \\
\end{array}$} \\
\hline 5,7 & 5,2 & ns & & & ns & ns & ns & & & & 0,49 & 2,9 & 1,4 & 0,00 & 4,30 \\
\hline
\end{tabular}

\begin{tabular}{|c|c|c|c|c|c|c|c|c|c|c|c|c|c|}
\hline \multirow{2}{*}{$\mathrm{SB} \underset{\text { cmolc } \mathrm{dm}^{-3}}{\mathrm{t}}$} & \multirow{2}{*}{\multicolumn{2}{|c|}{$\begin{array}{ll}\text { V m } \\
\%\end{array}$}} & \multicolumn{4}{|c|}{ Relação entre bases: } & \multicolumn{7}{|c|}{ Relação entre bases e T $(\%)$ : } \\
\hline & & & $\mathrm{Ca} / \mathrm{Mg}$ & $\mathrm{Ca} / \mathrm{K}$ & $\mathrm{Mg} / \mathrm{K}$ & $\mathrm{Ca}+\mathrm{Mg} / \mathrm{K}$ & $\mathrm{Ca} / \mathrm{T}$ & $\mathrm{Mg} / \mathrm{T}$ & $\mathrm{Na} / \mathrm{T}$ & $\mathrm{K} / \mathrm{T}$ & $\mathrm{H}+\mathrm{A}$ & $+\mathrm{MarT}$ & $\mathrm{Ca}+\mathrm{Mg}+\mathrm{Na}+\mathrm{K} / \mathrm{T}$ \\
\hline $4,81 \quad 4,81 \quad 9,11$ & 53 & 0 & 2,0 & 5,9 & 2,9 & 8,8 & 32 & 16 & ns & 5 & 47 & 47 & 53 \\
\hline
\end{tabular}

\begin{tabular}{|c|c|c|c|c|c|c|c|c|c|c|c|}
\hline $\begin{array}{r}\text { M.O. } \\
\text { da }\end{array}$ & $\begin{array}{l}\text { C.O. } \\
\mathrm{kg}^{-1}\end{array}$ & B & $\mathrm{Cu}$ & $\begin{array}{r}\mathrm{Fe} \\
\mathrm{mg} \mathrm{dr}\end{array}$ & Mn & $\mathrm{Zn}$ & Co & $\begin{array}{l}\text { Mo } \\
3\end{array}$ & $\begin{array}{c}\mathrm{Si} \\
\mathrm{mg} \mathrm{kg}^{-1}\end{array}$ & \begin{tabular}{|c|} 
Nivel Critico de P \\
$\mathrm{mg} \mathrm{dm}^{-3}$ \\
\end{tabular} & $\begin{array}{c}\text { Valor Relativo de P } \\
\% \\
\end{array}$ \\
\hline 2,0 & 1,19 & 0,39 & 1,7 & 26 & 5,7 & 1,9 & $\mathrm{~ns}$ & $\mathrm{~ns}$ & ns & ns & ns \\
\hline
\end{tabular}

Resultados da Análise Textura:

\begin{tabular}{|c|c|c|c|c|c|}
\hline $\begin{array}{c}\text { Areia } \\
\text { Grossa }\end{array}$ & $\begin{array}{c}\text { Areia } \\
\text { Fina }\end{array}$ & $\begin{array}{c}\text { Areia } \\
\text { Total } \\
\mathrm{g} \mathrm{kg}^{-1}\end{array}$ & Silte & Argila & 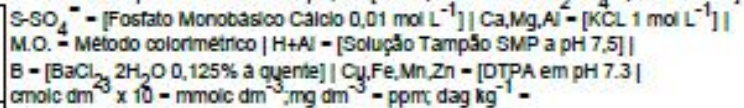 \\
\hline ns & ns & ns & ns & ns & \\
\hline
\end{tabular}

\begin{tabular}{|c|c|c|c|c|c|c|c|c|c|c|c|c|c|c|}
\hline \multirow{2}{*}{\multicolumn{11}{|c|}{$\begin{array}{l}\text { Niveis ideais de nutrientes no solo segundo Boletim de recomendaçäo CFSEMG(1999). } \\
\text { Obs: S-SO . B, Cu, Fe, Mn, Zn fonte: Boletim Técnico 100, LAC (1997). }\end{array}$}} & \multirow{3}{*}{$\begin{array}{c}\text { Argila } \\
60-100 \\
35-60\end{array}$} & \multirow{3}{*}{\begin{tabular}{|l|}
$\mathrm{P}$ meh $^{-1}$ \\
$8,1-12$ \\
$12,1-18$
\end{tabular}} & \multirow{3}{*}{$\begin{array}{c}\text { P rem. } \\
0-4 \\
4-10\end{array}$} & \multirow{2}{*}{\begin{tabular}{|c|}
$\mathrm{P}$ meh $^{-1}$ \\
$6,1-8$ \\
\end{tabular}} \\
\hline & & & & & & & & & & & & & & \\
\hline \begin{tabular}{|l|}
$\mathrm{pH}$ Água \\
\end{tabular} & $\mathrm{pH} \mathrm{CaCl}$ & $\mathbf{k}$ & S-SOz & $\mathrm{Ca}^{2+}$ & $\mathrm{Mg}^{2+}$ & $\mathrm{Al}^{3+}$ & $\mathrm{H}+\mathrm{Al}$ & $\mathrm{SB}$ & $t$ & $T$ & & & & $8,5-12,5$ \\
\hline $5,5-6,5$ & $4,9-5,9$ & $>80$ & $>10$ & $|2,4-4,0|$ & $0,8-1,5$ & 40,2 & $<2,0$ & $3,6-6,0$ & $4,6-8,0 \mid$ & $3,6-15,0$ & $15-35$ & $20,1-30$ & $10-18$ & $11,5-17,5$ \\
\hline $\mathrm{y}$ & $\mathrm{m}$ & Mo & Presina & & & & & & & & $0-15$ & $30,1-45,0$ & $19-30$ & $15,8-24$ \\
\hline $60-80$ & $\frac{m}{<20}$ & $2,1-4,5$ & $41-80$ & & & & & & & & & & $30-44$ & $29,1-33$ \\
\hline & & & & & & & & & & & & & $44-60$ & $30,1-60$ \\
\hline
\end{tabular}

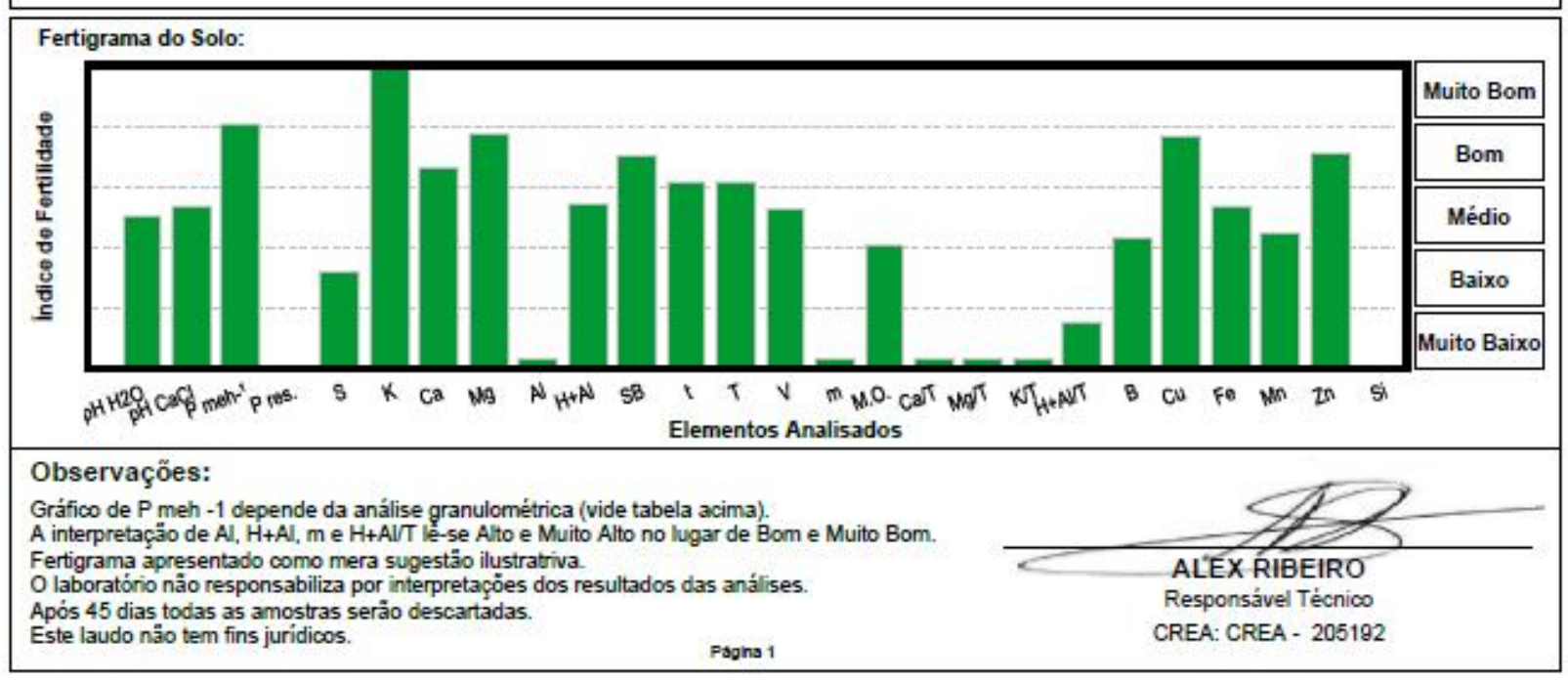


Talhão 2.3

CONFIANCCA E CREDIBILIDADE AO SEU ALCANCE

Laudo de Análise de Solo

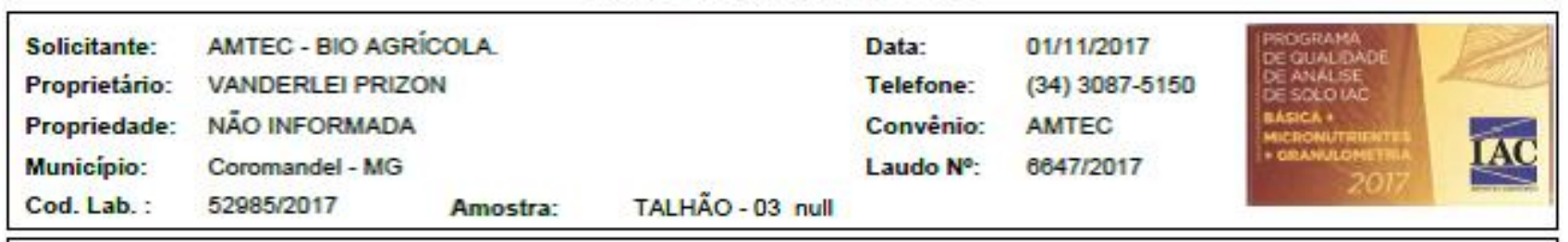

\begin{tabular}{|c|c|c|c|c|c|c|c|c|c|c|c|c|c|c|c|}
\hline \multicolumn{16}{|c|}{ Resultados da Análise Química: } \\
\hline \multicolumn{3}{|c|}{$\underset{1: 2,5}{\mathrm{pH} \mathrm{H}_{2} \mathrm{O} \mathrm{pH} \mathrm{CaCl}_{2} \mathrm{pH} \mathrm{Kcl}}$} & \multirow{2}{*}{$\begin{array}{c}\text { C.E. } \\
\text { ms. }\end{array}$} & \multirow{2}{*}{$\begin{array}{r}\text { P meh. } \\
32,3\end{array}$} & \multirow{2}{*}{$\begin{array}{c}\text { P rem. } \\
\text { ns }\end{array}$} & \multirow{2}{*}{\multicolumn{2}{|c|}{$\begin{array}{r}\text { res. P total } \\
\mathrm{mg} \mathrm{dm}^{-2} \\
\end{array}$}} & \multirow{2}{*}{$\begin{array}{c}\mathrm{Na}^{+} \\
\mathrm{ns}\end{array}$} & \multirow{2}{*}{\multicolumn{2}{|c|}{$\begin{array}{|cc|}\mathrm{K}^{+} & \mathrm{S}-\mathrm{SO}_{4}^{=} \\
168 & 7 \\
\end{array}$}} & \multirow{2}{*}{$\begin{array}{c}\mathrm{K}^{+} \\
0,43\end{array}$} & \multicolumn{3}{|c|}{$\begin{array}{c}\mathrm{Ca}^{2+} \mathrm{Mg}^{2+} \mathrm{Al}^{3+} \\
\text { cmolc dim } \\
\end{array}$} & \multirow{2}{*}{$\begin{array}{r}\mathrm{H}+\mathrm{Al} \\
5,20\end{array}$} \\
\hline 5,7 & 5,1 & ns & & & & & & & & & & 2,7 & 1,3 & 0,00 & \\
\hline
\end{tabular}

\begin{tabular}{|c|c|c|c|c|c|c|c|c|c|c|c|c|}
\hline \multirow{2}{*}{ SB $\underset{\text { cmolc } \mathrm{dm}^{-3}}{\mathrm{t}}$} & \multirow{2}{*}{$\begin{array}{l}\text { V m } \\
\%\end{array}$} & \multicolumn{4}{|c|}{ Relação entre bases: } & \multicolumn{7}{|c|}{ Relaçäo entre bases e T (\%): } \\
\hline & & $\mathrm{Ca} / \mathrm{Mg}$ & $\mathrm{Ca} / \mathrm{K}$ & $\mathrm{Mg} / \mathrm{K}$ & $\mathrm{Ca}+\mathrm{Mg} / \mathrm{K}$ & $\mathrm{Ca} / \mathrm{T}$ & $\mathrm{Mg} / \mathrm{T}$ & $\mathrm{Na} / \mathrm{T}$ & $\mathrm{K} / \mathrm{T}$ & $\mathrm{H}+\mathrm{Al} / \mathrm{T}$ & $\mathrm{Ca}+\mathrm{Mg} / \mathrm{T}$ & $\mathrm{Ca}+\mathrm{Mg}+\mathrm{Na}+\mathrm{K} / \mathrm{T}$ \\
\hline $4,45 \quad 4,45 \quad 9,65$ & 46 & 2,0 & 6,3 & 3,1 & 9,3 & 28 & 14 & ns & 4 & 54 & 42 & 46 \\
\hline
\end{tabular}

\begin{tabular}{|c|c|c|c|c|c|c|c|c|c|}
\hline $\begin{array}{l}\text { M.O. C.O. } \\
\text { dag } \mathrm{kg}^{-1}\end{array}$ & B & $\mathrm{Cu}$ & $\begin{array}{c}\mathrm{Fe} \\
\mathrm{mg} \mathrm{dm}^{-3}\end{array}$ & $\mathrm{Mn}$ & $\mathrm{Zn}$ & Co $\mathrm{mg} \mathrm{dm}^{-3}$ & $\begin{array}{c}\mathrm{Si} \\
\mathrm{mg} \mathrm{kg}^{-1}\end{array}$ & \begin{tabular}{|c|} 
Nivel Critico de P \\
$\mathrm{mg} \mathrm{dm}^{-3}$
\end{tabular} & $\begin{array}{c}\text { Valor Relativo de P } \\
\% \\
\end{array}$ \\
\hline 1,15 & 0,29 & 2,0 & 26 & 5,7 & 2,1 & ns & ns & $\mathrm{ns}$ & ns \\
\hline
\end{tabular}

Resultados da Análise Textura:

ns - Náo Solcitado | SB - Soma de Bases |t - CTC Elebva |T - CTC pH 7,0|

\begin{tabular}{|c|c|c|c|c|c|}
\hline $\begin{array}{c}\text { Areia } \\
\text { Grossa }\end{array}$ & $\begin{array}{c}\text { Areia } \\
\text { Fina }\end{array}$ & $\begin{array}{l}\text { Areia } \\
\text { Total } \\
\mathrm{g} \mathrm{kg-1}^{-1}\end{array}$ & Silte & Argila & 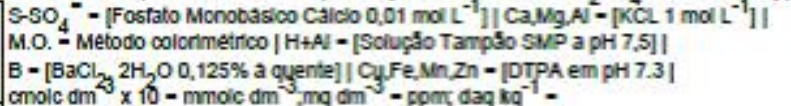 \\
\hline ns & ns & ns & $\mathrm{ns}$ & ns & \\
\hline
\end{tabular}

\begin{tabular}{|c|c|c|c|c|c|c|c|c|c|c|c|c|c|c|}
\hline \multirow{2}{*}{\multicolumn{11}{|c|}{$\begin{array}{l}\text { Níveis ideais de nutrientes no solo segundo Boletim de recomendaçäo CFSEMG(1999) - } \\
\text { Obs: S-SO . B, Cu, Fe, Mn, Zn fonte: Boletim Técnico 100, LAC (1997). }\end{array}$}} & \multirow{2}{*}{\begin{tabular}{c|c|} 
Argila \\
$60-100$ \\
\end{tabular}} & \multirow{2}{*}{\begin{tabular}{|l|} 
P meh $^{-1}$ \\
$8,1-12$ \\
\end{tabular}} & \multirow{2}{*}{$\begin{array}{c}\text { Prem. } \\
0-4 \\
\end{array}$} & \multirow{2}{*}{\begin{tabular}{|c|}
$\mathrm{P} \mathrm{meh}^{-1}$ \\
$6,1-8$ \\
\end{tabular}} \\
\hline & & & & & & & & & & & & & & \\
\hline pH Água & $\mathrm{pHCaCl}$ & 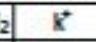 & $\mathrm{S}-\mathrm{SO}$ & $\mathrm{Ca}^{2+}$ & $\mathrm{Mg}^{2 *}$ & $\mathrm{Al}^{3+}$ & $\mathrm{H}+\mathrm{Al}$ & SB & $t$ & $T$ & $35-60$ & $12,1-18$ & $4-10$ & $8,5-12,5$ \\
\hline $5,5-6,5$ & $4,9-5,9$ & $>80$ & $>10$ & $2,4-4,0$ & $0,8-1,5$ & 40,2 & $<2,0$ & $3,6-6,0$ & $4,8-8,0$ & $8,6-15,0$ & $15-35$ & $20,1-30$ & $10-18$ & $11,5-17,5$ \\
\hline $\mathrm{v}$ & $\mathrm{m}$ & Mo. & Presina & & & & & & & & $0-15$ & $30,1-45,0$ & $18-30$ & $15,8-24$ \\
\hline $60-80$ & $<20$ & $2,1-4,5$ & $41-80$ & & & & & & & & & & $30-44$ & $29,1-33$ \\
\hline & & & & & & & & & & & & & $44-60$ & $30,1-60$ \\
\hline
\end{tabular}

\begin{tabular}{|l|l||c|c|c|}
\hline Fertigrama do Solo: & Muito Bom \\
\hline
\end{tabular}


Talhão 2.4

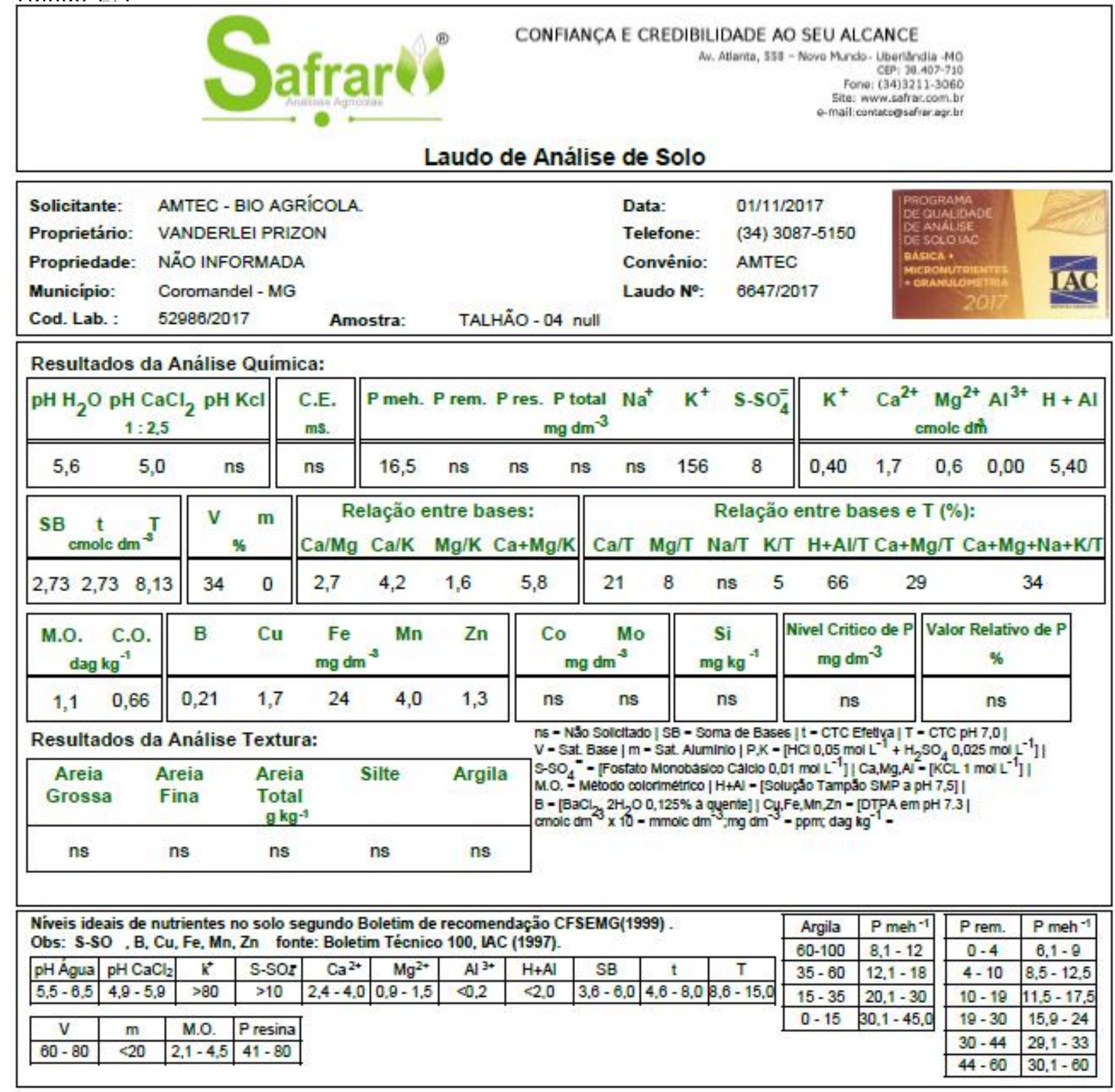

\begin{tabular}{|l|l|l||c|c|}
\hline \hline Fertigrama do Solo: & Muito Bom \\
\hline
\end{tabular}

